\title{
Evidência em Testes de Hipóteses: Alguns Casos Relacionados à Distribuição Binomial
}

José Marcelo Biagioni Baroni

\author{
Dissertação apresentada \\ ao \\ Instituto de Matemática e Estatística \\ da \\ Universidade de São Paulo \\ para \\ obtenção do grau \\ de \\ Mestre em Estatística
}

Área de Concentração: Estatística
Orientador: Prof. Dr. Carlos Alberto de Bragança Pereira

- São Paulo, novembro de 2004 - 


\title{
Evidência em Testes de Hipóteses: Alguns Casos Relacionados à Distribuição Binomial
}

\author{
Este exemplar corresponde à redação final \\ da dissertação devidamente corrigida $\mathrm{e}$ \\ defendida por José Marcelo Biagioni Baroni \\ e aprovada pela comissão julgadora.
}

São Paulo, 11 de novembro de 2004.

Banca examinadora:

- Prof. Dr. Carlos Alberto de Bragança Pereira (Orientador) - IME - USP

- Prof. Dr. Sérgio Wechsler - IME - USP

- Prof. Dr. Josemar Rodrigues - UFSCar 


\section{Agradecimentos}

Aos meus pais, que me deram vida, moldaram meu caráter e me apoiaram de forma carinhosa em todos os momentos.

Aos meus queridos irmãos, sobrinhos e amigos, companheiros de toda hora, que souberam incentivar-me mesmo em meus momentos de mau-humor quando o trabalho patinava.

À Elivanete, pelas montanhas de afeto e carinho que me injetaram força e confiança, muitas vezes sem que eu desse o devido valor.

Aos amigos do IME, pelo companheirismo, pelo apoio e pelas horas de estudo compartilhadas: Cléber, Mayra, Izabel, Conrad, Rosângela, Tatiana, Diana, Juvêncio, Elisa, Adriana, Eliane, João, Sueli, Marcos, Iracema, Humberto, Ricardo e muitos outros.

A todos os funcionários da USP, das secretarias e bibliotecas aos centros de fotocópias.

A todos os professores da USP, que me educaram no rigor científico sem esquecer o lado humano, mostrando-se mais do que tudo colegas de percurso.

À professora Cristina Cerri, da Matemática, que apoiou minha opção pelo curso na Estatística.

À professora Mônica Sandoval, que confirmou o acerto de minha escolha, renovando meu interesse, ainda na Especialização.

À professora Denise Botter, que mostrou-se extremamente generosa quando discutimos nossos projetos e propósitos.

À professora Lisbeth Cordani, que despertou-me em textos, conversas e e-mails para os problemas e as polêmicas relacionados à inferência e aos testes de hipóteses.

Ao professor Sérgio Wechsler, pelos comentários críticos bastante esclarecedores, além do forte incentivo.

Ao professor Josemar Rodrigues, pelas correções e sugestões importantes, pelo interesse e pela generosidade.

Finalmente, meu agradecimento ao professor Carlinhos, pela convivência alegre, pela injeção de criatividade, pela orientação segura que soube dosar apoio, liberdade, respeito e rigor. 


\section{Resumo}

Os testes de hipóteses representam uma ferramenta básica para a verificação de teorias científicas. Em diferentes áreas, a partir dos dados coletados, os pesquisadores querem avaliar se sua hipótese de trabalho está sendo estatisticamente corroborada ou refutada. Buscam uma medida da evidência que os resultados thes trazem.

Neste trabalho procuramos discutir os métodos padrão para os testes de hipóteses com foco principal na questão da evidência. Estudamos a utilização direta da razão de verossimilhanças para alguns problemas comuns relacionados à distribuição binomial. Quanto à controvertida questão das hipóteses precisas, analisamos as medidas de evidência tradicionais e consideramos a utilização da nova metodologia de teste denominada FBST. Neste sentido, comparamos as diferentes medidas em testes para proporção, teste de homogeneidade e teste de independência.

\footnotetext{
Abstract

Testing hypotheses represents a basic tool to verify scientific theories. In different fields, researchers want to know if their hypothesis is corroborated or refuted when data was collected. They look for a measure of evidence provided by the experiment.

In this work we discuss the standard methods of testing hypotheses focusing the evidence issue. We study the direct use of the likelihood ratio for common problems involving binomial distributions. For controversial case of precise hypotheses, we analyze the traditional measures of evidence and consider the use of a new method called FBST, comparing the different measures in three tests: success rate, homogeneity and independence.
} 


\section{Índice}

1 Introdução 1

2 Os Testes de Hipóteses e as Escolas de Inferência 3

2.1 Teste de Significância de Fisher . . . . . . . . . . . . . . . . . . . . . . . . 4

2.2 Teste de Hipóteses de Neyman-Pearson . . . . . . . . . . . . . . . . . 6

2.3 Inferência Bayesiana . . . . . . . . . . . . . . . . . 8

2.4 Inferência de Verossimilhança . . . . . . . . . . . . . . . . . . 10

3 Hipóteses e Evidência Estatística - O Uso Direto da Razão de Verossimilhanças 11

3.1 Avaliação de Hipóteses Simples . . . . . . . . . . . . . . . . . . . 15

3.1 .1 Quanta Evidência? . . . . . . . . . . . . . . . 17

3.1 .2 Intervalos de Plausibilidade . . . . . . . . . . . . . . 19

3.1.3 Parâmetros "Nuisance" . . . . . . . . . . . . . . . . . . . . . . . . . . . 24

3.2 Comparação entre Testes Diagnósticos . . . . . . . . . . . . . . . 27

4 FBST: Um Novo Teste Bayesiano para Hipóteses Precisas 33

5 Aplicação do FBST à Distribuição Binomial 38

5.1 Teste para Proporção de Sucesso . . . . . . . . . . . . . . . . . . . . 40

5.2 Teste de Homogeneidade . . . . . . . . . . . . . . . . . . . . 49

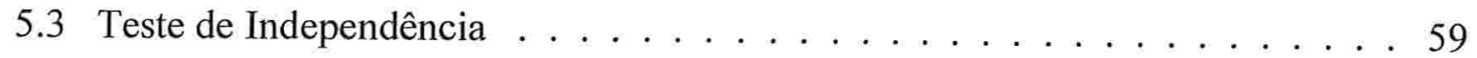

5.4 Conclusões. . . . . . . . . . . . . . . . . . . . . 68 
6 Erros Empíricos nos Testes Considerados

6.1 Erros no Teste para Proporção de Sucesso . . . . . . . . . . . . . . . . 70

6.2 Erros no Teste de Homogeneidade . . . . . . . . . . . . . . . . . 73

6.3 Erros no Teste de Independência . . . . . . . . . . . . . . . . 76

6.4 Erros Empíricos - Conclusões . . . . . . . . . . . . . . . . . 85

7 Considerações Finais $\quad 86$

Apêndice: Aspectos Computacionais no Cálculo de EV $\quad 88$

Referências Bibliográficas $\quad 90$ 


\section{Capítulo 1}

\section{Introdução}

Os testes de hipóteses compõem uma das mais abrangentes (e controversas) áreas do trabalho do estatístico. Paradigmas muitas vezes conflitantes formaram-se com a contribuição de renomados pesquisadores que, principalmente no século $\mathrm{XX}$, criaram as bases do que hoje se considera o campo da inferência estatística. A partir dos trabalhos pioneiros, diferentes leituras e interpretações foram realizadas, consolidando uma variada gama de procedimentos.

Há sempre riqueza nas controvérsias científicas mas, num mundo de desenvolvimento tecnológico acelerado, em que a urgência de respostas práticas muitas vezes atropela a possibilidade de maiores reflexões sobre os fundamentos da disciplina, a comunidade que faz uso da estatística enquanto ferramenta para testagem tem buscado a simplificação e padronização de métodos que possibilitem a obtenção de resultados de maneirá rápida e segura.

No campo dos testes de hipóteses, certas expressões se tornaram relativamente conhecidas pelos usuários e aparecem nos resumos obtidos a partir da manipulação de softwares (ou pacotes) estatísticos: "ao nível de 5\%, podemos dizer que o tratamento é eficaz"; "a hipótese nula não é rejeitada, já que o p-value obtido foi de 0,15 ". Mais raramente, encontramos algo como: "sob priori $\pi(\theta)$, o Fator de Bayes é..."

As frases acima, algo caricaturais, relacionam-se às duas principais "escolas" de inferência estatística e seu desenvolvimento durante o século passado: a chamada escola freqüentista (clássica), nos dois primeiros casos, e a escola bayesiana, no terceiro.

Sabemos que os estatísticos clássicos são ainda preponderantes mas nas duas últimas décadas têm havido grande expansão do número de estatísticos bayesianos. De toda forma, muitos pesquisadores não se sentem confortáveis com a diferenciação e preferem ser chamados de ... estatísticos.

Felizmente, é como estatísticos que a comunidade usuária identifica os especialistas da área. Quando existe um problema prático que exige conhecimento aprofundado de estatística, o "cliente" não quer explicações de um clássico ou de um bayesiano mas tãosomente de um estatístico. Nesse sentido, parece-nos sugestivo o título de um artigo 
publicado por Box (1983), renomado pesquisador do campo da Inferência: Apologia pelo Ecumenismo em Estatística.

Em sua argumentação, Box nos lembra algo aparentemente óbvio que muitas vezes é negligenciado: cada problema deve ser atacado da maneira que proporcione a melhor solução. E simplesmente não há uma escola de inferência que apresente as soluções perfeitas para todos os tipos de problemas.

Neste texto procuramos trabalhar a idéia de evidência associada a hipóteses, concentrando-nos em eventos binomiais. No capítulo 2, traçamos um painel das principais tendências da inferência no que se refere aos testes de hipóteses.

Na perspectiva de tratamento dos dados como evidência para a hipótese testada, o capítulo 3 apresenta os testes de hipóteses simples e os testes diagnósticos, onde sugerimos a abordagem do uso direto da verossimilhança.

No capítulo 4 apresentamos o FBST como um novo teste bayesiano que trabalha a quantificação da evidência em testes de hipóteses precisas.

A comparação de três medidas de evidência, o p-value, o Fator de Bayes e EV, do FBST, é realizada no capítulo 5, onde estudamos a aplicação dos testes a três problemas tradicionais relacionados à binomial/multinomial: teste para proporção, teste de homogeneidade e teste de independência.

O capítulo 6 apresenta estudos de simulação de erros para a comparação do tradicional p-value com a nova medida EV com relação aos testes trabalhados no capítulo precedente. 


\section{Capítulo 2}

\section{Os Testes de Hipóteses e as Escolas de Inferência}

Indução é o processo pelo qual se parte de constatações do particular (amostra) para conclusões no geral (população). Resumindo enormemente a história, pode-se dizer que desde o século XVIII até o início do século XX, tendo Hume e Laplace como referências principais, a indução era aceita e se utilizava freqüentemente o cálculo da probabilidade inversa, a partir da conhecida fórmula de Bayes, para o teste de hipóteses.

O raciocínio indutivo é ainda hoje fortemente contestado por diversos filósofos da ciência. Entretanto, certamente fazemos uso dele em nosso cotidiano. É bastante freqüente em nossa experiência diária a utilização (consciente ou não) de informações passadas para, a partir de evidências presentes, "calcularmos" o que vai ocorrer em seguida.

Podemos afirmar que o raciocínio indutivo é bastante "natural". Porém, no início do século XX, a tradição Hume - Laplace - Bayes começou a perder força a partir dos estudos de Karl Pearson e, em seguida Gosset (Student), que desenvolveram, respectivamente, o teste de aderência (qui-quadrado) e o teste t. Pareceu a muitos estudiosos que os novos testes eram mais objetivos, $\mathrm{e}$ isso foi reforçado em seguida com a decisiva contribuição de Fisher.

A seguir, vamos tecer um pequeno esboço das quatro diferentes abordagens que lentamente foram se consolidando em relação aos testes de hipóteses. 


\section{1 - Teste de Significância de Fisher}

Na década de 1910, Sir Ronald Fisher começou a desenvolver a maior parte do que ainda hoje se ensina como estatística. Como, naquele momento, ele rejeitava a idéia de utilizar informação a priori, não era possível a aplicação direta do cálculo de probabilidade à avaliação de uma hipótese. Assim, aperfeiçoou os chamados testes de significância. Estes se baseiam no cálculo da probabilidade de se obter os dados que de fato foram obtidos, ou mais extremos, se for verdadeira a hipótese nula, justamente aquela que o cientista quer rejeitar. Desse modo, quanto menor a probabilidade dos dados sob aquela hipótese, menos aceitável ela é.

Uma probabilidade pequena indicaria que os dados favorecem a rejeição da hipótese nula. Sendo

$\mathrm{H}_{0}$ a hipótese nula,

$\mathrm{X}$ o espaço amostral de possíveis valores,

$\mathrm{x}$ os valores observados a partir de $\mathrm{X}$,

$\mathrm{T}(\mathrm{X})$, a estatística do teste, função dos dados,

$t(x)$ os valores efetivamente observados a partir de $T(X)$,

no teste de significância mede-se o grau de consistência com $\mathrm{H}_{0}$ através do p-value (PV):

$\mathrm{PV}=\mathrm{P}\left(\mathrm{T} \geq \mathrm{t}(\mathrm{x}) ; \mathrm{H}_{0}\right)$.

Quanto menor o p-value, menos os dados favorecem a hipótese nula. Fisher sempre ressaltou que cada caso deveria ser analisado cuidadosamente pelo cientista mas, ao sugerir o valor 0,05 como referência, acabou involuntariamente criando a tradição de tomar esse índice como padrão para rejeição.

Assim, em 1935, em The Design of Experiments ( $8^{\mathrm{a}}$ edição, pág. 13): "It is usual and convenient for experimenters to take 5 per cent as a standard level of significance..." Ao perceber que já se esboçava a indesejada padronização do p-value, Fisher retornou à questão em 1956, no Statistical Methods and Scientific Inference ( $2^{\mathrm{a}}$ edição, pág. 42): ...in fact no scientific worker has a fixed level of significance at which from year to year, and in all circumstances, he rejects hypotheses; he rather gives his mind to each particular case in the light of evidence and ideas." 
Para Fisher, um valor pequeno de PV poderia significar duas coisas: ou um fato extremamente raro ocorreu, ou a hipótese nula não é verdadeira. Não há o cálculo da probabilidade da hipótese, apesar dessa ser uma interpretação errônea bastante comum. Muitos associam, apesar dos alertas de Fisher, um p-value de 0,03, por exemplo, com a idéia de que a probabilidade da hipótese nula é de 3\%. Ele nunca admitiu isso: "Such a test of significance does not authorize us to make any statement about the hypothesis in question in terms of mathematical probability..." (Statistical Methods and Scientific Inference, $2^{\mathrm{a}}$ edição, pág. 35).

Em geral, os testes fisherianos não fazem qualquer referência à hipótese alternativa. Assim, o cientista utilizaria esse tipo de teste apenas para "desaprovar" uma hipótese nula, como, por exemplo, a hipótese de que determinado tratamento não tem nenhum efeito.

Um problema dos testes de significância baseados no p-value está na dependência que esse apresenta em relação ao tamanho da amostra. Muitas vezes, basta aumentar a amostra para que se obtenha a rejeição da hipótese nula. Se for fixado um nível de significância independentemente do tamanho da amostra, a utilização da metodologia do pvalue poderá produzir resultados pouco confiáveis.

Dessa forma, um p-value mais consistente deve ser sempre acompanhado por considerações a respeito do tamanho da amostra, como sugeriu o próprio Fisher ao discutir a sensitividade de um experimento. 


\section{2 - Teste de Hipóteses de Neyman-Pearson}

O teste de hipóteses mais largamente ensinado nos livros de estatística básica é fruto de uma mistura do teste de significância de Fisher com os conceitos desenvolvidos por Jerzy Neyman e Egon Pearson. De Neyman-Pearson herdamos a idéia de que o teste de hipóteses deve ser resolvido como um problema de decisão - aceitar ou rejeitar a hipótese nula, com base na existência de dois tipos de erros: I - rejeitá-la quando de fato ela é verdadeira; II - aceitá-la quando de fato ela é falsa. É, em geral, estabelecido um valor máximo aceitável para a probabilidade do erro de tipo I $(\alpha)$, normalmente 0,05 , e procurase minimizar a probabilidade do erro de tipo II ( $\beta$ ), já que é impossível obter valores de probabilidade mínimos para os dois erros ao mesmo tempo.

O espaço paramétrico $\theta$ é dividido em dois conjuntos, $\theta_{0}$ e $\theta_{1}$, aos quais associamse, respectivamente, as hipóteses $\mathrm{H}_{0}$ (hipótese nula) e $\mathrm{H}_{1}$ (hipótese alternativa). Uma das hipóteses é verdadeira. $\mathrm{O}$ espaço amostral é também dividido em dois conjuntos, a região de aceitação e a região de rejeição, mais conhecida como região crítica. Se a estatística utilizada para o teste, por exemplo a média amostral $\bar{x}$ (se estivermos testando um valor para a média $\mu$ ), "cair" na região crítica, rejeitamos a hipótese nula e aceitamos a alternativa.

Podemos dizer que o grande avanço dessa abordagem em relação à de Fisher é a consideração da existência de uma hipótese alternativa. Assim, rejeita-se uma hipótese sempre em comparação com outra.

Fisher não concordava com essa visão e teceu críticas ácidas em relação à idéia de hipótese alternativa e, mais ainda, à própria redução do teste de hipóteses a um problema de decisão. Para ele, isso serviria para uma situação de fábrica (aceitar/rejeitar um lote de artigos), nunca para ser uma ferramenta utilizada em pesquisa científica.

De todo modo, a escola Neyman-Pearson é considerada a mais fiel "freqüentista", já que baseia suas decisões na idéia de Von Mises de que probabilidade é uma freqüência relativa, um limite quando o número de casos possíveis tende ao infinito. No teste de hipóteses, para $\alpha=0,05$, a interpretação é de que "se $\mathrm{H}_{0}$ for verdadeira e o experimento for repetido 100 vezes, sob as mesmas condições, em 5 delas se cometerá o erro do tipo I", isto é, em 5 ocasiões rejeitaremos a hipótese nula sendo ela verdadeira. 
Como se vê, novamente não é atribuída nenhuma probabilidade à hipótese em si e sim aos erros possíveis. A nenhum evento único pode ser atribuída uma probabilidade mas apenas à hipotética repetição infinita dos eventos.

A teoria de Neyman-Pearson, também conhecida como NPW devido ao trabalho de Wald, desenvolve procedimentos para a escolha de um conjunto de ações, não para a interpretação dos dados como evidência. Incontestavelmente, ela é extremamente útil para a fase do planejamento. Nas palavras de Royall (1997), "ao escolher testar ao nível 0,05 o pesquisador controla a probabilidade do erro de tipo I; ao escolher o tamanho da amostra, controla a probabilidade do erro de tipo II."

Neyman-Pearson buscaram desenvolver testes com poder máximo, isto é, testes com erro do tipo II mínimo. Daí foi-se construindo uma linguagem ainda hoje dominante na área de testes de hipóteses: testes mais poderosos, uniformemente mais poderosos (ump), etc. Nessa linha, o que podemos denominar paradigma NPW acabou por abandonar o objetivo da quantificação da evidência em testes de hipóteses, substituindo-o pela busca de procedimentos considerados ótimos para a tomada de decisões. 


\section{3 - Inferência Bayesiana}

Os bayesianos consideram que o parâmetro $\theta$ deve ser tratado como variável aleatória, não como entidade fixa. Assim, são atribuídas probabilidades diretas às hipóteses, ao contrário das abordagens vistas anteriormente. A probabilidade é vista como medida de incerteza e, portanto, medida de "crença". Numa simplificação do esquema bayesiano, pode-se dizer que quando um cientista elabora uma hipótese $(\theta)$ que deve ser testada, ele já possui uma idéia de sua plausibilidade e isso é transformado em um número, a probabilidade a priori, $\pi(\theta)$. Os dados são obtidos e a partir deles calcula-se a função de verossimilhança $\mathrm{P}(\mathrm{x} \mid \theta)$. Se nosso interesse é avaliar o quanto uma hipótese é apoiada pelos dados do experimento, queremos saber quanto é $\mathrm{P}(\theta \mid \mathrm{x})$, a chamada probabilidade a posteriori. A partir do cálculo da probabilidade inversa pela fórmula de Bayes, podemos escrever:

$$
P(\theta \mid x)=\frac{\pi(\theta) \cdot P(x \mid \theta)}{\int_{\theta} \pi(\theta) \cdot P(x \mid \theta) d \theta}
$$

Assim, $\mathrm{P}(\theta \mid x) \propto \pi(\theta) \cdot P(x \mid \theta)$.

Dessa forma, a posteriori é proporcional à priori vezes a verossimilhança. Ela é a priori atualizada pelos dados. A partir daí, pode-se avaliar a força da hipótese nula calculando, por exemplo, a razão entre a posteriori sob $\mathrm{H}_{0}$ e a posteriori sob $\mathrm{H}_{1}$. Se essa razão resultar em um número acima de 1 , os dados favorecem a adoção da hipótese nula. Caso contrário, favorecem a hipótese alternativa.

Em testes de hipóteses, um procedimento comumente utilizado pela inferência bayesiana é o cálculo do Fator de Bayes, que não é uma probabilidade mas uma medida do quanto os dados aumentam (ou diminuem) as chances de $\mathrm{H}_{0}$ em relação a $\mathrm{H}_{1}$ :

$$
F B_{01}=\frac{\int_{0} P(x \mid \theta) \cdot \pi_{0}(\theta) d \theta}{\int_{\theta_{1}} P(x \mid \theta) \cdot \pi_{1}(\theta) d \theta}
$$


Como se vê, a metodologia é baseada em avaliações no espaço paramétrico $(\Theta)$ e não no espaço amostral ( $\aleph$ ), como no caso freqüentista. Uma grande crítica que se faz aos testes freqüentistas baseados no p-value pode ser resumida por Jeffreys (1939), que assim se referiu ao teste de significância que considera valores mais extremos do que o observado: "uma hipótese que talvez seja verdadeira pode ser rejeitada porque não previu resultados observáveis que de fato não ocorreram. Isso parece um procedimento notável."

Por outro lado, a maior crítica que o procedimento tipicamente bayesiano recebe dos "clássicos" é que diferentes prioris (ou seja, diferentes opiniões iniciais) resultam em diferentes posterioris e, portanto, o procedimento carece de objetividade, já que várias pessoas, a partir dos mesmos dados, chegarão a conclusões diferentes. Os bayesianos (ou sua maioria) se assumem "subjetivistas" mas alegam que devem ser testadas diversas prioris para evitar distorções. Outros, bayesianos "objetivos", procuram prioris "nãoinformativas" para deixar os dados falarem por si.

Sem pretender desmerecer os esforços dos estatísticos freqüentistas em sua busca por procedimentos livres de subjetividade, parece-nos correta a postura de utilização de informações passadas para atualização com dados presentes, base da metodologia bayesiana.

Além disso, procedimentos bayesianos propiciam algo totalmente negado pela estatística clássica mas altamente desejado pela comunidade que faz uso da estatítica: o cálculo da probabilidade de uma hipótese, ou de sua credibilidade. 


\section{4 - Inferência de Verossimilhança}

Outra linha da inferência que tem conquistado bom número de aderentes é a dos "likelihoodists", palavra intraduzível que vamos denominar "adeptos da verossimilhança". A partir de uma certa leitura dos escritos de Fisher, principalmente do seu último livro (1956), bem distante dos procedimentos de Neyman-Pearson, autores como Barnard, Birnbaum, Hacking, Edwards, e, mais recentemente, Royall e Pawitan são expoentes dessa tendência. Eles buscam, de maneira simples, solucionar os problemas apresentados pelas escolas majoritárias. Assim, evitam-se avaliações baseadas em todo o espaço amostral (que usam dados que não "apareceram") e também evita-se a utilização de informações a priori, causadoras de excesso de "subjetividade". Procura-se apreender o que os dados coletados nos informam, de maneira mais direta.

Aparentemente, essa abordagem se assemelha à dos bayesianos "objetivos". A diferença fundamental é que aqui não se está trabalhando com distribuição de probabilidade. A função de verossimilhança não é uma distribuição de probabilidade, a área sob a curva da verossimilhança não tem qualquer significado. Assim, a verossimilhança só pode ser utilizada num sentido relativo, como uma medida de plausibilidade relativa, "relative support", nas palavras de Edwards (1972).

De todo modo, a inferência baseada na verossimilhança parece ser a menos ambiciosa das escolas aqui tratadas. Procura circunscrever-se a problemas específicos e não pretende abarcar toda a inferência estatística. Segundo Pawitan (2000), "Ambos os métodos, freqüentistas e bayesianos, obtêm resultados mais fortes do que o método da verossimilhança, mas à custa de maiores suposições". Ele comenta ainda que a probabilidade oferece o necessário para o raciocínio em termos de grupo ("group reasoning") mas a verossimilhança é melhor aplicada para casos singulares ("uniquecase"). 


\section{Capítulo 3}

\section{Hipóteses e Evidência Estatística - O Uso Direto da Razão de Verossimilhanças}

Desde há muito se procuram fundamentos lógicos para uma teoria de "suporte" ou "sustentação" para hipóteses científicas a partir da análise estatística dos dados. Quais são as evidências que os dados nos trazem a respeito de determinada hipótese? Como quantificar essas evidências? Enfim, como utilizar o cálculo de probabilidades para avaliar determinada hipótese?

Os freqüentistas rejeitam qualquer avaliação quantitativa sobre hipóteses, isto é, não se pode calcular a probabilidade de determinada hipótese. Desse modo, essa tradição concentrou esforços no sentido de desenvolver métodos com o objetivo de minimizar a possibilidade de erros de avaliação, encontrar testes mais poderosos, etc.

Ao contrário, os bayesianos calculam a probabilidade de hipóteses, o que nos parece fundamental. Entretanto, essa metodologia depende do estabelecimento da probabilidade a priori e muitos discordam desse procedimento, mesmo que seja utilizada uma priori uniforme, como era a regra para Laplace.

Entre essas duas tendências, que podemos, numa liberdade didática, qualificar como extremas, muitos autores (por vezes "acusados" de bayesianos disfarçados) têm buscado desenvolver uma teoria de suporte para hipóteses que evite o uso de probabilidades a priori. Neste sentido aparece a utilização da verossimilhança e de razões entre verossimilhanças como um instrumento adequado para avaliação de hipóteses. Historicamente, pode-se destacar Fisher como um simpatizante dessa idéia, apesar dela aparecer dispersa em diferentes escritos.

Barnard (1949), buscou instrumentalizar a avaliação das evidências a partir dos lods, os "logs of the odds", isto é, os logaritmos naturais das chances de duas hipóteses simples. Na mesma linha, Good (1950) falava em avaliar o peso da evidência (weight of evidence) a partir da razão de chances, desta vez numa perspectiva bayesiana. Em 1962, Birnbaum criou grande controvérsia ao estabelecer o princípio da verossimilhança (L likelihood) a partir de dois conceitos que, separadamente, eram aceitos pelas diferentes 
escolas, os princípios da condicionalidade (C) e da suficiência (S). Para ele, C e S conjuntamente implicam L.

Hacking (1965), Edwards (1972), Royall (1997) e Blume (2002), entre outros, defendem a aplicação direta da inferência de verossimilhança. Suas idéias partem do pressuposto de que a análise do suporte para teorias e hipóteses deve ser feita sempre de forma comparativa. Um teste só pode rejeitar uma hipótese se existe outra com melhor suporte. É disso que trata a Lei de Verossimilhança.

A Lei não deve ser confundida com o controverso Princípio da Verossimilhança. $\mathrm{O}$ Princípio, como adiantamos acima, foi formalizado por Birnbaum e é defendido largamente pelos bayesianos, com destaque para James Berger. O Princípio afirma:

Se E e E' são dois experimentos no mesmo espaço paramétrico e se x e y são os respectivos resultados que determinam funções de verossimilhança satisfazendo $f(x, \theta)=$ $c . g(y, \theta)$ para alguma constante $c=c(x, y)$ e para todo $\theta$, então $E v(E, x)=E v(E, y)$. Ou seja, o significado de evidência (evidential meaning) $E v(E, x)$ de qualquer resultado $x$ de um experimento $E$ é caracterizado completamente pela função de verossimilhança $c . f(x, \theta)$ $e$ é independente da estrutura de (E, $x)$.

Em outras palavras, o Princípio assegura que dois experimentos produzem significado de evidência equivalente se suas funções de verossimilhança são proporcionais.

O Princípio é fortemente combatido por estatísticos clássicos porque acaba por estabelecer a irrelevância das regras de parada. Assim, não importa a idéia inicial que tem o pesquisador a respeito da hora certa de parar seu experimento. Se ele vai encerrar um experimento, por exemplo, após a ocorrência de 6 sucessos ou se planejou um total de 10 tentativas e obteve 6 sucessos, isso não faz diferença para a inferência que deve ser realizada, já que num caso ou noutro as verossimilhanças serão proporcionais.

A idéia de que o espaço amostral e a regra de parada não são relevantes para a avaliação da evidência resultante do experimento é fundamental quando pensamos, por exemplo, num experimento envolvendo a saúde de pacientes. Essa questão é longamente debatida por Mayo (1996, 2001), que se posiciona contra o Princípio. A importância para assuntos ligados à área de saúde é discutida na dissertação de Inoue (1995), favorável à adoção do Princípio. 
Em um texto didático dedicado à área de bioestatística, Blume (2002) sugere a utilização de métodos baseados na verossimilhança como os mais adequados para medir a evidência estatística. Baseando-se em Royall, afirma que nem a abordagem freqüentista nem a bayesiana respondem diretamente a questão "o que os dados nos dizem?" Enquanto os primeiros respondem a pergunta "o que eu deveria fazer?", os últimos respondem a questão "no que eu deveria acreditar?"

Além disso, tanto um quanto o outro acrescentam informação que a princípio não existe nos dados coletados: os freqüentistas ao incluir dados relativos a todo o espaço amostral, os bayesianos ao incluir informação a priori. Blume propõe que unicamente os dados efetivamente observados devem ser base para a avaliação de duas hipóteses simples, no mesmo sentido de Edwards: "Os dados sustentam melhor a hipótese que é mais capaz de prever a ocorrência dos mesmos."

Blume reforça a diferença entre Incerteza (Uncertainty) e Evidência Estatística, já antecipada por Fisher e endossada, mais recentemente, por Pawitan (2000): "A incerteza é medida por probabilidades, que descrevem como um experimento vai ocorrer se teoricamente houver muitas repetições do mesmo ("long run performance"). Uma quantidade matemática diferente, a razão de verossimilhanças, é necessária para medirmos a força da evidência estatística."

Royall enfatiza que a incerteza medida por uma função de densidade de probabilidade desaparece quando a observação já foi realizada. A partir de então, a função de verossimilhança passa a representar a evidência obtida. Considerando

$\mathrm{P}_{1}(\mathrm{x})=\mathrm{P}\left(\mathrm{x} \mid \mathrm{H}_{1}\right)$ : probabilidade de observar $\mathrm{x}$ dado que $\mathrm{H}_{1}$ é verdadeira;

$\mathrm{P}_{2}(\mathrm{x})=\mathrm{P}\left(\mathrm{x} \mid \mathrm{H}_{2}\right)$ : probabilidade de observar $\mathrm{x}$ dado que $\mathrm{H}_{2}$ é verdadeira;

$\mathrm{H}_{1}$ e $\mathrm{H}_{2}$ : hipóteses simples, a Lei da Verossimilhança estabelece o seguinte:

Se a primeira hipótese, $H_{l}$, implica que a probabilidade de que uma variável aleatória $X$ assuma o valor $x$ é $P_{1}(x)$ enquanto a segunda hipótese, $H_{2}$, implica que a probabilidade é $P_{2}(x)$, então a observação $X=x$ é evidência sustentando $H_{1}$ em relação a $H_{2}$ se e só se $P_{I}(x)>P_{2}(x)$, e a razão de verossimilhança $P_{I}(x) / P_{2}(x)$ mede a força dessa evidência. 
Assim, a Lei sugere como os dados devem ser interpretados como evidência estatística de uma hipótese sobre outra. É, neste sentido, mais fraca do que o Princípio, mas sua força está justamente em simplificar a interpretação da evidência de hipóteses a partir dos dados que estão efetivamente disponíveis.

Finalmente, devemos ressaltar que a utilização direta de razões de verossimilhança para a realização de inferência sobre hipóteses pressupõe que o modelo em questão seja suposto verdadeiro. Citemos Birnbaum em sua famosa apresentação de 1962: "Deliberadamente delimitamos e idealizamos a presente discussão considerando somente modelos cuja adequação é postulada e não está em questão."

Quase toda a inferência é realizada na suposição de adequação do modelo. De toda maneira, uma utilização ingênua da Lei impediria que avaliássemos se outro modelo não explicaria melhor os resultados obtidos. Aqui, vale a pena lembrarmos que toda ortodoxia tende a engessar a ciência. Box, no artigo citado, defende a adoção de diferentes instrumentos estatísticos para a realização de diferentes tarefas (seleção de modelos, estimação, testes, etc). Assim, muitas vezes o autor sugere a utilização de ferramentas bayesianas. Em outras ocasiões, endossa o ideário clássico:

"Na fase de crítica (ou escolha do modelo) estamos considerando se, dado A (o que foi assumido como verdadeiro), a amostra y é a que tem ocorrência mais provável. Para fazer isso, devemos considerá-la em relação a outras amostras que poderiam ter ocorrido mas não ocorreram.” (Box, 1983, pág. 75).

Como se vê, o que se realizou até hoje em teoria estatística deve ser considerado da forma mais abrangente possível. Isso não impedirá que tenhamos de realizar escolhas metodológicas ou até filosóficas mas nos servirá sempre de alerta para que prestemos atenção ao que outros pesquisadores acreditam ser a melhor forma de resolver os problemas que resolvemos do nosso modo. 


\section{1 - Avaliação de Hipóteses Simples}

Um modelo de probabilidade avalia a incerteza sobre os valores possíveis de uma variável aleatória dentro do espaço amostral $\aleph$ a partir de dado parâmetro $\theta$. Para um $\theta$ fixado, calculamos $P(X=x \mid \theta)$. Quando os dados foram observados, $x$ está fixado $e$ procedemos à investigação do quanto determinados valores paramétricos são plausíveis para a geração daquele resultado. Temos então a verossimilhança $L(\theta \mid x)=P(x \mid \theta)$. A Lei da Verossimilhança nos permite a avaliação de uma hipótese sempre em relação a outra, o que é feito através da razão de verossimilhanças.

Vamos supor que uma nova droga está sendo testada e que uma eficácia de $60 \%$ a igualaria a uma droga tradicional. O pesquisador imagina que a nova droga tem eficácia de $90 \%$ e quer testar se este índice é mais provável do que $60 \%$.

É desenvolvido um experimento em que a nova droga é administrada a 20 pacientes e se revela eficaz em 17 deles. Usamos aqui um modelo binomial:

$$
\mathrm{P}(\mathrm{X}=\mathrm{x} \mid \theta)=\left(\begin{array}{l}
n \\
x
\end{array}\right) \cdot \theta^{\mathrm{x}} \cdot(1-\theta)^{\mathrm{n}-\mathrm{x}}
$$

A verossimilhança para 17 sucessos em 20 pacientes é:

$$
\begin{aligned}
& P(X=17 \mid \theta)=\left(\begin{array}{l}
20 \\
17
\end{array}\right) \cdot \theta^{17} \cdot(1-\theta)^{3} \\
& P(X=17 \mid \theta)=L(\theta)=1.140 . \theta^{17}(1-\theta)^{3} . \\
& \text { Logo, } L(\theta) \propto \theta^{17}(1-\theta)^{3} .
\end{aligned}
$$

Se queremos testar $H_{1}: \theta=0,90$ versus $H_{0}: \theta=0,60$, calculamos

$$
\frac{L\left(H_{1}\right)}{L\left(H_{0}\right)}=\frac{L(0,90)}{L(0,60)}=\left[\frac{(0,90)}{(0,60)}\right]^{17} \cdot\left[\frac{(0,10)}{(0,40)}\right]^{3}=15,39
$$

O valor acima demonstra que, para a nova droga, o índice de sucesso de $90 \%$ é bem mais plausível do que o índice de $60 \%$. Qualquer razão acima de 1 evidencia maior plausibilidade para $\mathrm{H}_{1}$. Aqui, surge a questão sobre "quanto" o valor 15,39 representa de evidência, já que não estamos falando de probabilidade. Isso será discutido mais à frente. 
Para esse exemplo, a estimativa de máxima verossimilhança é $\hat{\theta}=0,85$. Se testarmos $H_{1}: \theta=0,85$ versus $H_{0}: \theta=0,60$ obteremos uma razão $\frac{L\left(H_{1}\right)}{L\left(H_{0}\right)}=19,66$, mostrando, como esperado, evidência ainda maior a favor da estimativa de máxima verossimilhança (85\%) contra $\mathrm{H}_{0}$.

Para que o pesquisador verifique se a nova droga não é inferior à antiga pode testar, por exemplo, $\mathrm{H}_{1}: \theta=0,50$ versus $\mathrm{H}_{0}: \theta=0,60$. A razão $\frac{L\left(H_{1}\right)}{L\left(H_{0}\right)}$ é igual a 0,09 , bastante desfavorável à hipótese alternativa de eficácia menor. 


\subsection{1 - Quanta Evidência?}

Como se vê, o método direto é bastante útil no sentido de avaliar hipóteses simples aos pares. Voltando à questão do "quanta evidência" é representada pela razão de verossimilhanças (r.v.), Royall afirma que uma forma de avaliar a evidência gerada por esse método consiste em observar o quanto a r.v. aumenta a razão das probabilidades iniciais (prioris). Pelo teorema de Bayes,

$$
\begin{aligned}
\frac{P\left(H_{1} \mid x\right)}{P\left(H_{0} \mid x\right)}=\frac{P\left(H_{1}, x\right)}{P\left(H_{0}, x\right)} & =\frac{P\left(x \mid H_{1}\right)}{P\left(x \mid H_{0}\right)} * \frac{P\left(H_{1}\right)}{P\left(H_{0}\right)} \\
& =\quad \text { r.v. * razão das prioris }
\end{aligned}
$$

Nesse caso, não importam quais são as probabilidades iniciais mas sim a razão entre elas. Assim, uma r.v. igual a 4 significa que a razão das probabilidades iniciais foi quadruplicada.

Podemos adotar algumas convenções, seguindo Royall. Denotando a verossimilhança, sob cada hipótese, $L_{1}=L\left(H_{1}\right)$ e $L_{0}=L\left(H_{0}\right)$, e a razão entre as verossimilhanças, $r . v .=\frac{L_{1}}{L_{0}}$, temos:

- evidência forte a favor de $\mathrm{H}_{1}$ se $\frac{L_{1}}{L_{0}} \geq k$,

- evidência forte a favor de $\mathrm{H}_{0}$ se $\frac{L_{1}}{L_{0}} \leq \frac{1}{k}$,

- evidência fraca se $\frac{1}{k} \leq \frac{L_{1}}{L_{0}} \leq k$. 
Similarmente aos tradicionais níveis 0,05 e 0,01 da estatística clássica, Royall propõe os valores de referência $\mathrm{k}=8$ e $\mathrm{k}=32$. Uma razão maior ou igual a 8 representaria uma evidência forte; uma razão maior ou igual a 32 representaria uma evidência muito forte.

Na próxima seção adotaremos esses valores para a construção de gráficos. Cabe, porém, o alerta de que devemos sempre nos precaver contra a padronização excessiva em estatística, conforme discutimos anteriormente. 


\subsection{2 - Intervalos de Plausibilidade}

Uma maneira prática de utilizar a abordagem direta é a de construir gráficos da função de verossimilhança $L(\theta)$ sobre todo o espaço paramétrico. Dividindo $L(\theta)$ pelo seu valor máximo, $L(\hat{\theta})$, obtemos a chamada verossimilhança relativa ou padronizada (relative/standardized likelihood), $\frac{L(\theta)}{L(\hat{\theta})}$, permitindo que se estabeleça visualmente a plausibilidade dos valores do parâmetro testado, conforme figura abaixo:

FIGURA 3.1 - Verossimilhança Relativa

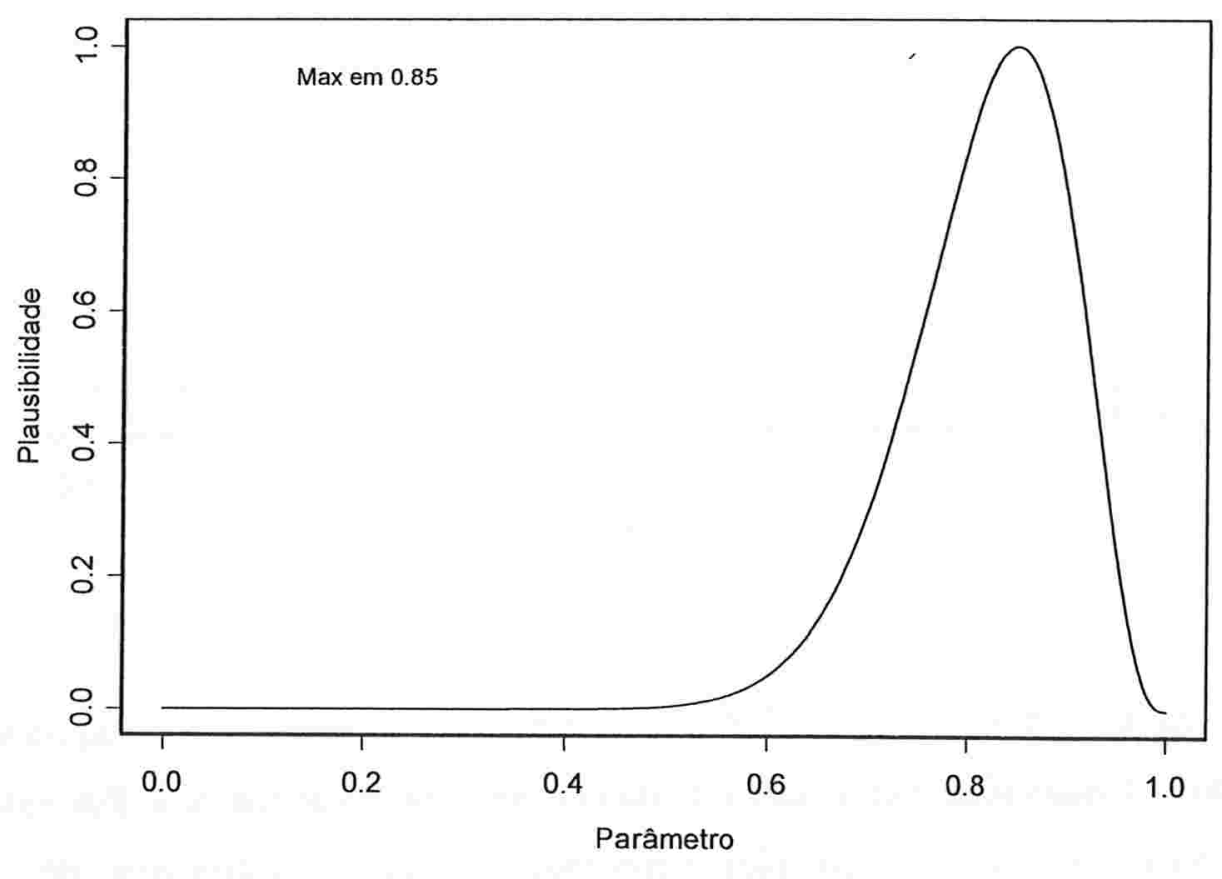

O gráfico acima mostra, para o exemplo anterior, que pontos de $\Theta$ são mais plausíveis, com destaque óbvio para a estimativa de máxima verossimilhança, $\hat{\theta}=0,85$. 
Como estamos desenhando a verossimilhança relativa, uma vantagem adicional desse tipo de procedimento gráfico é a construção de intervalos de plausibilidade (support intervals $=\mathrm{SI}$ ) . Assim, construímos os intervalos $1 / 8$ e 1/32, conforme sugerido por Royall e Blume. Isso pode ser observado na figura 3.2:

\section{FIGURA 3.2 - Verossimilhança Relativa}

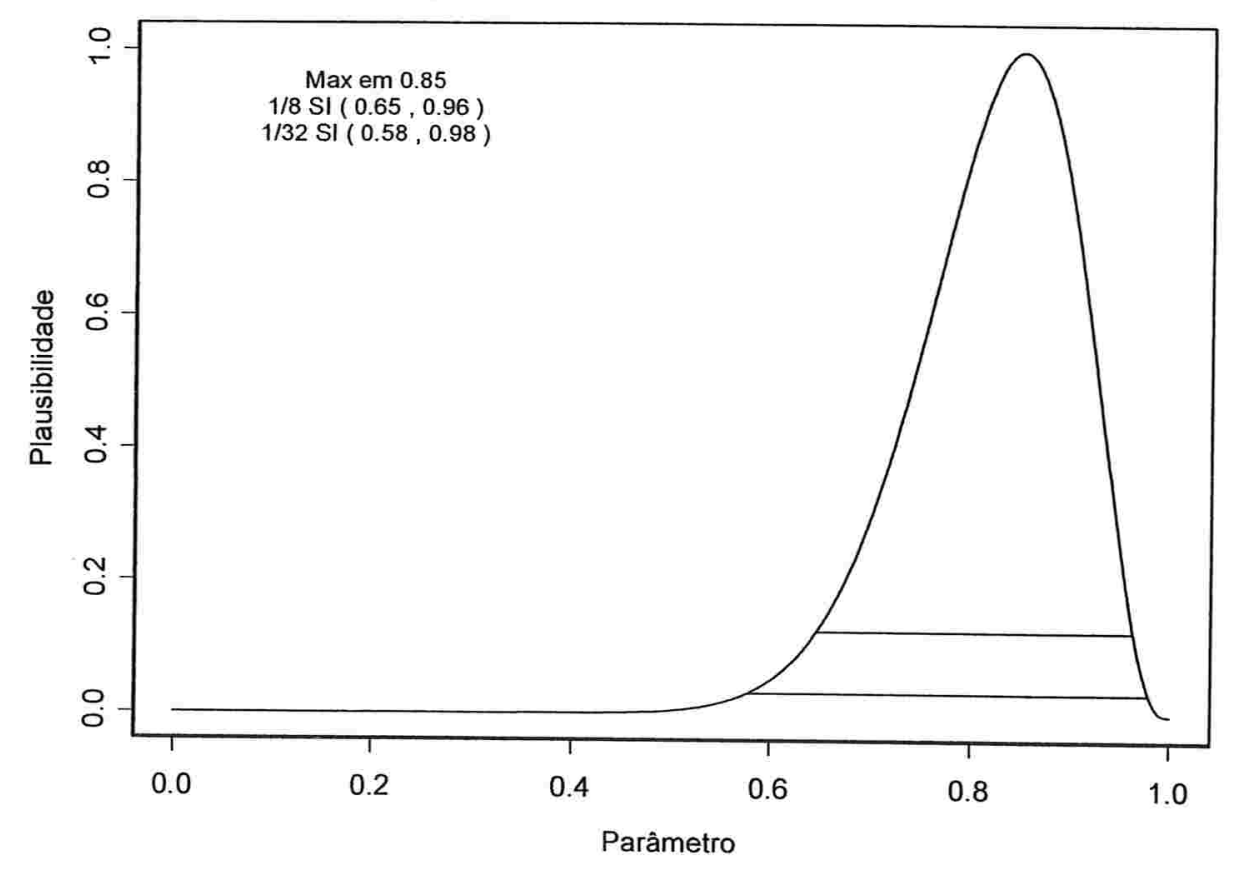

Dentro de um intervalo de 1/8 há diferença no suporte para as hipóteses mas nenhuma delas é mais plausível do que a outra por um fator (k) acima de 8. Por outro lado, hipóteses fora do intervalo são pior suportadas do que a estimativa de máxima verossimilhança por um fator sempre maior ou igual a 8 . De maneira análoga interpretamos o intervalo $1 / 32$. Neste caso, o fator é 32.

No exemplo acima, o intervalo $1 / 8$ compreende os pontos entre 0,65 e 0,96 e o intervalo $1 / 32$ compreende os pontos entre 0,58 e 0,98 . Assim, a hipótese $\theta=0,85$ é melhor suportada por um fator de no mínimo 32 em relação a uma hipótese $\theta=0,57$, por exemplo. 
Podemos também calcular a credibilidade dos intervalos de plausibilidade. Isso é feito a partir da razão $\frac{\int_{a}^{b}[L(\theta) / L(\hat{\theta})] d \theta}{\int_{\theta}[L(\theta) / L(\hat{\theta})] d \theta}=\frac{\int_{a}^{b} L(\theta) d \theta}{\int_{\theta} L(\theta) d \theta}$, isto é, dividimos a área sob a curva dentro do intervalo $[\mathrm{a}, \mathrm{b}]$ pela área total sob a curva. Esse procedimento é baseado na idéia da posteriori bayesiana sob priori uniforme.

Naturalmente, quanto maior o intervalo, maior a sua credibilidade. No exemplo estudado, a credibilidade do intervalo $1 / 8$ é 0,96 e a credibilidade do intervalo $1 / 32$ é 0,99 .

Podemos criar um intervalo a partir da hipótese que testamos no início, $\theta=0,90$. Essa hipótese tem plausibilidade $0,78=\frac{L(0,90)}{L(0,85)}$. O outro ponto que tem a mesma plausibilidade é $\theta=0,79$. Portanto, o "support interval" de 0.78 é $[0,79 ; 0,90]$, conforme a figura abaixo:

FIGURA 3.3 - Verossimilhança Relativa

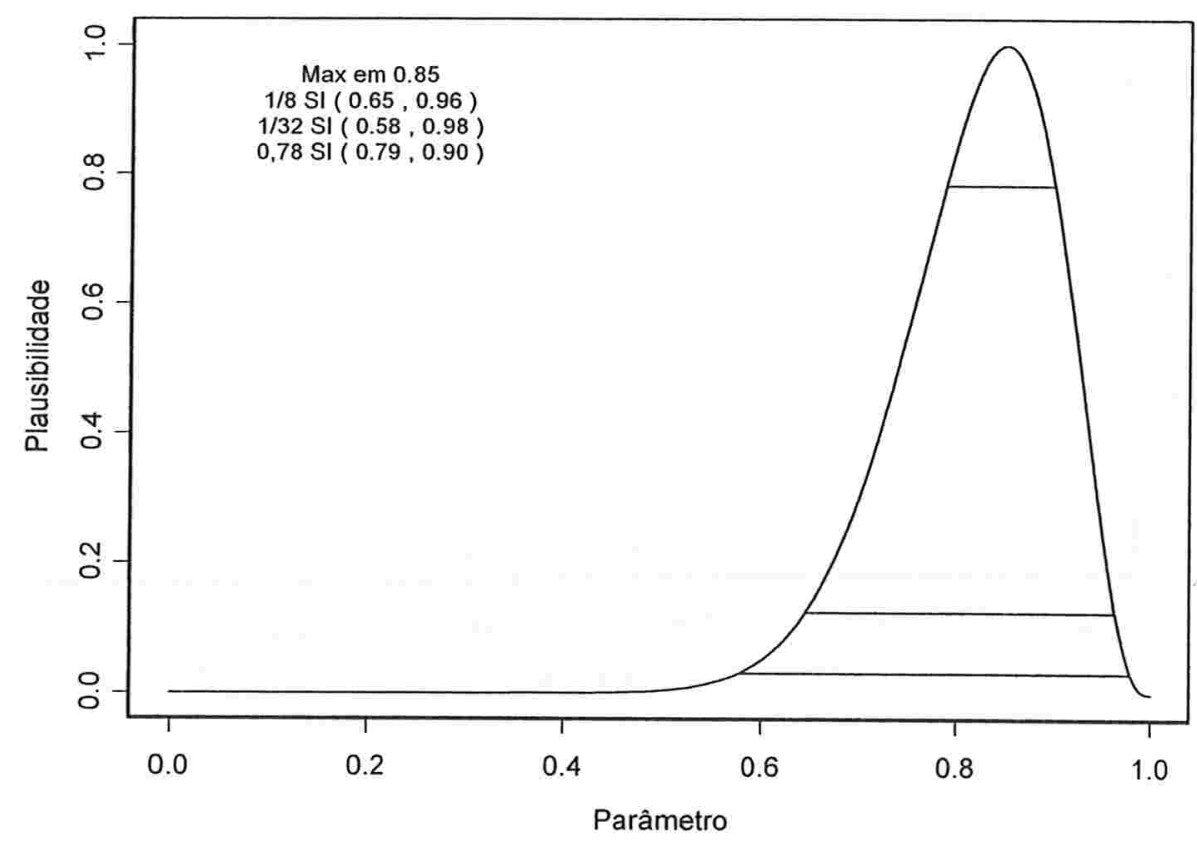

A credibilidade do intervalo $[0,79 ; 0,90]$ é 0,52 , menor do que nos casos anteriores mas para um intervalo também menor, de tamanho 0,11 . 
Suponhamos agora que um experimento de maior escala foi realizado com 150 pacientes e o número de curados por uma terceira droga foi de 119 pessoas. Os pesquisadores desejam testar a hipótese de que esse novo medicamento é eficaz com uma taxa de $85 \%$. Neste caso, a estimativa de máxima verossimilhança é $\hat{\theta}=0,79$.

A plausibilidade da hipótese $\theta=0,85$ é $0,18=\frac{L(0,85)}{L(0,79)}$. O intervalo com plausibilidade 0,18 é $[0,73 ; 0,85]$ e tem credibilidade igual a 0,93 .

O gráfico para esse exemplo encontra-se na figura 3.4, com os 3 intervalos propostos:

FIGURA 3.4 - Verossimilhança Relativa

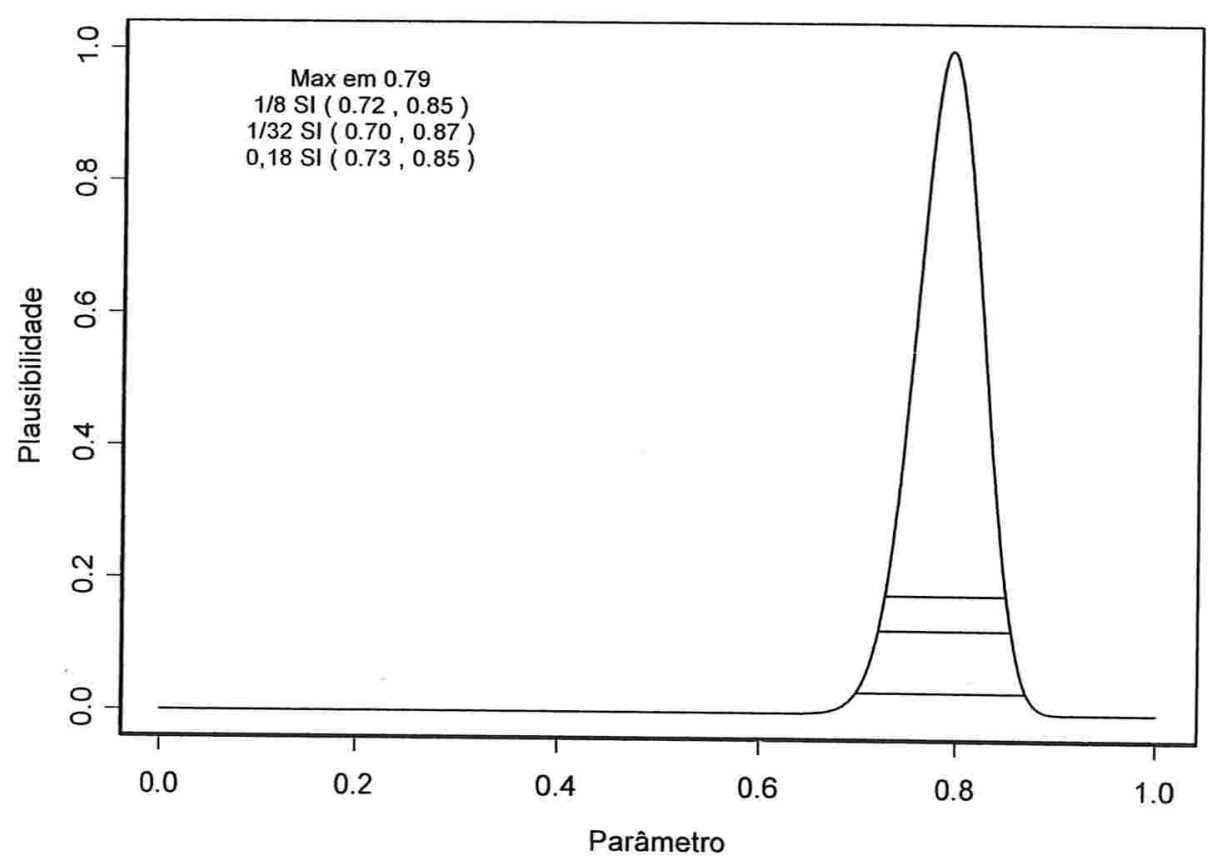

Os intervalos $1 / 8$ e 1/32 são, respectivamente, [0,72;0,85], com credibilidade igual a 0,95 e $[0,70 ; 0,87]$, com credibilidade igual a 0,99 . A taxa de cura de $90 \%$, por exemplo, é menos plausível do que a taxa de $79 \%$ por um fator acima de 32 , com $99 \%$ de credibilidade. 
Retomando a seção inicial deste capítulo, podemos avaliar a evidência pela razão entre pares de hipóteses. A tabela a seguir apresenta alguns exemplos de quanto o fator $\mathrm{k}$ favorece $\mathrm{H}_{1}$ em relação a $\mathrm{H}_{0}$ :

TABELA 3.1 - Fator de Plausibilidade de $\mathrm{H}_{1}$ sobre $\mathrm{H}_{0}$

\begin{tabular}{cccccc} 
& 1 & 2 & 3 & 4 & 5 \\
\hline $\mathrm{H}_{1}$ & 0,80 & 0,80 & 0,80 & 0,85 & 0,85 \\
$\mathrm{H}_{0}$ & 0,85 & 0,90 & 0,70 & 0,60 & 0,70 \\
$\mathrm{k}$ & 5,49 & $1.757,03$ & 27,68 & $62.491,75$ & 5,04
\end{tabular}

A partir da tabela, concluímos que há:

1 - Evidência fraca a favor de 0,80 contra 0,85 .

2 - Evidência muito forte a favor de 0,80 contra 0,90 .

3 - Evidência forte a favor de 0,80 contra 0,70 .

4 - Evidência muito forte a favor de 0,85 contra 0,60 .

5 - Evidência fraca a favor de 0,85 contra 0,70 .

Claramente, valores mais próximos à estimativa de máxima verossimilhança $(\hat{\theta}=0,79)$ têm plausibilidade acentuadamente maior, conforme já observado pelos intervalos obtidos nos gráficos. 


\subsection{3 - Parâmetros "Nuisance"}

Suponha que você queira realizar inferências sobre $\theta$ mas o vetor paramétrico é multidimensional e inclui, no caso bidimensional, por exemplo, um parâmetro $\phi$ que não interessa ao problema estudado. $\phi$ é chamado parâmetro de perturbação ou de incômodo, em geral, "nuisance parameter".

Quando você for avaliar a razão entre verossimilhanças para $\theta_{1}$ e $\theta_{2}$, por exemplo, ela incluirá o parâmetro nuisance: $\frac{L\left(\theta_{1}, \phi\right)}{L\left(\theta_{2}, \phi\right)}$. Assim, a comparação se torna impossível, a menos que você fixe $\phi$, o que seria arbitrário, ou consiga eliminá-lo.

Existem diversos métodos de eliminação de parâmetros nuisance quando considerados pela inferência de verossimilhança mas não há método geral: ortogonalização, verossimilhanças marginais, condicionais, estimadas, perfiladas, etc.

Quando os parâmetros são de variação independente (o espaço paramétrico de um não depende do outro) e podemos fatorar a verossimilhança em um produto, $L(\theta, \phi)=\mathrm{L}_{1}(\theta)$ * $\mathrm{L}_{2}(\phi)$, dizemos que os parâmetros são ortogonais e podemos realizar inferências sobre $\theta$ a partir de $L_{1}(\theta)$. Muitas vezes, isso não acontece diretamente mas a ortogonalização é possível a partir de uma reparametrização.

Exemplo clássico de reparametrização no sentido acima é a obtida a partir de duas Poisson independentes, conforme descrito por Royall. Suponha que $\mathrm{Y}_{1}$ e $\mathrm{Y}_{2}$ são duas variáveis Poisson independentes com parâmetros $\lambda_{1}$ e $\lambda_{2}$, respectivamente, e queiramos realizar inferências sobre a razão $\theta=\frac{\lambda_{1}}{\lambda_{2}}$. A verossimilhança dependerá da soma $\lambda_{1}+\lambda_{2}=$ $\phi$ e esse parâmetro é nuisance.

Com a reparametrização, obtemos $\lambda_{1}=\frac{\theta \cdot \phi}{1+\theta}$ e $\lambda_{2}=\frac{\phi}{1+\theta}$.

Desse modo, chegamos à verossimilhança $\mathrm{L}(\theta, \phi)$, que será proporcional a $\frac{\theta^{y_{1}}}{(1+\theta)^{y_{1}+y_{2}}} \cdot \phi^{y_{1}+y_{2}} \cdot e^{-\phi}$. A evidência sobre a razão $\theta=\frac{\lambda_{1}}{\lambda_{2}}$ fica dada pelo fator $\frac{\theta^{y_{1}}}{(1+\theta)^{y_{1}+y_{2}}}$ e a evidência sobre a soma $\phi=\lambda_{1}+\lambda_{2}$ fica dada pelo fator $\phi^{y_{1}+y_{2}} \cdot e^{-\phi}$. 
A ortogonalização é extremamente útil mas dificilmente é obtida. Outra forma bastante difundida é a utilização da verossimilhança marginal. Nesse caso, trabalha-se não com a função de verossimilhança inteira mas apenas com parte dela, a que possui quase toda a informação desejada. Pereira e Lindley (1987) mostram que esse método freqüentemente despreza informação importante sobre o parâmetro de interesse contida na parte descartada da verossimilhança.

Outra saída é a utilização da verossimilhança condicional, isto é, trabalhamos com a idéia de que "dada determinada condição" a inferência pode ser realizada apenas através do parâmetro de interesse. Exemplo tradicional é o que trata de duas binomiais independentes onde se deseja inferir sobre a razão de chances (odds ratio) e faz-se o condicionamento no total do número de sucessos.

Os métodos que utilizam verossimilhança estimada ou perfilada conseguem bons resultados mas estes são principalmente assintóticos, isto é, exigem amostras grandes.

O método bayesiano, ao trabalhar com distribuições a priori e posteriori, possui sem dúvida a melhor maneira (e a mais simples) de se lidar com parâmetros nuisance. Basta integrá-los que a verossimilhança desejada é obtida.

Suponha que se queira trabalhar com a verossimilhança $P(y \mid \psi)$ mas se tenha acesso a $P(y \mid \psi, \lambda)$, isto é, desejamos realizar inferências sobre o parâmetro $\psi$ mas $\lambda$ aparece como nuisance. Se for escolhida uma priori para $\lambda$ dado $\psi$, isto é, $P(\lambda \mid \psi)$, podese trabalhar com $\int_{\lambda} P(y \mid \psi, \lambda) \cdot P(\lambda \mid \psi) \partial \lambda=P(y \mid \psi)$.

Cordeiro (1992) admite a funcionalidade de se trabalhar com a verossimilhança integrada mas ressalva que a maior dificuldade "reside em obter densidades a priori precisas sobre $\lambda$ envolvendo apenas $\psi$." Quando isso é possível, trabalha-se com a verossimilhança real, sem necessidade de realizar estimações.

O processo bayesiano prossegue com a obtenção da posteriori a partir da verossimilhança integrada e da priori para $\psi: P(\psi \mid y) \propto P(y \mid \psi) \cdot P(\psi)$. A posteriori é de fato uma função de probabilidade e facilita as interpretações. Depende, no entanto, como vimos, do subjetivismo envolvido na escolha de prioris. 
Royall, defensor da abordagem de verossimilhança pura, critica o elemento subjetivo envolvido no processo bayesiano e vai mais longe, ao atacar mesmo os bayesianos chamados objetivos que se utilizam das ditas prioris não informativas.

Segundo Royall, a ignorância absoluta (pure ignorance) não pode ser representada por uma distribuição de probabilidade, apenas estados (ou graus) de conhecimento incerto. Nenhuma distribuição pode representar ausência de conhecimento. Com toda a admiração que demonstramos pelo autor ao considerar várias de suas idéias, essa afirmação parece-nos exagerada e tão subjetiva quanto a de que determinada priori deve ser escolhida.

Aqui cabem as questões: a utilização de procedimentos comprovadamente eficazes, em diversas aplicações, deve ser evitada pelo fato deles não fazerem parte de um paradigma que seguimos ou tentamos estabelecer? Não será possível que tenhamos uma filosofia de trabalho/pensamento, em seu eixo central, e ao mesmo tempo aceitemos algumas sugestões exteriores ao seu núcleo? 


\section{2 - Comparação entre Testes Diagnósticos}

A razão de verossimilhanças é um instrumento bastante útil para a análise de testes diagnósticos. Nesta seção realizamos um breve estudo da utilização da razão para a comparação das habilidades desses testes. A notação a seguir baseia-se em Pereira (2003):

$$
\begin{aligned}
& \mathrm{D}^{+}=\text {Doente; } \\
& \mathrm{D}^{-}=\text {Não Doente; } \\
& \mathrm{T}^{+}=\mathrm{O} \text { teste apresenta resultado positivo; } \\
& \mathrm{T}^{-}=\mathrm{O} \text { teste apresenta resultado negativo. }
\end{aligned}
$$

\begin{tabular}{|c|c|c|c|}
\hline & $\mathbf{D}^{+}$ & $\mathbf{D}^{-}$ & Total \\
\hline $\mathbf{T}^{+}$ & $\mathrm{N}++$ & N-+ & N.+ \\
\hline $\mathbf{T}^{-}$ & N+- & N-- & N.- \\
\hline Total & N+. & N-. & N.. \\
\hline
\end{tabular}

As principais quantidades de interesse nesse tipo de estudo são:

1 - Sensitividade $(\mathrm{S})=\mathrm{P}\left(\mathrm{T}^{+} \mid \mathrm{D}^{+}\right)=$Probabilidade do teste dar positivo dado que o indivíduo é de fato doente;

2 - Especificidade $(\mathrm{E})=\mathrm{P}\left(\mathrm{T}^{-} \mid \mathrm{D}^{-}\right)=$Probabilidade do teste dar negativo dado que o indivíduo não possui a doença;

3 - Valor de Predição Positiva (Positive Predictive Value $=\mathrm{PPV})=\mathrm{P}\left(\mathrm{D}^{+} \mid \mathrm{T}^{+}\right)=$ Probabilidade do indivíduo estar de fato doente se o teste deu positivo;

4 - Valor de Predição Negativa (Negative Predictive Value $=N P V)=\mathrm{P}^{-}\left(\mathrm{D}^{-} \mid \mathrm{T}^{-}\right)=$ Probabilidade do indivíduo não estar doente se o teste deu negativo.

Para o médico, as quantidades 3 e 4 são as mais importantes e um valor alto é desejável nos dois casos, assim como se requer alta sensitividade e alta especificidade.

Definimos ainda:

Razão de Verossimilhança Positiva $=L R^{+}=\frac{S}{1-E}=$ razão entre as taxas de positivo verdadeiro e positivo falso; 
Razão de Verossimilhança Negativa $=L R^{-}=\frac{1-S}{E}=$ razão entre as taxas de negativo falso e negativo verdadeiro.

Aqui, os ideais são valores grandes para $\mathrm{LR}^{+}$e valores pequenos para $\mathrm{LR}^{-}$. A razão entre eles pode ser medida por $R=\frac{L R^{+}}{L R^{-}}$.

Estudando a habilidade dos testes diagnósticos, Biggerstaff (2000) estabelece relação direta entre os valores preditivos e as razões de verossimilhança. Assim, um teste tem PPV maior do que outro se e só se tem também $\mathrm{LR}^{+}$maior. Por outro lado, um teste tem NPV maior do que outro se e só se tem LR $^{-}$menor. A partir dessas relações, as razões de verossimilhança passam a ser o principal interesse para medir a habilidade do teste.

Detalhando o apresentado em Pereira (2003):

$$
\begin{aligned}
R=\frac{L R^{+}}{L R^{-}} & =\frac{S \cdot E}{(1-S) \cdot(1-E)} \\
& =\frac{P\left(T^{+} \mid D^{+}\right) \cdot P\left(T^{-} \mid D^{-}\right)}{\left[1-P\left(T^{+} \mid D^{+}\right)\right] \cdot\left[1-P\left(T^{-} \mid D^{-}\right)\right]} \\
& =\frac{P\left(T^{+} \mid D^{+}\right) \cdot P\left(T^{-} \mid D^{-}\right)}{P\left(T^{-} \mid D^{+}\right) \cdot P\left(T^{+} \mid D^{-}\right)} \\
& =\frac{P\left(T^{+}, D^{+}\right) \cdot P\left(T^{-}, D^{-}\right)}{P\left(T^{-}, D^{+}\right) \cdot P\left(T^{+}, D^{-}\right)} \\
& =\frac{P\left(D^{+}, T^{+}\right) \cdot P\left(D^{-}, T^{-}\right)}{P\left(D^{-}, T^{+}\right) \cdot P\left(D^{+}, T^{-}\right)} \\
& =\frac{P\left(D^{+} \mid T^{+}\right) \cdot P\left(D^{-} \mid T^{-}\right)}{P\left(D^{-} \mid T^{+}\right) \cdot P\left(D^{+} \mid T^{-}\right)} \\
& =\frac{P\left(D^{+} \mid T^{+}\right) \cdot P\left(D^{-} \mid T^{-}\right)}{\left[1-P\left(D^{+} \mid T^{+}\right)\right] \cdot\left[1-P\left(D^{-} \mid T^{-}\right)\right]}
\end{aligned}
$$

Desse modo, $R=\frac{L R^{+}}{L R^{-}}=\frac{(P P V) \cdot(N P V)}{(1-P P V) \cdot(1-N P V)}$, isto é, quanto maior $\mathrm{R}$, maiores os valores preditivos e vice-versa. 
Para avaliar se a habilidade de um determinado teste é maior do que a de outro, os autores citados apresentam uma interessante forma gráfica, construída da seguinte maneira:

$A=\left(X_{0}, Y_{0}\right)=(1-E, S)$, ou seja, $X_{0}$ é a taxa de positivo falso e $Y_{0}$ é a taxa de positivo verdadeiro. Por esse ponto traçamos duas retas, uma iniciando no $(0,0)$ e terminando no $(X, 1)$ e a outra iniciando no $(1,1)$ e terminando no $(0, Y)$.

É fácil perceber que o coeficiente angular da primeira reta é dado por $\frac{S}{1-E}$ e o coeficiente angular da segunda reta é dado por $\frac{1-S}{E}$. Assim, as inclinações das retas representam, respectivamente, $\mathrm{LR}^{+}$e $\mathrm{LR}^{-}$.

Traçando-se as duas retas assim construídas, obtemos quatro regiões determinadas pelo teste, conforme a figura abaixo:

FIGURA 3.5 - Regiões Preferenciais

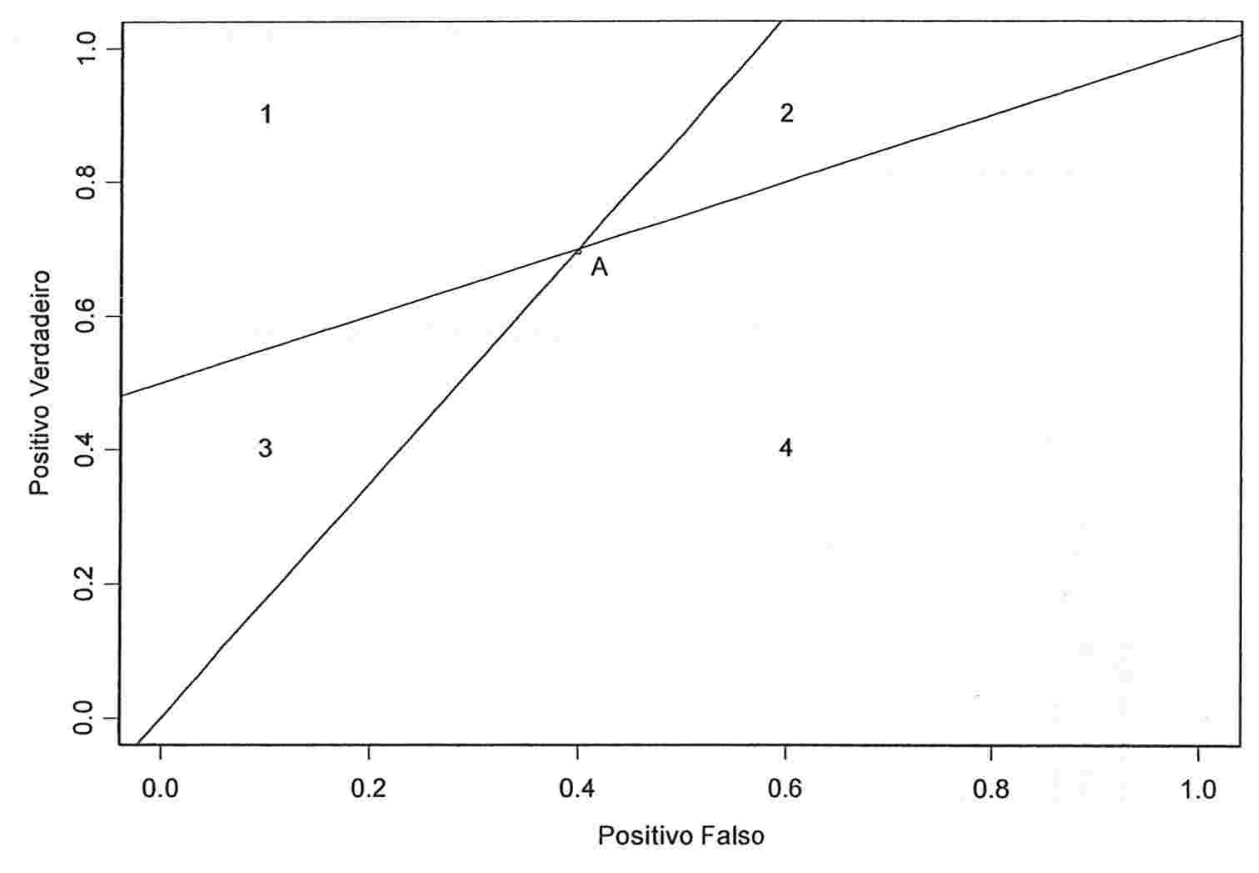

Se estamos medindo a habilidade de um novo teste $\mathrm{T}_{1}$ em relação ao teste conhecido $T$, a partir de sua sensitividade e especificidade obtemos o ponto $A_{1}=\left(1-E_{1}, S_{1}\right)$ e procedemos à comparação das habilidades a partir das regiões construídas: 
a) $A_{1}$ está na região 1: $T_{1}$ é superior a $T$ em todos os sentidos, pois tem $\mathrm{LR}^{+}$maior e $\mathrm{LR}^{-}$menor do que a de T;

b) $A_{1}$ está na região 2: $T_{1}$ é superior a $T$ para confirmar ausência de doença pois sua $\mathrm{LR}^{-}$é menor, mas é pior para confirmar presença pois sua $\mathrm{LR}^{+}$é também menor;

c) $A_{1}$ está na região 3: $T_{1}$ é superior a $T$ para confirmar a presença de doença pois sua $\mathrm{LR}^{+}$é maior, mas é pior para confirmar ausência pois sua $\mathrm{LR}^{-}$é também maior;

d) $\mathrm{A}_{1}$ está na região 4: $\mathrm{T}_{1}$ é inferior a $\mathrm{T}$ em todos os sentidos, pois tem $\mathrm{LR}^{+}$menor e $\mathrm{LR}^{-}$maior do que de T;

Vamos considerar um exemplo em que um teste conhecido possui sensitividade igual a 0,80 e especificidade também igual a 0,80 . Desse modo, $A=(0,20 ; 0,80)$. Construímos o gráfico determinando as quatro regiões. Suponha agora que um novo teste $A_{1}$ possui sensitividade igual a 0,90 e especificidade igual a 0,70 . Construímos $A_{1}=(0,30$; $0,90)$. Claramente, $A_{1}$ está na região 2 , ou seja, o novo teste é superior ao antigo para confirmar ausência de doença mas é inferior para confirmar a presença.

A figura 3.6 a seguir representa este caso:

\section{FIGURA 3.6 - Regiões Preferenciais}

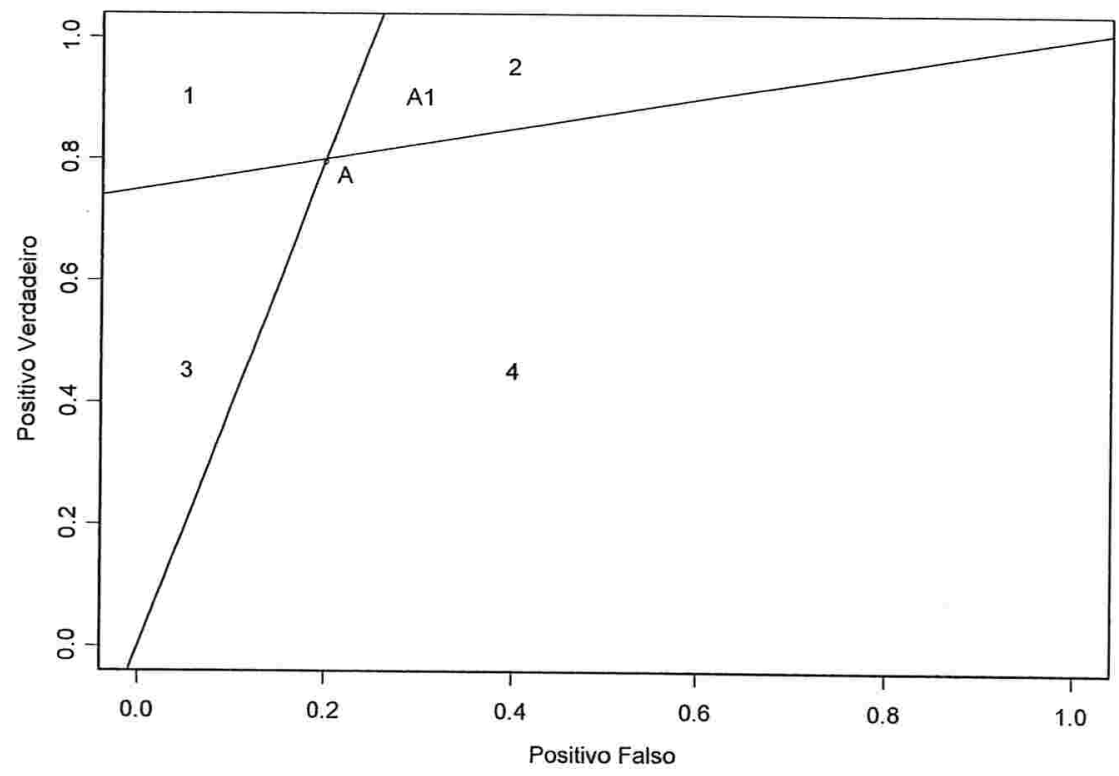


Em seguida, foi avaliado um novo teste $A_{2}$, que apresentou sensitividade igual a 0,90 e especificidade igual a 0,79 . Assim, $\mathrm{A}_{2}=(0,21 ; 0,90)$. Ao incluí-lo no gráfico junto com o teste tradicional A e o teste $\mathrm{A}_{1}$ obtemos:

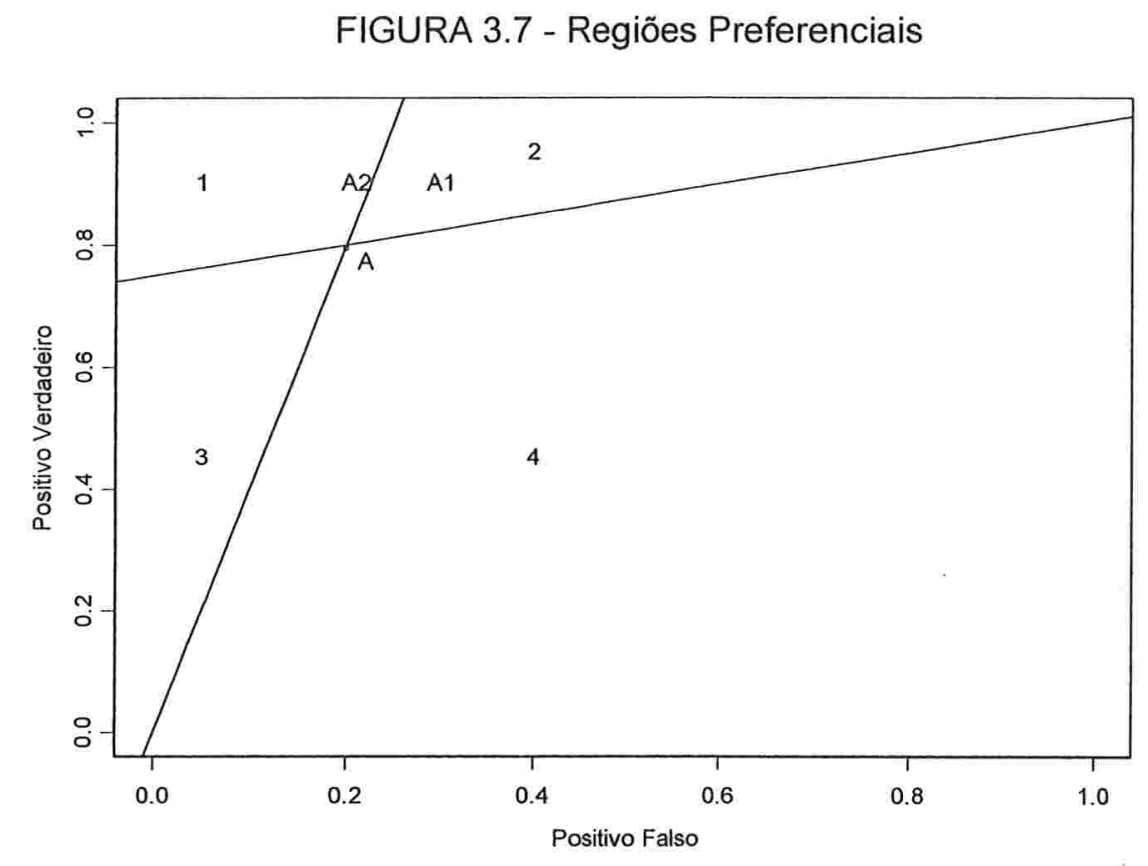

Notamos que o teste $\mathrm{A}_{2}$ está na região 1 e portanto é superior a $\mathrm{A}$ em todos os sentidos, para a confirmação de presença e para a confirmação de ausência de doença.

Como último exemplo, vamos comparar o teste $\mathrm{A}_{2}$ que acabamos de considerar, e um teste $A_{3}$ que foi desenvolvido recentemente no país. Lembrando que $A_{2}$ tem $S_{2}=0,90$ e $E_{2}=0,79, A_{3}$ está apresentando $S_{3}=0,85$ e $E_{3}=0,81$, ou seja, $A_{3}=(0,19 ; 0,85)$ tem sensitividade pouco menor e especificidade pouco maior do que $\mathrm{A}_{2}$.

Colocando $\mathrm{A}_{2}$ (agora como teste básico) e $\mathrm{A}_{3}$ no gráfico obtemos a figura 3.8: 


\section{FIGURA 3.8 - Regiões Preferenciais}

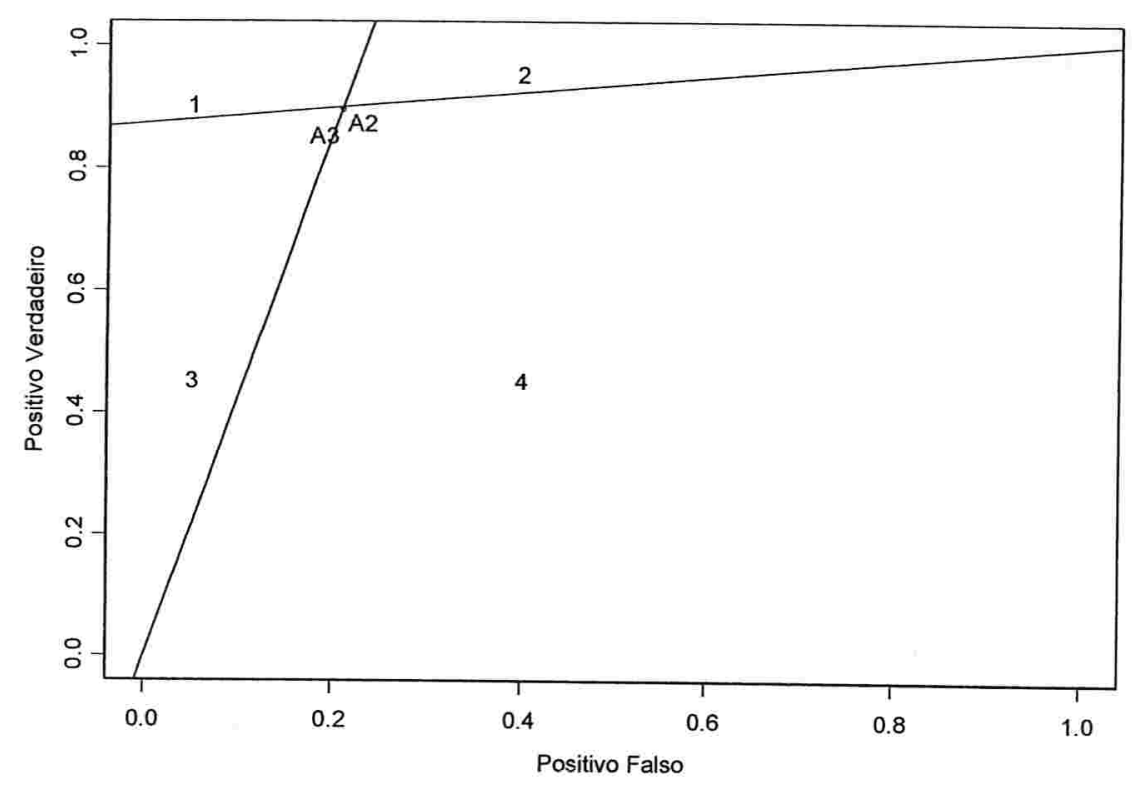

Como $\mathrm{A}_{3}$ está na região 3, pode-se dizer que esse teste apresenta maior habilidade para detectar a presença da doença e menor habilidade para detectar a ausência, sempre em comparação com $\mathrm{A}_{2}$. Cabe agora aos experts da área escolher em cada situação qual dos dois testes deve ser utilizado. 


\section{Capítulo 4}

\section{FBST: Um Novo Teste Bayesiano para Hipóteses Precisas}

Nos testes de hipóteses, o espaço paramétrico $\Theta$ é particionado em dois subconjuntos disjuntos, $\Theta_{0} \mathrm{e} \Theta_{1}$, sendo a hipótese nula de interesse, $\mathrm{H}_{0}, \theta \in \Theta_{0}$, enquanto que a alternativa, $\mathrm{H}_{1}$, consiste em assumirmos $\theta \in \Theta_{1}$. Testes de hipóteses precisas são aqueles em que $\Theta_{0}$ tem dimensão menor do que $\Theta$.

Vamos supor que precisamos testar $\mathrm{H}_{0}: \theta=\theta_{0}$ versus $\mathrm{H}_{1}: \theta \neq \theta_{0}$. A probabilidade a priori, $\pi(\theta)$, é zero no caso contínuo e portanto a probabilidade a posteriori $\mathrm{P}\left(\theta_{0} \mid \mathrm{x}\right)$ também será nula e qualquer teste desse tipo se torna impossível.

Uma solução bayesiana típica para esse problema foi dada por Jeffreys. Atribui-se uma massa de probabilidade positiva para a hipótese nula, $\mathrm{P}\left(\theta=\theta_{0}\right)=\gamma>0$, e a probabilidade que resta é distribuída em $\Theta_{1}$.

Conforme Madruga -Tavares (2002), as distribuições a posteriori terão a seguinte forma:

$$
\begin{gathered}
P\left(\theta_{0} \mid x\right)=\frac{\gamma \cdot P\left(x \mid \theta_{0}\right)}{P(x)} \mathrm{e} \\
P(\theta \mid x)=\frac{(1-\gamma) \cdot P(x \mid \theta) \cdot \pi(\theta)}{P(x)} \\
\operatorname{com} P(x)=\gamma \cdot P\left(x \mid \theta_{0}\right)+(1-\gamma) \cdot \int_{\theta \neq \theta_{0}} P(x \mid \theta) \cdot \pi(\theta) d \theta .
\end{gathered}
$$

A comparação entre o procedimento bayesiano citado e o teste de significância clássico no caso de uma distribuição normal leva ao conhecido "Paradoxo de Lindley" (ou "Paradoxo de Jeffreys"): a probabilidade a posteriori de $\mathrm{H}_{0}$ tende a 1 quando aumenta o tamanho da amostra; ao mesmo tempo, a estatística do teste, $\bar{x}$, difere de $\theta_{0}$ a um nível $\alpha$ por cento de significância, ou (100- $\alpha$ ) por cento de confiança. Nas palavras de Lindley, em 
um artigo famoso de 1957, "com $\alpha=5$ nós temos $95 \%$ de confiança de que $\theta$ é diferente de $\theta_{0}$ e temos uma credibilidade de $95 \%$ de que $\theta$ é igual a $\theta_{0}$."

Na prática, muitas vezes o aumento do tamanho da amostra é utilizado para que o cientista prove sua hipótese. Isso pode ser feito nos dois sentidos: "aumente o tamanho da amostra para rejeitar" ou "aumente o tamanho da amostra para aceitar", numa clara tentativa de "burlar" a evidência que os dados trouxeram.

Mais recentemente, Berger e Selke (1987) e Berger e Delampady (1987) mostraram a dificuldade de conciliação entre o p-value clássico e medidas de evidência bayesianas para diversas classes de distribuições a priori. Segundo esses autores, o mais comum não é a proximidade entre as medidas mas, pelo contrário, o afastamento relativamente grande entre elas. Assim, rejeita-se a hipótese nula numa análise clássica mas essa mesma hipótese é freqüentemente confirmada numa perspectiva bayesiana.

A medida de evidência bayesiana proposta por Pereira e Stern (1999) procura superar os problemas citados na avaliação de hipóteses precisas a partir da construção de um teste denominado FBST, Full Bayesian Significance Test, Teste de Significância Completamente (Genuinamente) Bayesiano.

A medida de evidência em favor de uma hipótese, que denominaremos EV $\left(\mathrm{H}_{1}\right)$, considera todos os pontos do espaço paramétrico cujos valores da densidade superior são no mínimo tão grandes quanto seu supremo em $\theta_{0}$.

O procedimento proposto no FBST é chamado bayesiano porque envolve apenas a densidade a posteriori e o cálculo de credibilidade em determinado conjunto. Parece-nos de vital importância que possamos calcular o quanto uma hipótese é plausível, qual sua credibilidade, e não nos limitemos ao cálculo de erros em processos de decisão.

Além disso, o FBST evita a necessidade de introdução de uma probabilidade positiva a priori, como sugerido por Jeffreys, e, ao mesmo tempo, torna irrelevantes quaisquer considerações a respeito do espaço amostral e a utilização de dados "mais extremos" e que "poderiam ocorrer", como é feito no cálculo do p-value.

O teste é definido a seguir. 
Sejam

$\mathrm{X}_{1}, \ldots, \mathrm{X}_{\mathrm{n}}$ variáveis aleatórias com densidade conjunta $\mathrm{f}\left(\mathrm{x}_{1}, \ldots, \mathrm{x}_{\mathrm{n}} ; \theta\right)$, indexadas por um vetor paramétrico $\theta \in \Theta$;

$\mathrm{p}(\theta)$ densidade a priori;

$\mathrm{L}\left(\theta ; \mathrm{x}_{1}, \ldots, \mathrm{x}_{\mathrm{n}}\right)$ função de verossimilhança de $\theta$ em $\Theta ;$

$\mathrm{p}_{\mathrm{n}}(\theta)$ densidade a posteriori, $\operatorname{com} \mathrm{p}_{\mathrm{n}}(\theta) \propto \mathrm{L}\left(\theta ; \mathrm{x}_{1}, \ldots, \mathrm{x}_{\mathrm{n}}\right) \cdot \mathrm{p}(\theta) ;$

$\mathrm{H}_{0}: \theta \in \theta_{0} \subset \Theta$ hipótese nula. Neste caso, $\operatorname{dim}\left(\theta_{0}\right)<\operatorname{dim}(\theta)$.

$\mathrm{O}$ valor da evidência contra a hipótese $\mathrm{H}_{0}, \mathrm{EV}\left(\mathrm{H}_{1}\right)$, está assim definido (Stern, 2002; Madruga et al, 2003):

$$
\begin{aligned}
& \mathrm{EV}\left(\mathrm{H}_{1}\right)=\int_{\Gamma_{H}} p_{n}(\theta) d \theta \quad, \text { onde } \\
& \mathrm{T}_{\mathrm{H}}=\left\{\theta \in \Theta \mid \mathrm{S}(\theta)>\mathrm{S}_{\mathrm{H}}\right\} \\
& \mathrm{S}_{\mathrm{H}}=\operatorname{sup~} \mathrm{S}\left(\theta_{\mathrm{H}}\right) \\
& \mathrm{S}(\theta)=\frac{p_{n}(\theta)}{r(\theta)} .
\end{aligned}
$$

$\mathrm{S}(\theta)$ é conhecido como a surpresa a posteriori relativa à densidade de referência $\mathrm{r}(\theta)$. Seu papel é tornar EV $\left(\mathrm{H}_{1}\right)$ explicitamente invariante sob reparametrizações adequadas.

O conjunto tangente $T_{H}$ é o conjunto de mais alta surpresa relativa, Highest Relative Surprise Set (HRSS). Contém os pontos do espaço paramétrico que, relativamente à densidade de referência, apresentam surpresa maior do que qualquer ponto no conjunto nulo $\theta_{\mathrm{H}}$.

Quando $\mathrm{r}(\theta)$ é igual a 1, $\mathrm{T}_{\mathrm{H}}$ é o conjunto de mais alta densidade posterior, Highest Density Probability Set (HPDS), tangente ao conjunto nulo $\theta_{\mathrm{H}}$. Na formulação original do 
FBST (1999) era empregado o HPDS. Entretanto, o fato do teste original não ser invariante exigiu a introdução de $r(\theta)$ e, conseqüentemente, do HRSS.

Basicamente, o procedimento proposto consiste na maximização da posteriori sob $\mathrm{H}_{0}$, obtendo-se $\mathrm{S}_{\mathrm{H}}$, seguido pela integração da posteriori em todo o conjunto em que ela se apresenta maior do que $S_{H}$. Se a probabilidade a posteriori de $T_{H}$ é grande, o conjunto nulo está numa região de baixa densidade a posteriori e os dados trazem bastante evidência contra $\mathrm{H}_{0}$. Se a probabilidade a posteriori de $\mathrm{T}_{\mathrm{H}}$ é pequena, os dados trazem pouca evidência contra $\mathrm{H}_{0}$.

O cálculo da evidência é feito, portanto, em duas etapas: otimização e integração. $O$ primeiro passo refere-se à obtenção do máximo da posteriori sob $\mathrm{H}_{0}, \mathrm{~S}_{\mathrm{H}}$. O segundo passo relaciona-se ao cálculo da credibilidade do conjunto dos pontos que aparecem acima de $\mathrm{S}_{\mathrm{H}}$. Em geral, essa segunda etapa é feita numericamente através de técnicas de simulação de Monte Carlo.

Para problemas mais complexos, a realização das duas etapas exigirá bastante trabalho computacional. Madruga et al apresentam diversas referências bibliográficas a respeito dos algoritmos de otimização e de integração numérica. Nesse caso, o trabalho fundamental do estatístico relaciona-se à formulação do problema e à obtenção da posteriori. Para as tarefas numéricas complexas será necessária a associação entre o estatístico e pesquisadores das áreas de computação e matemática aplicada, conforme reivindica o professor Julio Stern.

Entre outras coisas, Madruga-Tavares (2002) mostra que o FBST não viola o Princípio da Verossimilhança e é consistente, ou seja,

$$
\begin{aligned}
& \lim _{n \rightarrow \infty} E V\left(H_{1}\right)=1, \theta \neq \theta_{0} \\
& \lim _{n \rightarrow \infty} E V\left(H_{1}\right)=0, \theta=\theta_{0}
\end{aligned}
$$

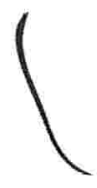

Em diferentes papers, Pereira, Stern e associados listam diversas características vantajosas da medida de evidência resultante do FBST quando comparado com os testes tradicionais, bayesianos ou clássicos. Vamos resumir algumas delas: 
- $\quad$ O FBST é realizado sem necessidade de introdução de massa artificial para a hipótese precisa;

- a evidência é computada no espaço paramétrico, considerando apenas a amostra observada;

- tem o "sabor" da significância proporcionada pelo tradicional p-value;

- o FBST permanece no espaço paramétrico original em sua inteira dimensão, sem necessidade de eliminação de parâmetros nuisance;

- o teste considera apenas a localização do ponto de máxima verossimilhança sob a hipótese nula, independentemente de sua parametrização, dando à metodologia uma caracterização geométrica, ao contrário do que ocorre, por exemplo, no teste exato de Fisher;

o procedimento permite a construção de uma regra de decisão tipo "rejeitar $\mathrm{H}_{0}$ quando $\mathrm{EV}<\alpha$ ", conforme desejo de muitos estatísticos e pesquisadores.

No artigo intitulado "Significance test, belief calculi and burden of proof in legal and scientific discourse" (2002), o professor Júlio Stern procura detalhar o embasamento da medida de evidência desenvolvida com seu colega Carlos Pereira a partir do princípio jurídico conhecido como Onus Probandi (ônus da prova, burden of proof).

O princípio afirma que a responsabilidade pela prova está no reclamante ("plaintiff"). Assim, o FBST baseia-se na idéia de que a hipótese nula é a hipótese de trabalho do cientista e cabem aos dados efetivamente coletados na amostra a tarefa de refutá-la. O "benefício da dúvida" está com a hipótese nula.

No próximo capítulo, estudamos a aplicação do FBST a três conhecidos testes de hipóteses precisas relacionados à distribuição binomial, comparando a nova medida de evidência aos tradicionais p-value e Fator de Bayes. 


\section{Capítulo 5}

\section{Aplicação do FBST à Distribuição Binomial}

As medidas mais comuns utilizadas em testes de hipóteses precisas, o p-value e o Fator de Bayes, são medidas de evidência para a hipótese nula. O Fator de Bayes é em geral calculado como $F B_{01}=\frac{\int_{0} P(x \mid \theta) \cdot \pi_{0}(\theta) d \theta}{\int_{b_{1}} P(x \mid \theta) \cdot \pi_{1}(\theta) d \theta}$ e valores maiores que 1 favorecem a hipótese nula.

No caso do p-value, calculamos a probabilidade de obter valores iguais ou "mais extremos" do que os observados, dada a hipótese nula. Na prática, apesar da falta de rigor, essa medida costuma ser vista como o grau de evidência de $\mathrm{H}_{0}$.

Desse modo, neste trabalho, para efeito de comparação, devemos utilizar o FBST em sua formulação original (Pereira e Stern, 1999), em que o resultado é uma medida de evidência para $\mathrm{H}_{0}, \mathrm{EV}(\mathrm{H})$. Aqui, essa medida será denominada $\mathrm{EV}$.

Designando d os dados coletados, $\theta$ o parâmetro de interesse e usando prioris uniformes, o FBST resume-se a:

1 - Obtenção da posteriori $\mathrm{f}(\theta \mid \mathrm{d})$;

2 - maximização da posteriori sob $\mathrm{H}_{0}, \mathrm{f}^{*}\left(\theta_{0} \mid \mathrm{d}\right)$;

3 - integração da posteriori no conjunto em que ela se apresenta igual ou maior do que seu máximo sob $H_{0}, f(\theta \mid d) \geq f^{*}\left(\theta_{0} \mid d\right)$. Representando esse conjunto por $T_{\varphi}$,

$k=\int_{\Gamma_{\varphi}} f(\theta \mid d) d \theta$ é a medida de sua credibilidade;

4 - cálculo da evidência da hipótese nula: $\mathrm{EV}=1-k$.

Há três testes de hipóteses precisas diretamente relacionados à distribuição binomial/multinomial: teste para a proporção de sucesso; teste de homogeneidade em tabela 
$2 \times 2$; teste de independência em tabela $2 \times 2$. Vamos abordá-los a partir das duas metodologias dominantes, a que resulta no p-value clássico (PV) e a que resulta no Fator de Bayes $($ Bayes Factor $=$ BF); em seguida, calculamos a medida de evidência gerada pelo FBST, EV. 


\section{1 - Teste para Proporção de Sucesso}

Queremos testar se determinada proporção de sucesso $\theta$ é igual a um valor específico ou diferente desse valor, $\theta=\theta_{0}$ versus $\theta \neq \theta_{0}$. Aqui, ao contrário dos exemplos estudados a partir da aplicação direta da verosssimilhança, não há um valor específico para a hipótese alternativa. Assim, essa hipótese cobre todo o espaço paramétrico com exceção do ponto $\theta=\theta_{0}$. Este teste também é chamado de Teste do Parâmetro da Binomial.

Vamos ver um exemplo desse tipo de teste, descrevendo os procedimentos para a obtenção das três medidas de evidência.

$$
\begin{aligned}
& \mathrm{H}_{0}: \theta=0,4 \text { versus } \mathrm{H}_{1}: \theta \neq 0,4 \\
& \mathrm{n}=50 \text { ensaios } \\
& \mathrm{x}=\text { número de sucessos observados } \\
& \Theta=\{0 \leq \theta \leq 1\}
\end{aligned}
$$




\section{a) P-VALUE}

Em testes para proporções, o p-value costuma ser calculado a partir da estatística qui-quadrado. Sabemos que $\chi_{o b s}^{2}=\sum_{i=1}^{k} \frac{\left(O_{i}-E_{i}\right)^{2}}{E_{i}} \sim \chi_{k-1}^{2}$, onde

$\mathrm{k}=\mathrm{n}^{\circ}$ de categorias mutuamente exclusivas;

$\mathrm{O}_{i}=$ freqüências observadas;

$\mathrm{E}_{i}=$ freqüências esperadas;

$\chi_{k-1}^{2}=$ distribuição qui-quadrado com $\mathrm{k}-1$ graus de liberdade.

No teste para proporções, pode-se dizer que há duas categorias a considerar: com determinada característica, por exemplo, resultado positivo em um exame, e sem a característica. Assim, $\mathrm{k}=2$ e portanto a estatística utilizada é $\chi_{1}^{2}$. O p-value é calculado da seguinte forma:

$$
\mathrm{PV}=\mathrm{P}\left(\chi_{1}^{2} \geq \chi_{\text {obs }}^{2} \mid \mathrm{H}_{\mathrm{o}} \text { é verdadeira }\right) \text {. }
$$

Para $\mathrm{n}=50$ e a hipótese nula $\theta=\theta_{0}=0,4$, o valor esperado na categoria de interesse é $50 \cdot 0,4=20$, enquanto o valor esperado na outra categoria é $50 \cdot 0,6=30$. A partir do número $\mathrm{x}$ de sucessos observados, calculamos

$$
\begin{aligned}
& \chi_{o b s}^{2}=\frac{(x-n \cdot \theta)^{2}}{n \cdot \theta}+\frac{((n-x)-n \cdot(1-\theta))^{2}}{n \cdot(1-\theta)} . \text { Desta forma, } \\
& \chi_{o b s}^{2}=\frac{(x-n \cdot \theta)^{2}}{n \cdot \theta}+\frac{(n \cdot \theta-x)^{2}}{n \cdot(1-\theta)}=(x-n \cdot \theta)^{2} \cdot\left[\frac{1}{n \cdot \theta}+\frac{1}{n \cdot(1-\theta)}\right] .
\end{aligned}
$$

No caso presente, $\chi_{o b s}^{2}=\frac{(x-20)^{2}}{12}$. $\left(\right.$ sob H $\left.\mathrm{H}_{0}\right)$ 


\section{b) FATOR DE BAYES}

$$
B F=\frac{P(x \mid \theta) \cdot \pi_{0}(\theta)}{\int_{\delta_{1}} P(x \mid \theta) \cdot \pi_{1}(\theta) d \theta} .
$$

Usando como prioris $P\left(H_{0}\right)=0,5$ e $P\left(H_{1}\right)=0,5$ e uma densidade uniforme para $\theta$ sob $\mathrm{H}_{1}$,

$$
B F=\frac{P\left(x \mid H_{0}\right)}{\int_{\theta} P\left(x \mid H_{1}\right) d \theta} .
$$

Para a hipótese precisa $\mathrm{H}_{0}: \theta=\theta_{0}$,

$$
P\left(x / H_{0}\right)=\left(\begin{array}{l}
n \\
x
\end{array}\right) \cdot \theta_{0}{ }^{x} \cdot\left(1-\theta_{0}\right)^{n-x}
$$

Para a hipótese alternativa $\mathrm{H}_{1}: \theta \neq \theta_{0}$,

$$
\begin{aligned}
\int_{\theta} P\left(x \mid H_{1}\right) d \theta & =\int_{0}^{1}\left(\begin{array}{l}
n \\
x
\end{array}\right) \cdot \theta^{x} \cdot(1-\theta)^{n-x} d \theta \\
& =\left(\begin{array}{l}
n \\
x
\end{array}\right) \frac{\Gamma(x+1) \cdot \Gamma(n-x+1)}{\Gamma(n+2)} \cdot \int_{0}^{1} \frac{\theta^{x+1-1} \cdot(1-\theta)^{n-x+1-1} \cdot \Gamma(n+2)}{\Gamma(x+1) \cdot \Gamma(n-x+1)} d \theta .
\end{aligned}
$$

Assim, $\theta \sim \operatorname{beta}(\mathrm{x}+1, \mathrm{n}-\mathrm{x}+1)$ e o valor da integral é um. Logo, 


$$
\begin{aligned}
& \int_{b} P\left(x \mid H_{1}\right) d \theta=\left(\begin{array}{l}
n \\
x
\end{array}\right) \frac{\Gamma(x+1) \cdot \Gamma(n-x+1)}{\Gamma(n+2)} \Rightarrow \\
& \int_{b} P\left(x \mid H_{1}\right) d \theta=\frac{n !}{x ! \cdot(n-x) !} \cdot \frac{x ! \cdot(n-x) !}{(n+1) !} \Rightarrow \\
& \int_{b} P\left(x \mid H_{1}\right) d \theta=\frac{1}{n+1} .
\end{aligned}
$$

Desse modo,

$$
B F=(\mathrm{n}+1) \cdot\left(\begin{array}{l}
n \\
x
\end{array}\right) \cdot \theta_{0}{ }^{x} \cdot\left(1-\theta_{0}\right)^{n-x}
$$

Para $n=50$ e $\theta_{0}=0,4$,

$$
B F=(51) \cdot\left(\begin{array}{l}
50 \\
x
\end{array}\right) \cdot 0,4^{x} \cdot(0,6)^{n-x} \text {. }
$$




\section{c) $\mathrm{EV}$}

Uma distribuição conjugada para a binomial é a beta. Utilizando uma priori uniforme - equivalente a uma beta $(1,1)$, obtemos a posteriori

$$
f(\theta \mid d) \propto \theta^{x} .(1-\theta)^{n-x}
$$

$\mathrm{O}$ máximo da posteriori sob $\mathrm{H}_{0}$ é obtido a partir do estimador de máxima verossimilhança. Aqui, entretanto, a hipótese nula é $\theta=\theta_{0}=0,4$, levando à seguinte posteriori sob $\mathrm{H}_{0}$ :

$$
f^{*}\left(\theta_{0} \mid d\right) \propto 0,4^{x} \cdot(1-0,4)^{n-x} .
$$

Utilizamos simulação de Monte Carlo para obter $k=\int_{\Gamma_{H}} f(\theta \mid d) d \theta$ da seguinte maneira:

1 - Geramos 10.000 valores $\left(u_{i}\right)$ de uma uniforme $(0,1)$;

2 - com cada um desses valores, calculamos 10.000 posterioris $u_{i}^{x} \cdot\left(1-u_{i}\right)^{n-x}$;

3 - somamos todas as posterioris que resultaram em valor igual ou superior a $f^{*}\left(\theta_{0} \mid d\right)$, obtendo $S_{M}$;

4 - somamos todas as 10.000 posterioris, obtendo $S_{T}$;

$5-$ calculamos $k=\frac{S_{M}}{S_{T}} ;$

6 - calculamos $\mathrm{EV}=1-k$.

As três medidas de evidência, para x entre 0 e 40, encontram-se na tabela 5.1 a seguir: 
TABELA 5.1 - Evidência no Teste para Proporção

\begin{tabular}{ccccc}
\hline $\boldsymbol{x}$ & PV & BF & EV & $\boldsymbol{x}$ \\
\hline 0 & 0,00 & 0,00 & 0,00 & 0 \\
1 & 0,00 & 0,00 & 0,00 & 1 \\
2 & 0,00 & 0,00 & 0,00 & 2 \\
3 & 0,00 & 0,00 & 0,00 & 3 \\
4 & 0,00 & 0,00 & 0,00 & 4 \\
5 & 0,00 & 0,00 & 0,00 & 5 \\
6 & 0,00 & 0,00 & 0,00 & 6 \\
7 & 0,00 & 0,00 & 0,00 & 7 \\
8 & 0,00 & 0,01 & 0,00 & 8 \\
9 & 0,00 & 0,03 & 0,00 & 9 \\
10 & 0,00 & 0,07 & 0,00 & 10 \\
11 & 0,01 & 0,18 & 0,01 & 11 \\
12 & 0,02 & 0,39 & 0,02 & 12 \\
13 & 0,04 & 0,75 & 0,04 & 13 \\
14 & 0,08 & 1,32 & 0,08 & 14 \\
15 & 0,15 & 2,12 & 0,14 & 15 \\
16 & 0,25 & 3,09 & 0,24 & 16 \\
17 & 0,39 & 4,12 & 0,37 & 17 \\
18 & 0,56 & 5,04 & 0,56 & 18 \\
19 & 0,77 & 5,65 & 0,76 & 19 \\
20 & 1,00 & 5,84 & 1,00 & 20 \\
21 & 0,77 & 5,56 & 0,77 & 21 \\
22 & 0,56 & 4,89 & 0,56 & 22 \\
23 & 0,39 & 3,97 & 0,37 & 23 \\
24 & 0,25 & 2,98 & 0,24 & 24 \\
25 & 0,15 & 2,06 & 0,15 & 25 \\
26 & 0,08 & 1,32 & 0,08 & 26 \\
27 & 0,04 & 0,78 & 0,05 & 27 \\
\hline & & & & \\
\hline
\end{tabular}




\begin{tabular}{ccccc}
\hline $\boldsymbol{x}$ & $\mathbf{P V}$ & $\mathbf{B F}$ & $\mathbf{E V}$ & $\boldsymbol{x}$ \\
28 & 0,02 & 0,43 & 0,02 & 28 \\
29 & 0,01 & 0,22 & 0,01 & 29 \\
30 & 0,00 & 0,10 & 0,00 & 30 \\
31 & 0,00 & 0,04 & 0,00 & 31 \\
32 & 0,00 & 0,02 & 0,00 & 32 \\
33 & 0,00 & 0,01 & 0,00 & 33 \\
34 & 0,00 & 0,00 & 0,00 & 34 \\
35 & 0,00 & 0,00 & 0,00 & 35 \\
36 & 0,00 & 0,00 & 0,00 & 36 \\
37 & 0,00 & 0,00 & 0,00 & 37 \\
38 & 0,00 & 0,00 & 0,00 & 38 \\
39 & 0,00 & 0,00 & 0,00 & 39 \\
40 & 0,00 & 0,00 & 0,00 & 40 \\
\hline
\end{tabular}

A tabela acima nos mostra grande semelhança nos valores do p-value e de EV. No teste de Proporção, EV tende a ser um pouco menor do que PV. Aqui, isso ocorreu para 6 valores de $\mathrm{x}$. Para apenas um valor EV > PV. Para todos os demais valores, as medidas coincidem.

Quanto ao Fator de Bayes (BF), ele é maior do que 1, favorecendo a hipótese nula, para valores de $\mathrm{x}$ entre 14 e 26. Para $\mathrm{x}=14$ e $\mathrm{x}=26, \mathrm{BF}=1,32$. Para esses dois valores de $\mathrm{x}$, tanto PV quanto EV valem 0,08 . Esse seria o menor valor suficiente para dar suporte à hipótese nula.

Como era de se esperar, todas as medidas atingem o máximo para $\mathrm{x}=20$, compatível com a hipótese $\theta=0,4$ em 50 lançamentos. Nesse caso, $\mathrm{PV}=\mathrm{EV}=1 \mathrm{e} \mathrm{BF}=$ 5,84 .

O gráfico comparativo das medidas de evidência encontra-se a seguir: 
FIGURA 5.1 - Teste para Proporção de Sucesso

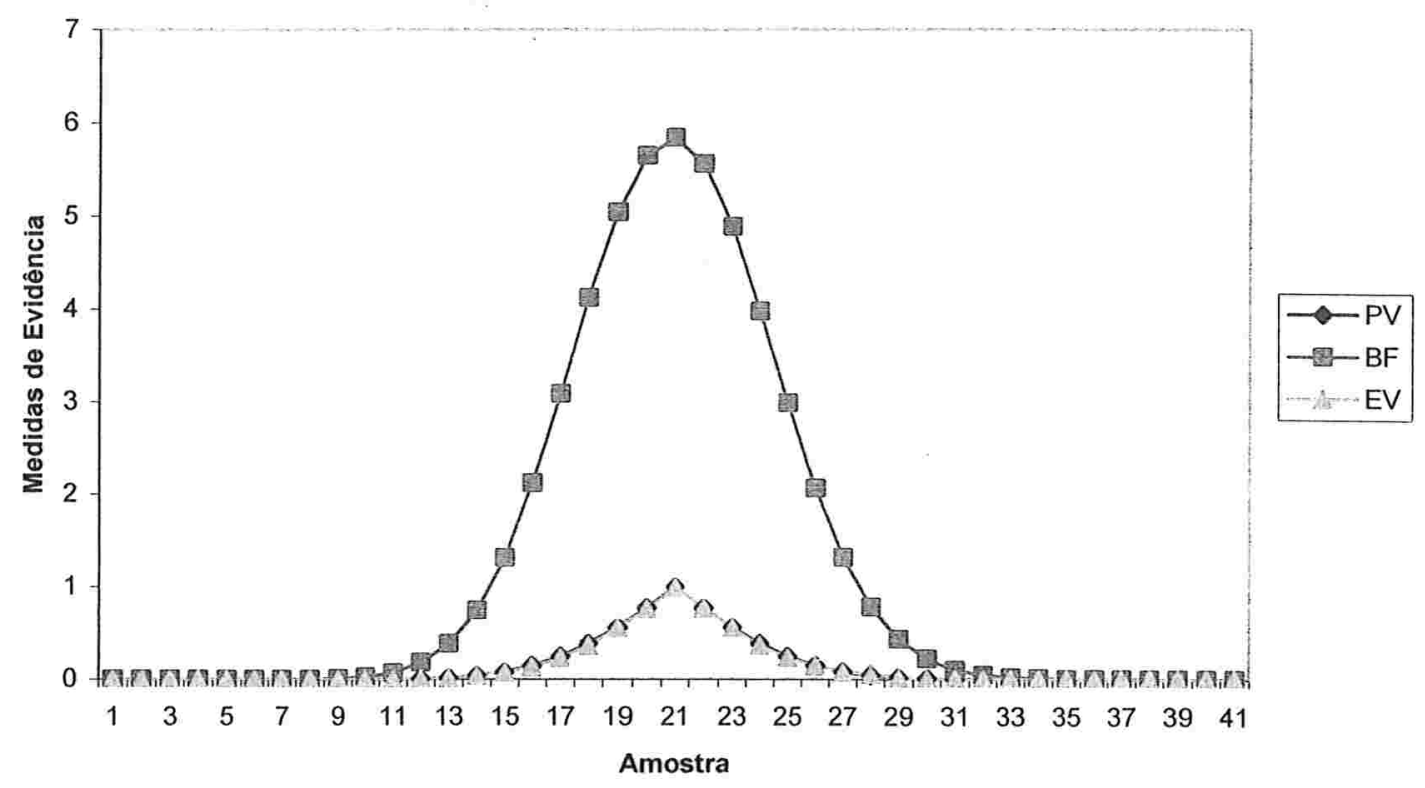

Para permitir uma melhor comparação visual em escala, pode-se transformar o Fator de Bayes (BF) na Probabilidade a Posteriori para $\mathrm{H}_{0}$, $\mathrm{PP}$, a partir da seguinte relação:

$\mathrm{PP}=\left\{1+\mathrm{BF}^{-1}\right\}^{-1}$.

É importante notar que um Fator de Bayes igual a 1 equivale a uma Probabilidade a Posteriori para $\mathrm{H}_{0}$ igual a $50 \%$, conforme se observa na figura 5.2: 
FIGURA 5.2 - Teste para Proporção de Sucesso

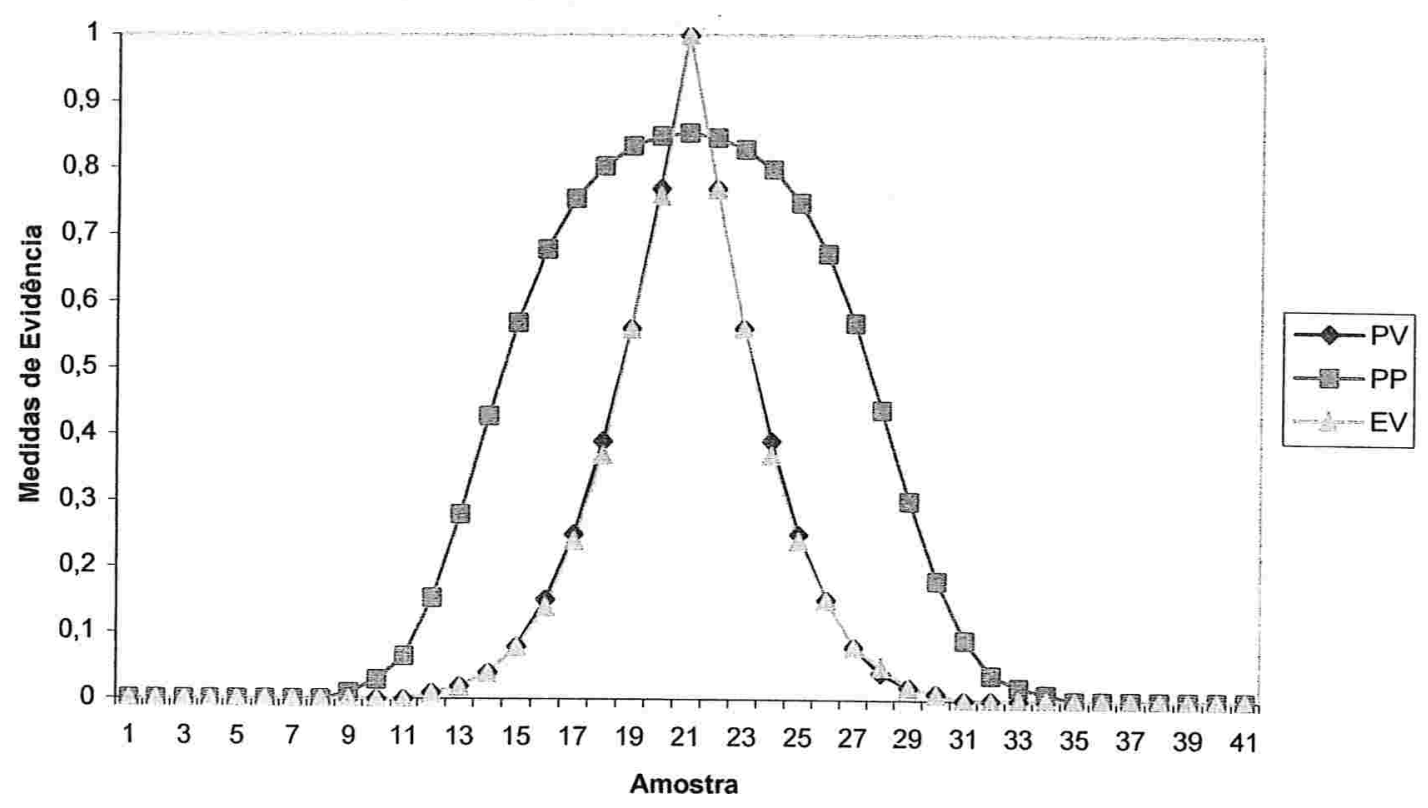




\section{2 - Teste de Homogeneidade}

Suponha a existência de duas populações $\mathrm{X}$ e $\mathrm{Y}$ independentes, ambas seguindo uma distribuição binomial, com parâmetros $\theta_{\mathrm{x}}$ e $\theta_{\mathrm{y}}$, respectivamente. $\mathrm{O}$ objetivo desse teste é verificar se as proporções de sucesso são iguais para as duas populações.

$$
\begin{aligned}
& X \sim b\left(m, \theta_{x}\right) \\
& Y \sim b\left(n, \theta_{y}\right)
\end{aligned}
$$

A tabela $2 \times 2$ resultante da amostra é:

\begin{tabular}{|c|c|c|}
\hline $\mathbf{x}$ & $\mathbf{y}$ & $\mathbf{x}+\mathbf{y}$ \\
\hline $\mathbf{m}-\mathbf{x}$ & $\mathbf{n}-\mathbf{y}$ & $\mathrm{m}+\mathrm{n}-(\mathrm{x}+\mathrm{y})$ \\
\hline $\mathrm{m}$ & $\mathrm{n}$ & $\mathrm{m}+\mathrm{n}$ \\
\hline
\end{tabular}

As hipóteses são:

$\mathrm{H}_{0}: \theta_{\mathrm{x}}=\theta_{\mathrm{y}}=\theta$

$\mathrm{H}_{1}: \theta_{\mathrm{x}} \neq \theta_{\mathrm{y}}$

Como exemplo, vamos examinar o caso $\mathrm{m}=\mathrm{n}=30$. 


\section{a) P-VALUE}

Sob a hipótese de homogeneidade, os valores esperados para $x, y, m-x$ e n-y são dados pela multiplicação das marginais dividida pelo total. Assim,

$$
\begin{aligned}
& e_{x}=\frac{(x+y) \cdot m}{m+n} \\
& e_{y}=\frac{(x+y) \cdot n}{m+n} \\
& e_{m-x}=\frac{[m+n-(x+y)] \cdot m}{m+n} \\
& e_{n-y}=\frac{[m+n-(x+y)] \cdot n}{m+n}
\end{aligned}
$$

Para $\mathrm{m}=\mathrm{n}$, temos

$$
\begin{aligned}
& e_{x}=\frac{x+y}{2}=e_{y} \\
& e_{m-x}=m-e_{x}=e_{n-y}
\end{aligned}
$$

O valor observado da estatística qui-quadrado será

$$
\chi_{o b s}^{2}=\frac{\left(x-e_{x}\right)^{2}}{e_{x}}+\frac{\left(y-e_{y}\right)^{2}}{e_{y}}+\frac{\left[(m-x)-e_{m-x}\right]^{2}}{e_{m-x}}+\frac{\left[(n-y)-e_{n-y}\right]^{2}}{e_{n-y}}
$$


Para $m=n$,

$\chi_{\text {obs }}^{2}=\left[\frac{1}{e_{x}}+\frac{1}{m-e_{x}}\right] \cdot\left[\left(x-e_{x}\right)^{2}+\left(y-e_{x}\right)^{2}\right], \quad$ onde $e_{x}=\frac{x+y}{2}$

$\mathrm{PV}=\mathrm{P}\left(\chi_{1}^{2} \geq \chi_{o b s}^{2} \mid \mathrm{H}_{\mathrm{o}}\right.$ é verdadeira $)$ 


\section{b) FATOR DE BAYES}

$\mathrm{H}_{0}: \theta_{\mathrm{x}}=\theta_{\mathrm{y}}=\theta$

$\mathrm{H}_{1}: \theta_{\mathrm{x}} \neq \theta_{\mathrm{y}}$

$$
B F=\frac{\int_{0}^{1} f(x, y \mid \theta) d \theta}{\int_{0}^{1} f\left(x \mid \theta_{x}\right) d \theta_{x} \cdot \int_{0}^{1} f\left(y \mid \theta_{y}\right) d \theta_{y}}
$$

Para $\mathrm{H}_{\mathrm{o}}$

$$
\begin{aligned}
& \int_{0}^{1} f(x, y \mid \theta) d \theta=\left(\begin{array}{l}
m \\
x
\end{array}\right) \cdot\left(\begin{array}{l}
n \\
y
\end{array}\right) \cdot \int_{0}^{1} \theta^{x+y} \cdot(1-\theta)^{m+n-(x+y)} d \theta= \\
& =\left(\begin{array}{l}
m \\
x
\end{array}\right) \cdot\left(\begin{array}{l}
n \\
y
\end{array}\right) \cdot \frac{\Gamma(x+y+1) \cdot \Gamma[m+n-(x+y)+1]}{\Gamma(m+n+2)} \cdot \int_{0}^{1} \frac{\theta^{x+y} \cdot(1-\theta)^{m+n-(x+y)} \Gamma(m+n+2)}{\Gamma(x+y+1) \cdot \Gamma[m+n-(x+y)+1]} d \theta= \\
& =\left(\begin{array}{l}
m \\
x
\end{array}\right) \cdot\left(\begin{array}{l}
n \\
y
\end{array}\right) \cdot \frac{\Gamma(x+y+1) \cdot \Gamma[m+n-(x+y)+1]}{\Gamma(m+n+2)}=\ldots= \\
& =\ldots=\int_{0}^{1} f(x, y \mid \theta) d \theta=\frac{\left(\begin{array}{l}
m \\
x
\end{array}\right) \cdot\left(\begin{array}{l}
n \\
y
\end{array}\right)}{\left(\begin{array}{l}
m+n \\
x+y
\end{array}\right) \cdot \frac{1}{m+n+1}}
\end{aligned}
$$

Para $\mathrm{H}_{1}$,

$$
\int_{0}^{1} f\left(x \mid \theta_{x}\right) d \theta_{x} \cdot \int_{0}^{1} f\left(y \mid \theta_{y}\right) d \theta_{y}=\left(\begin{array}{l}
m \\
x
\end{array}\right) \cdot \int_{0}^{1} \theta_{x}{ }^{x} \cdot\left(1-\theta_{x}\right)^{m-x} d \theta_{x} \cdot\left(\begin{array}{l}
n \\
y
\end{array}\right) \cdot \int_{0}^{1} \theta_{y}{ }^{y} \cdot\left(1-\theta_{y}\right)^{n-y} d \theta_{y}
$$




$$
\begin{aligned}
& =\ldots=\left(\begin{array}{l}
m \\
x
\end{array}\right) \cdot \frac{\Gamma(x+1) \Gamma(m-x+1)}{\Gamma(m+2)} \cdot\left(\begin{array}{l}
n \\
y
\end{array}\right) \cdot \frac{\Gamma(y+1) \Gamma(n-y+1)}{\Gamma(n+2)}=\ldots= \\
& =\ldots=\frac{1}{(m+1) \cdot(n+1)} .
\end{aligned}
$$

Portanto,

$$
B F=\frac{\left(\begin{array}{l}
m \\
x
\end{array}\right) \cdot\left(\begin{array}{l}
n \\
y
\end{array}\right)}{\left(\begin{array}{l}
m+n \\
x+y
\end{array}\right)} \cdot \frac{(m+1) \cdot(n+1)}{m+n+1} .
$$




\section{c) $\mathrm{EV}$}

Usando prioris uniformes, obtemos a posteriori

$$
f(\theta \mid d)=f\left(\theta_{x}, \theta_{y} \mid d\right) \propto \theta_{x}^{x} \cdot\left(1-\theta_{x}\right)^{m-x} \cdot \theta_{y}^{y} \cdot\left(1-\theta_{y}\right)^{n-y}
$$

A hipótese nula é $\theta_{x}=\theta_{y}=\theta$. O estimador de máxima verossimilhança sob $\mathrm{H}_{0}$ é:

$$
\hat{\theta}=\frac{x+y}{m+n} .
$$

Assim, o valor máximo da posteriori sob $\mathrm{H}_{0}$ é:

$$
f^{*}\left(\theta_{0} \mid d\right)=\hat{\theta}^{x+y} \cdot(1-\hat{\theta})^{m+n-(x+y)} .
$$

A simulação de Monte Carlo é feita da seguinte forma:

1 - Geramos 10.000 valores $\left(u_{1 i}\right)$ de uma uniforme $(0,1)$;

2 - geramos 10.000 valores $\left(u_{2 i}\right)$ de uma uniforme $(0,1)$;

3 - calculamos 10.000 posterioris $u_{1 i}^{x} \cdot\left(1-u_{1 i}\right)^{m-x} \cdot u_{2 i}^{y} \cdot\left(1-u_{2 i}\right)^{n-y}$;

4 - somamos todas as posteriores que resultaram em valor igual ou superior a $f^{*}\left(\theta_{0} \mid d\right)$, obtendo $S_{M}$;

5 - somamos todas as 10.000 posterioris, obtendo $S_{T}$;

6 - calculamos $k=\frac{S_{M}}{S_{T}}$

$7-$ calculamos $\mathrm{EV}=1-k$.

Escolhemos alguns valores de $\mathrm{x}$ e $\mathrm{y}$ para este teste e os resultados encontram-se na tabela 5.2: 
TABELA 5.2 - Evidência no Teste de Homogeneidade

\begin{tabular}{ccccccc}
\hline$x$ & $y$ & PV & BF & EV & $\boldsymbol{x}$ & $\boldsymbol{y}$ \\
\hline 10 & 6 & 0,24 & 1,88 & 0,50 & 10 & 6 \\
10 & 7 & 0,39 & 2,49 & 0,69 & 10 & 7 \\
10 & 8 & 0,57 & 2,99 & 0,85 & 10 & 8 \\
10 & 9 & 0,78 & 3,31 & 0,95 & 10 & 9 \\
10 & 10 & 1,00 & 3,39 & 1,00 & 10 & 10 \\
10 & 11 & 0,79 & 3,24 & 0,95 & 10 & 11 \\
10 & 12 & 0,59 & 2,89 & 0,85 & 10 & 12 \\
10 & 13 & 0,43 & 2,42 & 0,69 & 10 & 13 \\
10 & 14 & 0,29 & 1,91 & 0,55 & 10 & 14 \\
15 & 10 & 0,19 & 1,41 & 0,40 & 15 & 10 \\
15 & 11 & 0,30 & 1,91 & 0,57 & 15 & 11 \\
15 & 12 & 0,44 & 2,40 & 0,72 & 15 & 12 \\
15 & 13 & 0,60 & 2,82 & 0,88 & 15 & 13 \\
15 & 14 & 0,80 & 3,11 & 0,98 & 15 & 14 \\
15 & 15 & 1,00 & 3,21 & 1,00 & 15 & 15 \\
15 & 16 & 0,80 & 3,11 & 0,96 & 15 & 16 \\
15 & 17 & 0,60 & 2,82 & 0,87 & 15 & 17 \\
15 & 18 & 0,44 & 2,40 & 0,72 & 15 & 18 \\
15 & 19 & 0,30 & 1,91 & 0,53 & 15 & 19 \\
15 & 20 & 0,19 & 1,41 & 0,39 & 15 & 20 \\
20 & 13 & 0,07 & 0,64 & 0,18 & 20 & 13 \\
20 & 14 & 0,12 & 0,98 & 0,29 & 20 & 14 \\
20 & 15 & 0,19 & 1,41 & 0,43 & 20 & 15 \\
20 & 16 & 0,29 & 1,91 & 0,56 & 20 & 16 \\
20 & 17 & 0,43 & 2,42 & 0,71 & 20 & 17 \\
20 & 18 & 0,59 & 2,89 & 0,86 & 20 & 18 \\
20 & 19 & 0,79 & 3,24 & 0,97 & 20 & 19 \\
20 & 20 & 1,00 & 3,39 & 1,00 & 20 & 20 \\
\hline & & & & & & \\
\hline
\end{tabular}




\begin{tabular}{ccccccc}
\hline $\boldsymbol{x}$ & $\boldsymbol{y}$ & $\mathbf{P V}$ & $\mathbf{B F}$ & $\mathbf{E V}$ & $\boldsymbol{x}$ & $\boldsymbol{y}$ \\
20 & 21 & 0,78 & 3,31 & 0,95 & 20 & 21 \\
20 & 22 & 0,57 & 2,99 & 0,85 & 20 & 22 \\
20 & 23 & 0,39 & 2,49 & 0,68 & 20 & 23 \\
20 & 24 & 0,24 & 1,88 & 0,48 & 20 & 24 \\
20 & 25 & 0,14 & 1,27 & 0,31 & 20 & 25 \\
20 & 26 & 0,07 & 0,75 & 0,16 & 20 & 26 \\
20 & 27 & 0,03 & 0,37 & 0,07 & 20 & 27 \\
25 & 10 & 0,00 & 0,00 & 0,00 & 25 & 10 \\
25 & 11 & 0,00 & 0,00 & 0,00 & 25 & 11 \\
25 & 12 & 0,00 & 0,01 & 0,00 & 25 & 12 \\
25 & 13 & 0,00 & 0,02 & 0,00 & 25 & 13 \\
25 & 14 & 0,00 & 0,04 & 0,01 & 25 & 14 \\
25 & 15 & 0,01 & 0,08 & 0,02 & 25 & 15 \\
25 & 16 & 0,01 & 0,16 & 0,03 & 25 & 16 \\
25 & 17 & 0,02 & 0,29 & 0,07 & 25 & 17 \\
25 & 18 & 0,04 & 0,50 & 0,12 & 25 & 18 \\
25 & 19 & 0,08 & 0,82 & 0,19 & 25 & 19 \\
25 & 20 & 0,14 & 1,27 & 0,30 & 25 & 20 \\
25 & 21 & 0,22 & 1,85 & 0,45 & 25 & 21 \\
25 & 22 & 0,35 & 2,54 & 0,63 & 25 & 22 \\
25 & 23 & 0,52 & 3,27 & 0,80 & 25 & 23 \\
25 & 24 & 0,74 & 3,89 & 0,93 & 25 & 24 \\
25 & 25 & 1,00 & 4,24 & 1,00 & 25 & 25 \\
25 & 26 & 0,72 & 4,16 & 0,92 & 25 & 26 \\
25 & 27 & 0,45 & 3,56 & 0,71 & 25 & 27 \\
25 & 0,23 & 2,53 & 0,45 & 25 & 28 \\
25 & 0,09 & 1,35 & 0,20 & 25 & 29 \\
25 & 0,02 & 0,41 & 0,06 & 25 & 30 \\
25 & & & & & \\
25 & 25
\end{tabular}


No teste de homogeneidade, ocorre o contrário do que havia acontecido com o teste para proporção. Naquele caso, as medidas PV e EV coincidiam quase sempre e, quando não, PV tendia a ser maior. Aqui, as medidas só coincidem quando valem um, isto é, nos casos em que tanto a amostra de x quanto de y apresentaram o mesmo resultado (10-10, $15-15,20-20,25-25)$, ou nos 4 casos em que $\mathrm{x}$ e y apresentam valores muito discrepantes (25-10, 25-11, 25-12 e 25-13), quando ambas as medidas valem zero.

Para os demais 48 pares $\mathrm{x}, \mathrm{y}, \mathrm{PV}<\mathrm{EV}$, isto é, a medida resultante do FBST privilegia mais a hipótese nula do que o p-value, exigindo um valor maior para rejeição.

Quanto ao Fator de Bayes, ele é máximo quando $\mathrm{x}=\mathrm{y}$, como se imaginava. Por outro lado, ele é maior do que um, privilegiando a hipótese nula, para pares $\mathrm{x}, \mathrm{y}$ que resultam em PV de no mínimo 0,09 e EV de no mínimo 0,20. Isso mostra que se fizermos uma comparação um a um entre as três medidas para esse teste, o Fator de Bayes será o que rejeitará mais.

Os gráficos comparativos são apresentados a seguir, o primeiro com o Fator de Bayes e o segundo com a Probabilidade a Posteriori em seu lugar.

FIGURA 5.3 - Teste de Homogeneidade

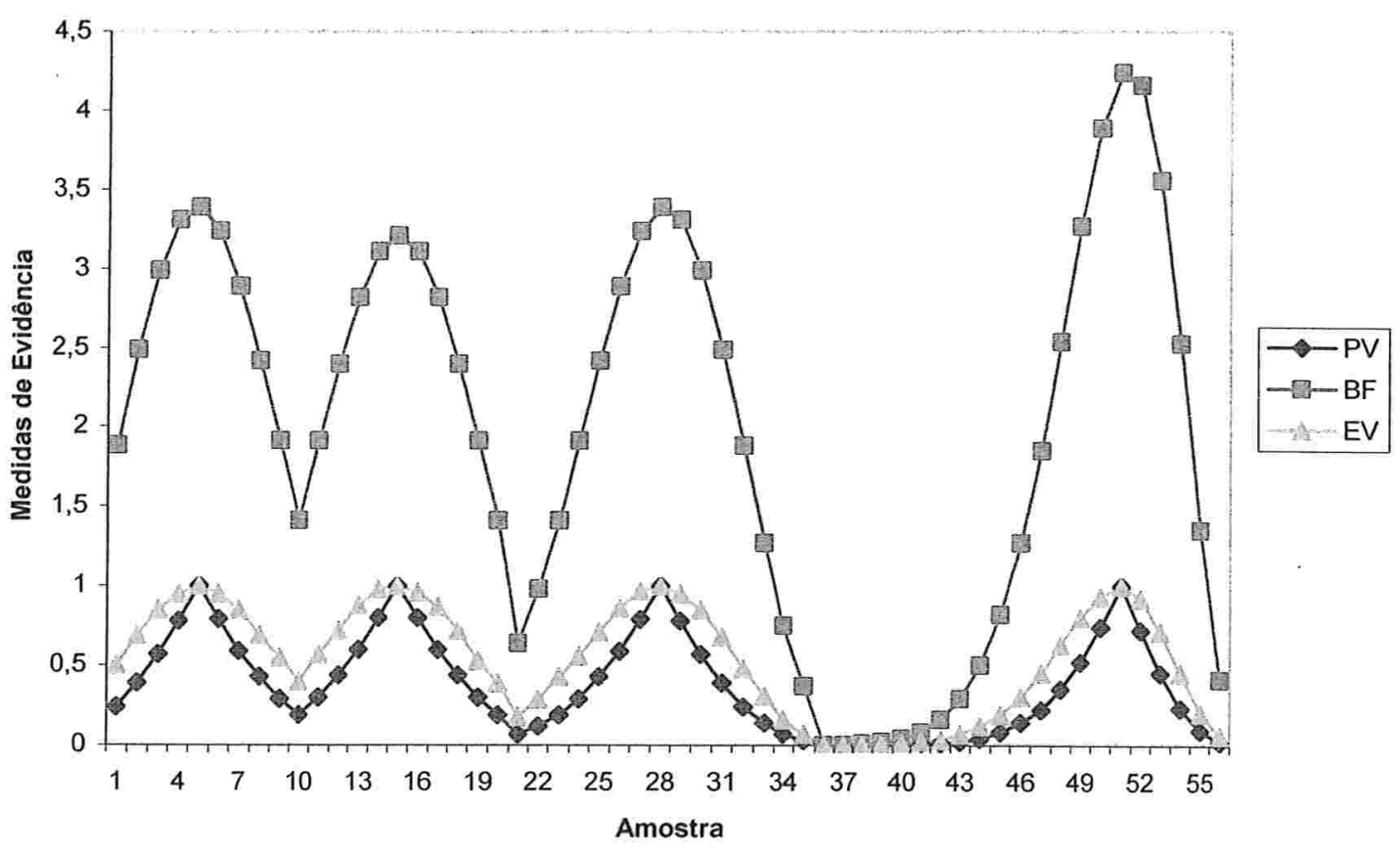




\section{FIGURA 5.4 - Teste de Homogeneidade}

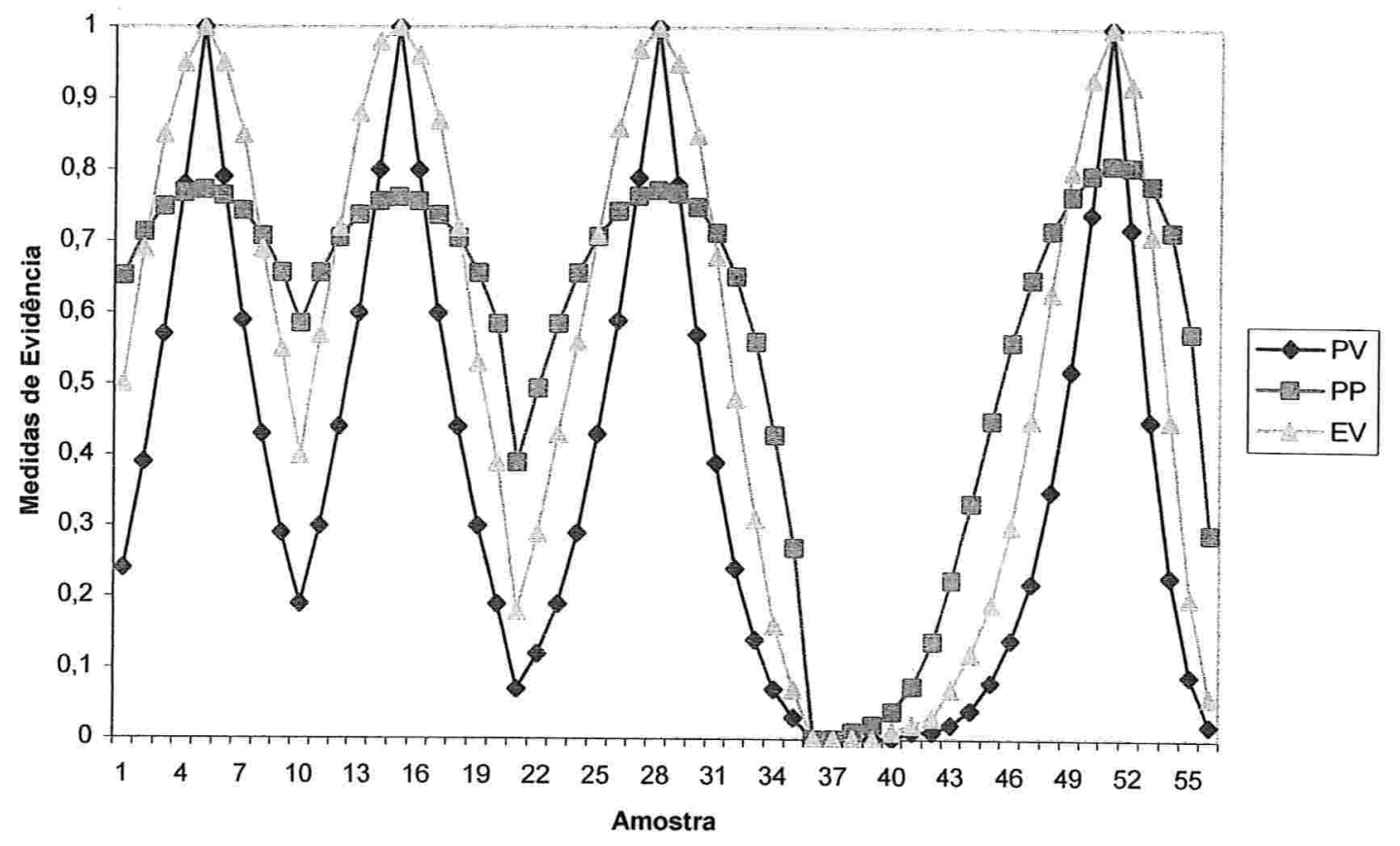




\section{3 - Teste de Independência}

Neste teste, desejamos descobrir se duas ou mais variáveis são independentes. Por exemplo, desejamos saber se um defeito na linha de produção de um artigo afeta ou não a qualidade de um outro produto; se a positividade de um teste realmente significa (ou não) que o indivíduo apresenta determinada doença, etc.

Vamos considerar as seguintes categorias amostrais:

\begin{tabular}{|c|c|c|}
\hline $\mathbf{x}$ & $\mathbf{y}$ & $\mathrm{x}+\mathrm{y}$ \\
\hline $\mathbf{w}$ & $\mathbf{z}$ & $\mathrm{w}+\mathrm{z}$ \\
\hline $\mathrm{x}+\mathrm{w}$ & $\mathrm{y}+\mathrm{z}$ & $\mathrm{n}$ \\
\hline
\end{tabular}

Os parâmetros são:

\begin{tabular}{|c|c|c|}
\hline $\mathbf{r}$ & $\mathbf{s}$ & $\mathrm{p}$ \\
\hline $\mathbf{t}$ & $\mathbf{u}$ & $1-\mathrm{p}$ \\
\hline $\mathrm{q}$ & $1-\mathrm{q}$ & 1 \\
\hline
\end{tabular}


Testar a independência significa assumir em $\mathrm{H}_{0}$ :

$r=p \cdot q$

$s=p \cdot(1-q)$

$t=(1-p) \cdot q$

$u=(1-p) \cdot(1-q)$

Como apenas a primeira igualdade já determina as demais, podemos resumir o teste de independência do seguinte modo:

$\mathrm{H}_{0}: r=p . q$ versus $\mathrm{H}_{1}: r \neq$ p.q.

É fácil ver que $\operatorname{dim}\left(\Theta_{0}\right)<\operatorname{dim}(\Theta)$ :

$\Theta_{0}=(p, q) ;$

$\Theta=(r, s, t, u)=(r, s, t, 1-[r+s+t]) ;$

$\operatorname{dim}\left(\Theta_{0}\right)=2 \mathrm{e} \operatorname{dim}(\Theta)=3$. 


\section{a) P-VALUE}

Sendo $\mathrm{n}=\mathrm{x}+\mathrm{y}+\mathrm{w}+\mathrm{z}$, os valores esperados sob a hipótese de independência são:

$$
\begin{aligned}
& e_{x}=\frac{(x+y) \cdot(x+w)}{n} \\
& e_{y}=\frac{(x+y) \cdot(y+z)}{n} \\
& e_{w}=\frac{(w+z) \cdot(x+w)}{n} \\
& e_{z}=\frac{(w+z) \cdot(y+z)}{n}
\end{aligned}
$$

Novamente calculamos a estatística qui-quadrado:

$$
\begin{aligned}
& \chi_{o b s}^{2}=\frac{\left(x-e_{x}\right)^{2}}{e_{x}}+\frac{\left(y-e_{y}\right)^{2}}{e_{y}}+\frac{\left(w-e_{w}\right)^{2}}{e_{w}}+\frac{\left(z-e_{z}\right)^{2}}{e_{z}} \\
& \mathrm{PV}=\mathrm{P}\left(\chi_{1}^{2} \geq \chi_{o b s}^{2} \mid \mathrm{H}_{0} \text { é verdadeira }\right) .
\end{aligned}
$$




\section{b) FATOR DE BAYES}

O cálculo do Fator de Bayes para testes de independência envolve certa complexidade e é explicado em Irony e Pereira (1995) e Samartini (2000). Utilizando prioris uniformes, chegamos à fórmula utilizada por Pereira e Stern (1999), aqui expressa em outra notação:

$$
B F=\frac{\left(\begin{array}{c}
x+y \\
x
\end{array}\right) \cdot\left(\begin{array}{c}
w+z \\
z
\end{array}\right)}{\left(\begin{array}{c}
n \\
x+w
\end{array}\right)} \cdot \frac{(n+2) \cdot\{(n+3)-(n+2)[P(1-P)+Q(1-Q)]\}}{4 \cdot(n+1)}
$$

onde $P=\frac{x+y}{n+2} \quad$ e $\quad Q=\frac{x+w}{n+2}$. 


\section{c) $\mathrm{EV}$}

No teste de independência em tabela $2 \times 2$, a verossimilhança é multinomial. Neste caso, devemos considerar a distribuição Dirichlet, conjugada para a multinomial.

Uma multinomial de ordem $\mathrm{k}$ (aqui, $\mathrm{k}=4$ ) tem a forma $n ! \cdot \prod_{i=0}^{k} \frac{\theta_{i}^{x_{i}}}{x_{i} !}$. No caso em exame,

$$
f(d \mid \theta)=n ! \cdot \frac{r^{x} \cdot s^{y} \cdot t^{w} \cdot u^{z}}{x ! \cdot y ! \cdot w ! \cdot z !}
$$

A distribuição Dirichlet escolhida para priori tem a forma

$$
\Gamma\left(\sum_{i=0}^{k} a_{i}\right) \prod_{i=0}^{k} \frac{\theta_{I}^{a_{i}-1}}{\Gamma\left(a_{i}\right)}
$$

No caso estudado,

$$
\pi(\theta) \propto r^{a_{1}-1} \cdot s^{a_{2}-1} \cdot t^{a_{3}-1} \cdot u^{a_{4}-1}
$$

Como nos testes anteriores trabalhamos com prioris uniformes, devemos considerar $a_{1}=a_{2}=a_{3}=a_{4}=1$.

Pela fórmula de Bayes, $f(\theta \mid d) \propto \pi(\theta) . f(d \mid \theta)$. Nesse caso, a posteriori será proporcional a $r^{1-1} \cdot s^{1-1} \cdot t^{1-1} \cdot u^{1-1} \cdot r^{x} \cdot s^{y} \cdot t^{w} \cdot u^{z}$. Logo,

$$
f(\theta \mid d)=f(r, s, t, u \mid d) \propto r^{(x+1)-1} \cdot s^{(y+1)-1} \cdot t^{(w+1)-1} \cdot u^{(z+1)-1} .
$$

Portanto, a posteriori é Dirichlet com parâmetros $(\mathrm{x}+1, \mathrm{y}+1, \mathrm{w}+1, \mathrm{z}+1)$.

Para facilitar os cálculos, trabalharemos com o logaritmo da posteriori:

$\log [f(\theta \mid d)] \propto x \cdot \log r+y \cdot \log s+w \cdot \log t+z \cdot \log u$ 
$H_{0}$ :

$r=p \cdot q$

$s=p \cdot(1-q)$

$t=(1-p) \cdot q$

$u=(1-p) .(1-q)$

$f\left(\theta_{0} \mid d\right) \propto(p \cdot q)^{x} \cdot[p \cdot(1-q)]^{y} \cdot[(1-p) \cdot q]^{w} \cdot[(1-p) \cdot(1-q)]^{z}$

$f\left(\theta_{0} \mid d\right) \propto p^{x+y} \cdot(1-p)^{w+z} \cdot q^{x+w} \cdot(1-q)^{y+z}$

Os estimadores de máxima verossimilhança para p e q são $\hat{p}=\frac{x+y}{n}$ e $\hat{q}=\frac{x+w}{n}$.

$\mathrm{O}$ valor máximo da posteriori sob $\mathrm{H}_{0}$ é:

$f^{*}\left(\theta_{0} \mid d\right)=\hat{p}^{x+y} \cdot(1-\hat{p})^{w+z} \cdot \hat{q}^{x+w} \cdot(1-\hat{q})^{y+z}$

Da mesma forma,

$\log \left[f^{*}\left(\theta_{0} \mid d\right)\right]=(x+y) \cdot \log (\hat{p})+(w+z) \cdot \log (1-\hat{p})+(x+w) \cdot \log (\hat{q})+(y+z) \cdot \log (1-\hat{q})$

Para trabalharmos com as posterioris Dirichlet, devemos lembrar que essa distribuição pode ser caracterizada a partir de gamas independentes:

Se $X_{\mathrm{k}} \sim \mathrm{G}\left(\mathrm{a}_{\mathrm{k}}, 1\right) \quad$ então $\quad Y=\frac{\underline{X}}{\sum_{\substack{k \\ i=1}} X_{k}} \sim \operatorname{Di}(\underline{a})$.

Em outras palavras, com r' $\sim \mathrm{G}\left(\mathrm{a}_{1}, 1\right), \mathrm{s}^{\prime} \sim \mathrm{G}\left(\mathrm{a}_{2}, 1\right), \mathrm{t}^{\prime} \sim \mathrm{G}\left(\mathrm{a}_{3}, 1\right), \mathrm{u}^{\prime} \sim \mathrm{G}\left(\mathrm{a}_{4}, 1\right)$, calculamos $\mathrm{S}=\mathrm{r}^{\prime}+\mathrm{s}^{\prime}+\mathrm{t}^{\prime}+\mathrm{u}^{\prime}$. Em seguida, $r=\frac{r^{\prime}}{S}, s=\frac{s^{\prime}}{S}, t=\frac{t^{\prime}}{S}, \quad u=\frac{u^{\prime}}{S}$. Assim, geramos uma Dirichlet com parâmetros $\left(\mathrm{a}_{1}, \mathrm{a}_{2}, \mathrm{a}_{3}, \mathrm{a}_{4}\right): f(\theta \mid d) \propto r^{a_{1}-1} \cdot s^{a_{2}-1} \cdot t^{a_{3}-1} \cdot u^{a_{4}-1}$

Aqui, devemos gerar gamas com parâmetros $a_{1}=x+1, a_{2}=y+1, a_{3}=w+1, a_{4}=z+1$ 
A simulação de Monte Carlo é feita da seguinte maneira:

1 - Geramos 10.000 valores $\left(g_{1 i}\right)$ de uma gama $(x+1,1)$;

2 - geramos 10.000 valores $\left(g_{2 i}\right)$ de uma gama $(y+1,1)$;

3 - geramos 10.000 valores $\left(g_{3 i}\right)$ de uma gama $(w+1,1)$;

4 - geramos 10.000 valores $\left(g_{4 i}\right)$ de uma gama $(\mathrm{z}+1,1)$;

5 - calculamos a soma $\operatorname{dos} g_{i}{ }^{\prime} s=S_{i}$;

$6-$ calculamos $v_{1 i}=\frac{g_{1 i}}{S_{i}}, v_{2 i}=\frac{g_{2 i}}{S_{i}}, v_{3 i}=\frac{g_{3 i}}{S_{i}}, v_{4 i}=\frac{g_{4 i}}{S_{i}} ;$

7 - calculamos o $\log$ da posteriori $x \cdot \log v_{1 i}+y \cdot \log v_{2 i}+w \cdot \log v_{3 i}+z \cdot \log v_{4 i}$;

8 - somamos todos os logs das posterioris que resultaram em valor igual ou superior a $\log \left[f^{*}\left(\theta_{0} \mid d\right)\right]$, obtendo $S_{M}$;

9 - somamos todos os $10.000 \operatorname{logs}$ das posterioris, obtendo $S_{T}$;

$10-$ calculamos $k=\frac{S_{M}}{S_{T}}$

$11-$ calculamos $\mathrm{EV}=1-k$.

Selecionamos 7 configurações $\mathrm{x}-\mathrm{y}-\mathrm{W}-\mathrm{Z}$ e os resultados dos testes são apresentados na tabela a seguir: 
TABELA 5.3 - Evidência no Teste de Independência

\begin{tabular}{ccccccccccc}
\hline $\boldsymbol{x}$ & $\boldsymbol{y}$ & $\boldsymbol{w}$ & $\boldsymbol{z}$ & $\mathbf{P V}$ & $\mathbf{B F}$ & $\mathbf{E V}$ & $\boldsymbol{x}$ & $\boldsymbol{y}$ & $\boldsymbol{w}$ & $\boldsymbol{z}$ \\
\hline 15 & 10 & 20 & 10 & 0,61 & 1,51 & 0,97 & 15 & 10 & 20 & 10 \\
30 & 18 & 23 & 20 & 0,38 & 1,41 & 0,86 & 30 & 18 & 23 & 20 \\
47 & 50 & 32 & 60 & 0,06 & 0,48 & 0,30 & 47 & 50 & 32 & 60 \\
19 & 20 & 31 & 30 & 0,84 & 2,14 & 1,00 & 19 & 20 & 31 & 30 \\
60 & 40 & 30 & 50 & 0,00 & 0,03 & 0,02 & 60 & 40 & 30 & 50 \\
17 & 12 & 9 & 25 & 0,01 & 0,07 & 0,07 & 17 & 12 & 9 & 25 \\
21 & 23 & 18 & 9 & 0,12 & 0,58 & 0,47 & 21 & 23 & 18 & 9 \\
\hline
\end{tabular}

Em linhas gerais, o teste de independência repete o ocorrido com o teste de homogeneidade, isto é, PV < EV. Aqui, no entanto, a distância entre os valores é bem maior: um p-value de 0,06 é comparado a uma evidência (a medida do FBST) de 0,30. De todo modo, das sete amostras $\mathrm{x}-\mathrm{y}-\mathrm{w}-\mathrm{z}$ testadas, em seis casos a decisão seria idêntica, se tomássemos valores de corte iguais para rejeição. Definindo 0,05 como corte, seis configurações seriam aceitas/rejeitadas de maneira semelhante usando PV ou EV. Em um caso, entretanto, 17-12-9-25, o p-value de 0,01 provavelmente faria o pesquisador rejeitar a hipótese de independência, enquanto um valor de 0,07 para EV pode deixar o pesquisador na dúvida.

O comportamento do Fator de Bayes para o teste de independência foi semelhante ao que vimos nos exemplos anteriores mas a tendência de rejeitar mais radicalizou-se: aqui, um p-value de 0,12 (que levaria à aceitação da hipótese nula) foi acompanhado por um $\mathrm{BF}$ de apenas 0,58 , privilegiando a hipótese alternativa, isto é, a hipótese de que não há independência entre as características. Do mesmo modo, uma evidência de 0,86, altamente favorável à aceitação de $\mathrm{H}_{0}$, foi acompanhada por um Fator de Bayes de apenas 1,41, levemente favorável a $\mathrm{H}_{0}$.

No caso 17-12-9-25, BF vale apenas 0,07 , sugerindo rejeição, analogamente ao pvalue $(0,01)$. O fato de EV valer 0,07 para esta configuração reforça a idéia de que, conforme o tipo de teste, as diferenças entre as medidas podem ser significativas e tomar decisões baseando-se nelas exige que essas diferenças sejam levadas em consideração. 
Os gráficos a seguir fazem uma comparação das medidas de evidência para os testes de independência estudados:

FIGURA 5.5 - Teste de Independência

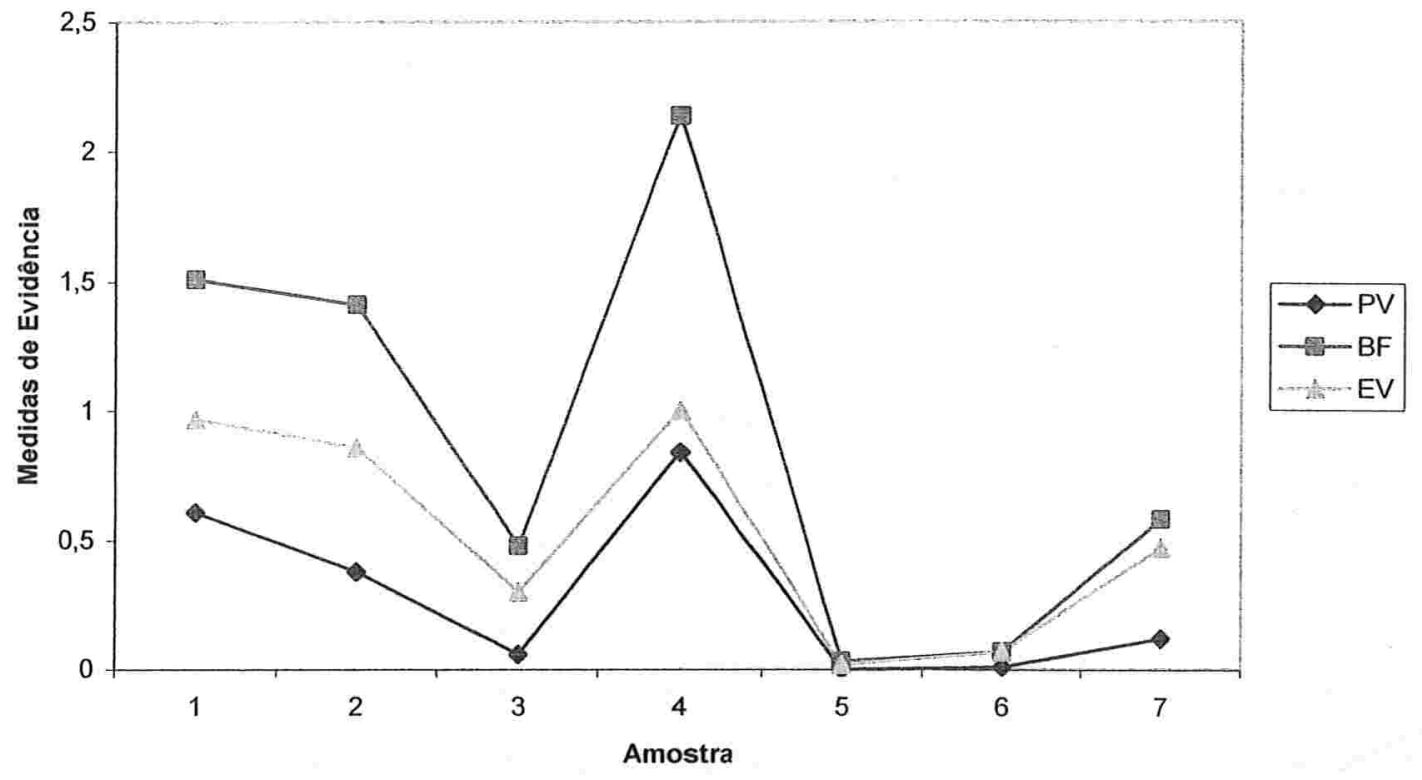

FIGURA 5.6 - Teste de Independência

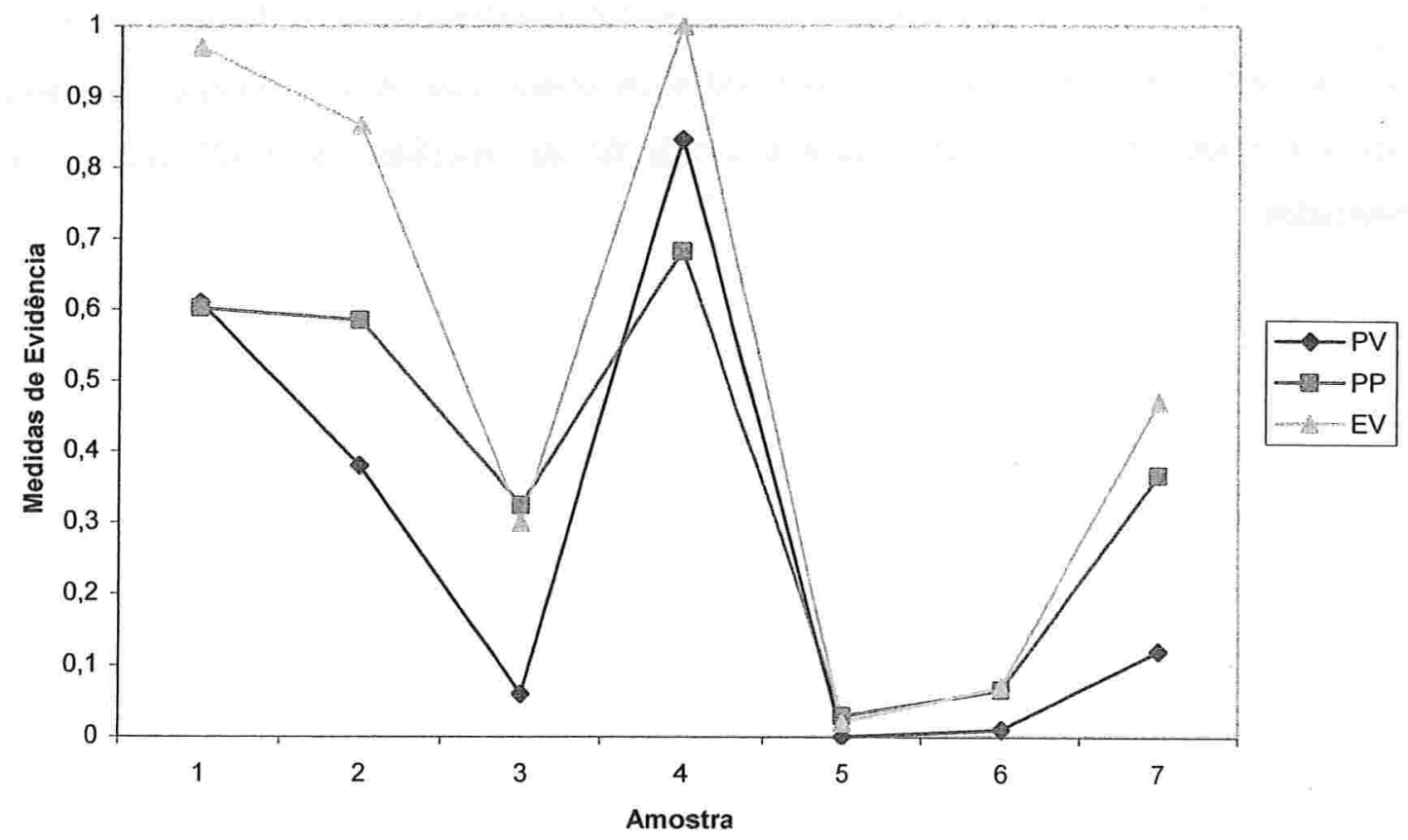




\section{4 - Conclusões}

A diversidade dos resultados expressos nos exemplos trabalhados demonstra que ainda é necessária a realização de muitos experimentos comparativos, ou seja, necessitamos de mais experiência no uso do FBST para que a medida EV possa substituir as medidas hoje mais utilizadas, o p-value dos clássicos e o Fator de Bayes dos bayesianos.

Madruga-Tavares (2002) mostra que já é possível obter uma relação empírica entre PV e EV, isto é, já se pode chegar a uma medida a partir da outra, o que torna as comparações ainda mais relevantes.

É claro que essa fase de comparação tem que ocorrer antes que uma nova metodologia se consolide na comunidade estatística e usuária, mesmo que ela aparente superioridade conceitual e prática, como no caso do FBST. Pesquisadores que durante anos têm utilizado PV ou BF não podem simplesmente "esquecer" essas medidas a partir do surgimento da nova. Mas devem estar abertos a conhecê-la e, a partir de sua própria experiência e com os novos desenvolvimentos que têm sido realizados, podem com o tempo percebê-la mais eficiente.

Nos dois primeiros testes, PV e EV estiveram bastante próximos. Entretanto, a diferença entre as medidas no teste de independência reforça a idéia de que não devemos utilizar valores de corte idênticos para todos os testes. Isso será trabalhado no próximo capítulo, onde simulamos erros para a avaliação das medidas de evidência nos testes estudados. 


\section{Capítulo 6}

\section{Erros Empíricos nos Testes Considerados}

Uma forma prática de compararmos as medidas de evidência é o cálculo dos erros empíricos, isto é, a simulação dos erros que podem ocorrer quando baseamos nossa decisão em determinada medida. Como o p-value (PV) é a medida de evidência mais largamente utilizada e estamos analisando as vantagens do uso da nova medida resultante do FBST $(\mathrm{EV})$, restringiremos nosso estudo à comparação dessas duas medidas.

Vamos considerar a nomenclatura tradicional, isto é, o erro do tipo I é o de rejeitar uma hipótese verdadeira e sua probabilidade é $\alpha$. O erro do tipo II é o de aceitar uma hipótese falsa e sua probabilidade é $\beta$. O poder do teste consiste em sua capacidade de rejeitar hipóteses falsas e sua probabilidade é $1-\beta$.

Evidentemente, queremos um teste que apresente baixos $\alpha$ e $\beta$ e alto poder. Poderíamos fixar uma probabilidade máxima para $\alpha$ e tentar minimizar $\beta$, como é feito com freqüência pelos estatísticos que seguem a linha Neyman-Pearson. Neste caso, estaremos atribuindo maior "gravidade" ao erro de tipo I do que ao de tipo II.

Parece-nos adequado, entretanto, tratar a questão dos erros a partir da perspectiva de minimização da combinação linear $\alpha+k . \beta$, tal qual discutido por DeGroot (1986) e Pereira and Irony (1986). Aqui, a hierarquização da importância dos erros é realizada a partir da escolha de diferentes valores para $\mathrm{k}$. Se utilizarmos $\mathrm{k}<1$, estaremos atribuindo maior importância ao erro de tipo I. Inversamente, ao escolhermos $\mathrm{k}>1$, estaremos assumindo maior gravidade para o erro de tipo II.

Neste trabalho adotamos $\mathrm{k}=1$ e devemos descobrir os "valores de corte" que minimizam $\alpha+\beta$. Nos três problemas relacionados à binomial aqui estudados, realizamos simulações para encontrar os valores que minimizam os erros para diversos tamanhos de amostra, para o p-value e EV. Em seguida, comparamos os erros mínimos apresentados por essas medidas de evidência. 


\section{1 - Erros no Teste para Proporção de Sucesso}

Realizamos simulações de erros para três tamanhos de amostra: $n=20, n=50$ e $n=$ 200. Deste modo, pode-se avaliar a influência do aumento amostral na obtenção dos valores que minimizam os erros.

O cálculo de alfa é feito da seguinte forma:

1 - Geram-se c binomiais com $\mathrm{p}=0,40$, assumindo a hipótese nula;

2 - Calcula-se PV e EV para cada uma das binomiais;

3 - Somam-se todas as binomiais que seriam rejeitadas nos diferentes níveis, de 0,01 a 0,15 ;

4 - Divide-se o número de rejeitadas por c, obtendo-se o alfa para cada nível.

O cálculo de beta é feito do seguinte modo:

1 - Geram-se $\mathrm{c}$ binomiais com $\mathrm{q}=0,05$, negando a hipótese nula;

2 - Calcula-se PV e EV para cada uma das binomiais;

3 - Somam-se todas as binomiais que seriam aceitas nos diferentes níveis, de 0,01 a 0,15 ;

4 - Divide-se o número de aceitas por c, obtendo-se $\beta_{0,05}$;

5 - Repetem-se os passos anteriores com $q=0,10 ; 0,15 ; \ldots ; 0,35 ; 0,45 ; \ldots ; 0,95$. Dessa forma obtém-se $\beta_{0,10} ; \beta_{0,15} ; \ldots ; \beta_{0,35} ; \beta_{0,45} ; \ldots ; \beta_{0,95}$. A média aritmética dos 18 valores leva a um beta médio para cada nível testado.

A tabela 6.1 lista os valores de corte que minimizam os erros para os diferentes tamanhos de amostra.

TABELA 6.1 - Valores de Corte no Teste para Proporção

\begin{tabular}{ccc} 
Tamanho da Amostra (n) & Corte para PV & Corte para EV \\
\hline 20 & 0,07 & 0,10 \\
50 & 0,05 & 0,05 \\
200 & 0,03 & 0,03 \\
\hline
\end{tabular}


É clara a influência do tamanho da amostra na escolha do valor de corte que minimiza a combinação $\alpha+\beta$. Quanto maior a amostra, menores devem ser os valores de corte para que os erros se tornem mínimos, como têm alertado seguidamente estatísticos críticos da idéia de utilizar sempre o mesmo nível, 0,05 ou 0,01 .

No teste para proporção, adotamos $n=50$ e neste caso o corte 0,05 coincide para PV e EV. A simulação para o p-value foi realizada a partir da geração de 100.000 binomiais, enquanto a simulação para a medida EV foi feita a partir de 1.000 binomiais e, depois, pela geração de 1.000 uniformes para cada uma. Assim, foram obtidos 1.000.000 de valores de posterioris.

Utilizando o mesmo valor de corte $(0,05)$ para as duas medidas de evidência, os alfas obtidos por simulação foram 0,06 para $\mathrm{PV}$ e 0,05 para EV.

A tabela a seguir mostra os resultados das simulações dos diferentes betas, com q assumindo os valores paramétricos diferentes de 0,40 .

TABELA 6.2 - Betas Simulados

\begin{tabular}{ccc}
\hline \multicolumn{3}{c}{ Teste para Proporção: $p=0,40$} \\
\hline$q$ & Beta - PV & Beta - EV \\
0,05 & 0,00 & 0,00 \\
0,10 & 0,00 & 0,00 \\
0,15 & 0,01 & 0,01 \\
0,20 & 0,11 & 0,12 \\
0,25 & 0,36 & 0,34 \\
0,30 & 0,67 & 0,66 \\
0,35 & 0,88 & 0,88 \\
0,45 & 0,87 & 0,87 \\
0,50 & 0,66 & 0,64 \\
0,55 & 0,39 & 0,37 \\
0,60 & 0,16 & 0,17 \\
0,65 & 0,04 & 0,04 \\
0,70 & 0,01 & 0,00 \\
\hline
\end{tabular}




\begin{tabular}{ccc}
$\mathbf{q}$ & Beta - PV & Beta - EV \\
0,75 & 0,00 & 0,00 \\
0,80 & 0,00 & 0,00 \\
0,85 & 0,00 & 0,00 \\
0,90 & 0,00 & 0,00 \\
0,95 & 0,00 & 0,00 \\
\hline
\end{tabular}

A tabela mostra que para este teste o desempenho das medidas de evidência é bastante semelhante. Tomando o beta médio, 0,23 para as duas medidas, obtivemos $\alpha+\beta=$ 0,29 para o p-value e $\alpha+\beta=0,28$ para EV. Se considerarmos a eficiência de um teste a partir da minimização dos erros que ele pode gerar, as simulações demonstram que, para o teste da proporção, as medidas PV e EV apresentam-se igualmente eficientes, conforme podemos confirmar no gráfico do poder:

FIGURA 6.1 - Teste para Proporção: $p=0,40$

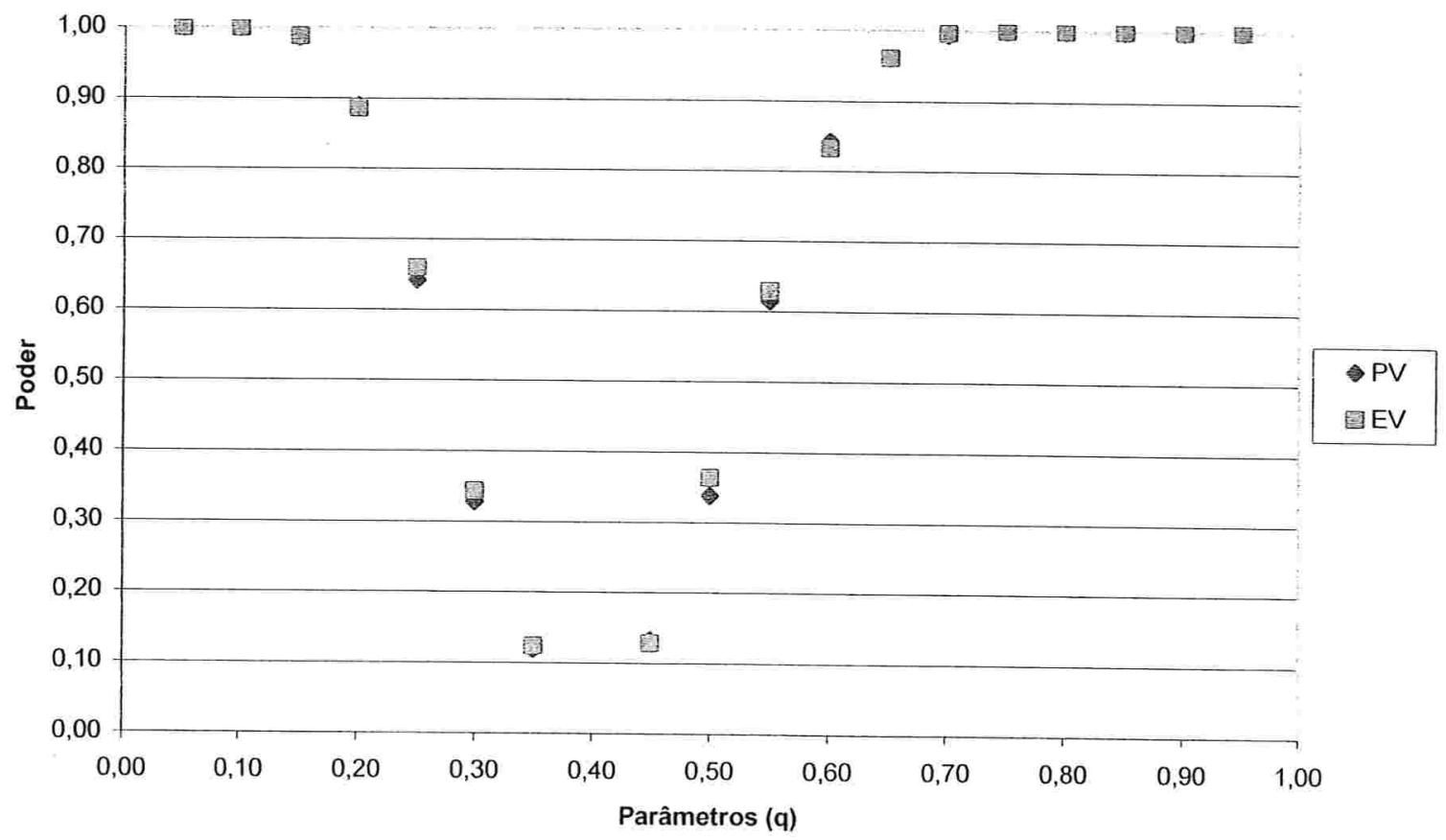




\section{2 - Erros no Teste de Homogeneidade}

No caso de teste de homogeneidade, precisamos gerar binomiais para a simulação de $X$, com tamanho de amostra m, e outras para a simulação de $\mathrm{Y}$, com tamanho de amostra n. Aqui escolhemos sempre $m=n$ e os tamanhos adotados são $m=20, m=50$ e m $=200$.

O cálculo de alfa é feito da seguinte forma:

1 - Geram-se $\mathrm{c}$ binomiais para X com $\mathrm{p}=0,50$ e $\mathrm{c}$ binomiais para $\mathrm{Y} \operatorname{com} \mathrm{q}=0,50$, assumindo a hipótese nula;

2 - Calcula-se PV e EV para cada par de binomiais;

3 - Somam-se todos os pares que seriam rejeitados nos diferentes níveis, de 0,01 a 0,50

4 - Divide-se o número de rejeitados por c, obtendo-se o alfa para cada nível.

O cálculo de beta é feito do seguinte modo:

1 - Geram-se c binomiais para X com $p=0,50$ e $\mathrm{c}$ binomiais para $Y \operatorname{com} q=0,05$, negando a hipótese de homogeneidade;

2 - Calcula-se PV e EV para cada um dos pares;

3 - Somam-se todos os pares que seriam aceitos nos diferentes níveis, de 0,01 a 0,50

4 - Divide-se o número de aceitos por c, obtendo-se $\beta_{0,05}$;

5 - Repetem-se os passos anteriores com $q=0,10 ; 0,15 ; \ldots ; 0,45 ; 0,55 ; \ldots ; 0,95$. Dessa forma obtém-se $\beta_{0,10} ; \beta_{0,15} ; \ldots ; \beta_{0,45} ; \beta_{0,55} ; \ldots ; \beta_{0,95}$. A média aritmética dos 18 valores leva a um beta médio para aquele nível testado.

Abaixo listamos os valores de corte que minimizam os erros:

TABELA 6.3 - Valores de Corte no Teste de Homogeneidade

\begin{tabular}{ccc} 
Tamanho da Amostra (m) & Corte para PV & Corte para EV \\
\hline 20 & 0,20 & 0,50 \\
50 & 0,07 & 0,20 \\
200 & 0,04 & 0,09 \\
\hline
\end{tabular}


Novamente, amostras maiores exigem corte menor.

No teste de homogeneidade, adotamos como tamanho de amostra $m=n=50$ e portanto os valores de corte são 0,07 para o p-value e 0,20 para EV.

Para o cálculo dos erros no p-value, geramos 100.000 binomiais para $\mathrm{X} \mathrm{e}$ 100.000 binomiais para Y. Para o cálculo de alfa e beta da medida EV, geramos 1.000 binomiais para X e 1.000 para $Y$; em seguida, 1.000 uniformes para cada binomial X e 1.000 uniformes para cada binomial Y.

Os alfas obtidos foram 0,06 para o p-value e 0,08 para EV. Poderíamos esperar uma diferença ainda maior entre os alfas devido à diversidade dos valores de corte para cada medida. A tabela 6.4 apresenta os diferentes betas obtidos:

TABELA 6.4 - Betas Simulados

\begin{tabular}{ccc}
\hline \multicolumn{3}{c}{ Teste de Homogeneidade: $\mathbf{p}=\mathbf{0 , 5 0}$} \\
\hline $\mathbf{q}$ & Beta - PV & Beta - EV \\
0,05 & 0,00 & 0,00 \\
0,10 & 0,00 & 0,00 \\
0,15 & 0,02 & 0,02 \\
0,20 & 0,08 & 0,08 \\
0,25 & 0,20 & 0,23 \\
0,30 & 0,39 & 0,39 \\
0,35 & 0,61 & 0,57 \\
0,40 & 0,79 & 0,77 \\
0,45 & 0,90 & 0,87 \\
0,55 & 0,90 & 0,86 \\
0,60 & 0,79 & 0,78 \\
0,65 & 0,61 & 0,61 \\
0,70 & 0,39 & 0,38 \\
0,75 & 0,20 & 0,19 \\
0,80 & 0,08 & 0,09 \\
0,85 & 0,02 & 0,01 \\
\hline
\end{tabular}




$\begin{array}{ccc}q & \text { Beta - PV } & \text { Beta - EV } \\ 0,90 & 0,00 & 0,00 \\ 0,95 & 0,00 & 0,00\end{array}$

Como no Teste para Proporção, os Testes de Homogeneidade apresentaram eficiência semelhante para as duas medidas de evidência estudadas. Tomando o beta médio, 0,33 para PV e 0,32 para EV, obtivemos $\alpha+\beta=0,39$ para o $p$-value e $\alpha+\beta=$ 0,40 para EV. O gráfico de poder encontra-se abaixo e corrobora a idéia de testes com eficiência similar.

FIGURA 6.2 - Teste de Homogeneidade: $p=0,50$

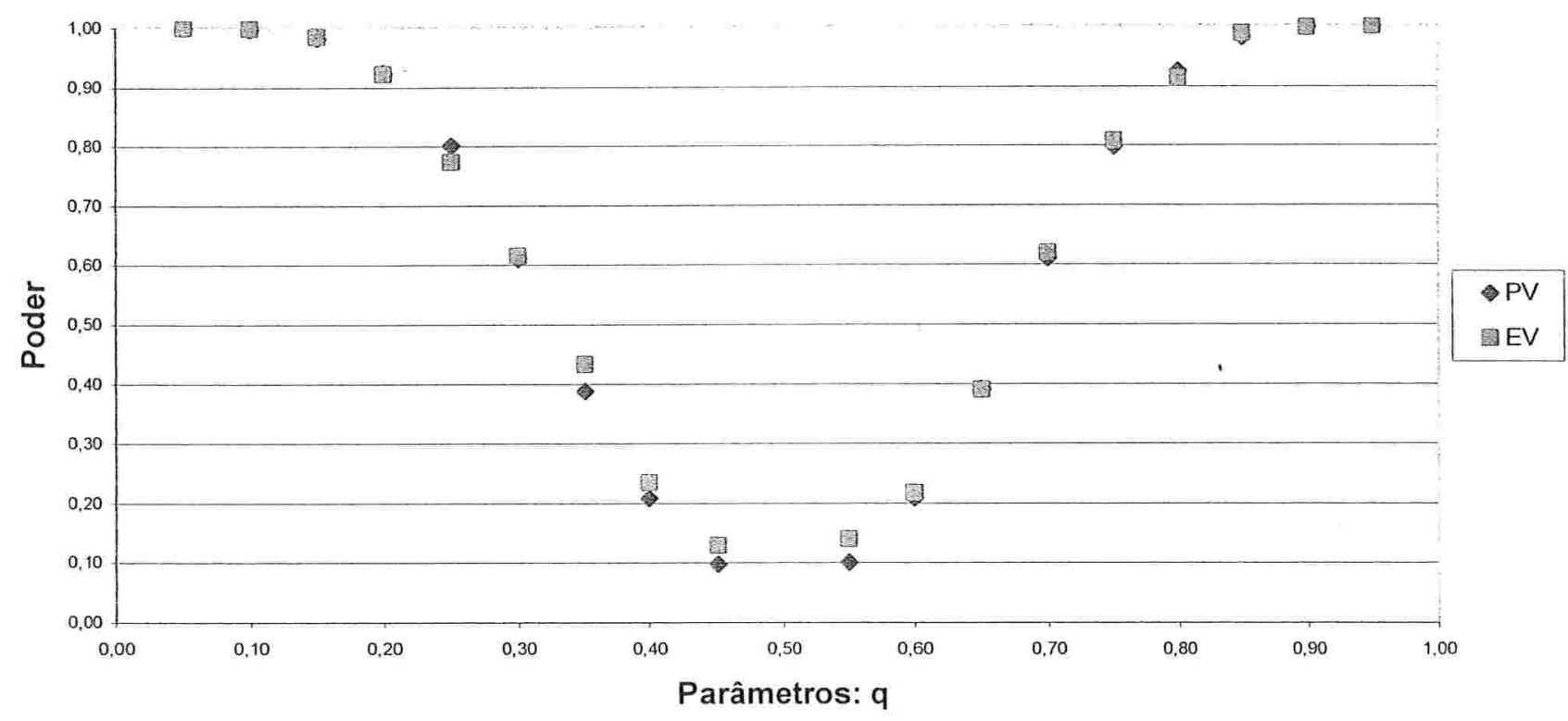




\section{3 - Erros no Teste de Independência}

No teste de independência, precisamos gerar binomiais para a simulação de $\mathrm{X}, \mathrm{Y}, \mathrm{W}$ e Z. Os três tamanhos de amostra estudados inicialmente foram $n=20, n=60$ e $n=200, n$ representando $\mathrm{x}+\mathrm{y}+\mathrm{w}+\mathrm{z}$ em cada configuração.

Aqui, o cálculo dos erros se torna mais complexo do que nos testes para proporção e de homogeneidade. Para o cálculo de alfa, precisamos escolher configurações que simulem independência e para o cálculo de beta devemos escolher configurações que simulem o afastamento dessa hipótese.

Lembremos que estamos considerando as categorias amostrais

\begin{tabular}{|c|c|c|}
\hline $\mathbf{x}$ & $\mathbf{y}$ & $\mathrm{x}+\mathrm{y}$ \\
\hline $\mathbf{w}$ & $\mathbf{z}$ & $\mathrm{w}+\mathrm{z}$ \\
\hline $\mathrm{x}+\mathrm{w}$ & $\mathrm{y}+\mathrm{z}$ & $\mathrm{n}$ \\
\hline
\end{tabular}

e os respectivos parâmetros

\begin{tabular}{|c|c|c|}
\hline $\mathbf{r}$ & $\mathbf{s}$ & $\mathrm{p}$ \\
\hline $\mathbf{t}$ & $\mathbf{u}$ & $1-\mathrm{p}$ \\
\hline $\mathrm{q}$ & $1-\mathrm{q}$ & 1 \\
\hline
\end{tabular}


Assumir a independência em $\mathrm{H}_{0}$, vale repetir, significa considerar

$$
\begin{aligned}
& r=p \cdot q \\
& s=p \cdot(1-q) \\
& t=(1-p) \cdot q \\
& u=(1-p) \cdot(1-q)
\end{aligned}
$$

Para o cálculo de alfa, geramos binomiais com os parâmetros r, s, t, u, assumindo a hipótese nula. Dessa maneira, a partir dos valores de $\mathrm{x}, \mathrm{y}, \mathrm{w}, \mathrm{z}$, calculamos:

$$
\begin{aligned}
& r=\frac{(x+y) \cdot(x+w)}{n^{2}} \\
& s=\frac{(x+y) \cdot(y+z)}{n^{2}} \\
& t=\frac{(w+z) \cdot(x+w)}{n^{2}} \\
& u=\frac{(w+z) \cdot(y+z)}{n^{2}}
\end{aligned}
$$

Para o cálculo de beta, a hipótese nula não deve ser assumida e, dados $x, y, w, z$, geramos binomiais a partir de:

$$
\begin{aligned}
& r=\frac{x}{n} \\
& s=\frac{y}{n}
\end{aligned}
$$




$$
\begin{aligned}
& t=\frac{w}{n} \\
& u=\frac{z}{n}
\end{aligned}
$$

A escolha dos valores de $\mathrm{x}, \mathrm{y}, \mathrm{w}, \mathrm{z}$ para a simulação dos erros considera um afastamento pequeno do valor ideal para o cálculo de alfa e um afastamento maior para o cálculo de beta.

A tabela 6.5 mostra os valores escolhidos para a simulação de alfa.

TABELA 6.5 - Configurações para o cálculo de Alfa

\begin{tabular}{ccccccccccc}
\hline $\boldsymbol{x}$ & $\boldsymbol{y}$ & $\boldsymbol{w}$ & $\boldsymbol{z}$ & $\mathbf{n}$ & $\mathbf{x}$ ideal & $\mathbf{x}$ real & afast-dif & afast-\% & PV & EV \\
5 & 4 & 6 & 5 & 20 & 4,95 & 5 & $-0,05$ & $-1,0$ & 0,96 & 1,00 \\
4 & 5 & 5 & 6 & 20 & 4,05 & 4 & 0,05 & 1,3 & 0,96 & 1,00 \\
6 & 3 & 7 & 4 & 20 & 5,85 & 6 & $-0,15$ & $-2,5$ & 0,89 & 1,00 \\
7 & 5 & 5 & 3 & 20 & 7,2 & 7 & 0,20 & 2,9 & 0,85 & 1,00 \\
8 & 7 & 3 & 2 & 20 & 8,25 & 8 & 0,25 & 3,1 & 0,80 & 0,99 \\
15 & 12 & 18 & 15 & 60 & 14,85 & 15 & $-0,15$ & $-1,0$ & 0,94 & 1,00 \\
12 & 15 & 15 & 18 & 60 & 12,15 & 12 & 0,15 & 1,3 & 0,94 & 1,00 \\
18 & 9 & 21 & 12 & 60 & 17,55 & 18 & $-0,45$ & $-2,5$ & 0,81 & 1,00 \\
21 & 15 & 15 & 9 & 60 & 21,6 & 21 & 0,60 & 2,9 & 0,75 & 0,99 \\
24 & 21 & 9 & 6 & 60 & 24,75 & 24 & 0,75 & 3,1 & 0,65 & 0,98 \\
50 & 40 & 60 & 50 & 200 & 49,5 & 50 & $-0,50$ & $-1,0$ & 0,89 & 1,00 \\
40 & 50 & 50 & 60 & 200 & 40,5 & 40 & 0,50 & 1,3 & 0,89 & 1,00 \\
60 & 30 & 70 & 40 & 200 & 58,5 & 60 & $-1,50$ & $-2,5$ & 0,66 & 0,98 \\
70 & 50 & 50 & 30 & 200 & 72 & 70 & 2,00 & 2,9 & 0,56 & 0,95 \\
80 & 70 & 30 & 20 & 200 & 82,5 & 80 & 2,50 & 3,1 & 0,41 & 0,88 \\
\hline
\end{tabular}

Dados $\mathrm{x}$ e y, o valor que denominamos $\mathrm{x}$ ideal é aquele que representa a hipótese de independência, isto é, $x=\frac{(x+y) \cdot(x+w)}{n}$. A tabela apresenta duas colunas para 
afastamento, uma com a diferença entre $\mathrm{o} x$ ideal e $\mathrm{o} x$ real (afast-dif) e a outra com $\mathrm{o}$ percentual de afastamento entre eles (afast-\%). Além disso, apresenta as medidas de evidência (PV e EV) resultantes dessas configurações.

Assim, temos 15 valores para o cálculo de alfa, sendo cinco com $n=20$, cinco com $n=60$ e cinco com $n=200$. Calculamos um alfa médio para cada um dos três tamanhos de amostra, com valores de corte que vão de 0,01 a 0,50 .

Analogamente, escolhemos os seguintes valores para a simulação de beta:

TABELA 6.6 - Configurações para o cálculo de Beta

\begin{tabular}{ccccccccccc}
$\boldsymbol{x}$ & $\boldsymbol{y}$ & $\boldsymbol{w}$ & $\boldsymbol{z}$ & $\mathrm{n}$ & $\mathrm{x}$ ideal & $\mathrm{x}$ real & afast-dif afast- $\%$ & $\mathrm{PV}$ & $\mathrm{EV}$ \\
3 & 9 & 6 & 2 & 20 & 5,4 & 3 & 2,40 & 80,0 & 0,03 & 0,14 \\
4 & 9 & 6 & 1 & 20 & 6,5 & 4 & 2,50 & 62,5 & 0,02 & 0,09 \\
5 & 3 & 2 & 10 & 20 & 2,8 & 5 & $-2,20$ & $-44,0$ & 0,04 & 0,17 \\
5 & 6 & 8 & 1 & 20 & 7,15 & 5 & 2,15 & 43,0 & 0,04 & 0,19 \\
7 & 5 & 1 & 7 & 20 & 4,8 & 7 & $-2,20$ & $-31,4$ & 0,04 & 0,17 \\
9 & 27 & 18 & 6 & 60 & 16,2 & 9 & 7,20 & 80,0 & 0,00 & 0,00 \\
12 & 27 & 18 & 3 & 60 & 19,5 & 12 & 7,50 & 62,5 & 0,00 & 0,00 \\
15 & 9 & 6 & 30 & 60 & 8,4 & 15 & $-6,60$ & $-44,0$ & 0,00 & 0,00 \\
15 & 18 & 24 & 3 & 60 & 21,45 & 15 & 6,45 & 43,0 & 0,00 & 0,00 \\
21 & 15 & 3 & 21 & 60 & 14,4 & 21 & $-6,60$ & $-31,4$ & 0,00 & 0,00 \\
30 & 90 & 60 & 20 & 200 & 54 & 30 & 24,00 & 80,0 & 0,00 & 0,00 \\
40 & 90 & 60 & 10 & 200 & 65 & 40 & 25,00 & 62,5 & 0,00 & 0,00 \\
50 & 30 & 20 & 100 & 200 & 28 & 50 & $-22,00$ & $-44,0$ & 0,00 & 0,00 \\
50 & 60 & 80 & 10 & 200 & 71,5 & 50 & 21,50 & 43,0 & 0,00 & 0,00 \\
70 & 50 & 10 & 70 & 200 & 48 & 70 & $-22,00$ & $-31,4$ & 0,00 & 0,00 \\
\hline
\end{tabular}

De modo idêntico ao cálculo de alfa, fizemos a média dos cinco betas com $n=20$, cinco com $n=60$ e cinco com $n=200$, para cortes entre 0,01 e 0,50 .

Os valores encontrados que minimizam os alfas + betas médios estão na tabela a seguir: 
TABELA 6.7 - Valores de Corte no Teste de Independência

\begin{tabular}{ccc} 
Tamanho da Amostra (n) & Corte para PV & Corte para EV \\
\hline 20 & 0,10 & 0,25 \\
60 & 0,02 & 0,08 \\
200 & 0,01 & 0,01 \\
\hline
\end{tabular}

Para este teste de independência, adotamos como tamanho de amostra $n=60$ e portanto os valores de corte são 0,02 para o p-value e 0,08 para EV.

Foram geradas 100.000 binomiais para $\mathrm{X}$, o mesmo ocorrendo para $\mathrm{Y}, \mathrm{W}$ e $\mathrm{Z}$, no cálculo dos erros para a medida PV. Para EV, geramos 1.000 binomiais para $\mathrm{X}$ e o mesmo para Y, W e Z; depois, 1.000 Dirichlets para cada um deles. Aqui, o trabalho computacional é bastante intenso.

As configurações utilizadas e os resultados dos erros empíricos encontram-se nas tabelas 6.8 e 6.9 :

TABELA 6.8 - Alfas Simulados

\begin{tabular}{cccccc}
\hline \multicolumn{2}{c}{ Configurações consideradas Independentes } & \multicolumn{3}{c}{ ALFA } \\
\hline $\boldsymbol{x}$ & $\boldsymbol{y}$ & $\boldsymbol{w}$ & $\boldsymbol{z}$ & $\mathrm{PV}$ & $\mathrm{EV}$ \\
15 & 12 & 18 & 15 & 0,03 & 0,07 \\
12 & 15 & 15 & 18 & 0,03 & 0,06 \\
18 & 9 & 21 & 12 & 0,03 & 0,11 \\
21 & 15 & 15 & 9 & 0,03 & 0,11 \\
24 & 21 & 9 & 6 & 0,03 & 0,19 \\
& & & & & \\
& & & Média & 0,03 & $\mathbf{0 , 1 1}$ \\
\hline
\end{tabular}


TABELA 6.9 - Betas Simulados

\begin{tabular}{cccccc}
\hline \multicolumn{2}{c}{ Configurações consideradas Não-Independentes } & \multicolumn{3}{c}{ BETA } \\
\hline$x$ & $y$ & $w$ & $z$ & PV & EV \\
9 & 27 & 18 & 6 & 0,02 & 0,03 \\
12 & 27 & 18 & 3 & 0,01 & 0,01 \\
15 & 9 & 6 & 30 & 0,04 & 0,08 \\
15 & 18 & 24 & 3 & 0,04 & 0,05 \\
21 & 15 & 3 & 21 & 0,04 & 0,06 \\
& & & & & \\
& & & Média & 0,03 & 0,05 \\
\hline
\end{tabular}

Observa-se que as simulações para os valores escolhidos revelaram maior eficiência para a medida $\mathrm{p}$-value com relação à medida EV. A média da soma dos erros foi $\alpha+\beta=$ 0,06 para o p-value e $\alpha+\beta=0,16$ para EV. De todo modo, as simulações demonstraram que para amostras maiores os betas tendem a zero para ambas as medidas. Da mesma forma, com o aumento do tamanho da amostra os alfas diminuem consideravelmente e tendem a ser semelhantes para as duas medidas.

Para finalizar o estudo dos erros, realizamos uma análise para o teste de independência considerando uma amostra de tamanho reduzido, $\mathrm{n}=10$. Neste caso existem 286 configurações possíveis e calculamos PV e EV para todos os pontos amostrais.

Em 48 configurações as medidas coincidiram, $\mathrm{PV}=\mathrm{EV}=1,00$, sustentando a hipótese de independência. Nos demais 238 casos, a medida EV obtida é maior do que a medida do p-value. Em nenhuma configuração este último é superior.

Aqui aparece um problema de aproximação para a utilização da estatística quiquadrado para o cálculo do p-value. Conforme DeGroot (1986), a aproximação é considerada ótima para valores esperados (n.p) maiores ou iguais a 5. Para valores iguais ou superiores a 1,5 a aproximação ainda é considerada razoável.

Para a simulação de alfa, selecionamos as 8 configurações em que PV e EV valem 1,00, excluindo-se todos os casos em que algum valor de $\mathrm{X}, \mathrm{Y}, \mathrm{W}$ ou $\mathrm{Z}$ é igual a zero. Deste modo, garantimos maior qualidade para as aproximações, apesar da existência de valores esperados inferiores a 1,5. Analogamente, também excluímos os zeros para o 
cálculo de beta, escolhendo 6 configurações que apresentam $\mathrm{EV}<0,26$, supondo que elas indicam não haver independência.

As configurações escolhidas encontram-se nas tabelas 6.10 e 6.11 :

TABELA 6.10 - Configurações para o cálculo de Alfa

\begin{tabular}{cccccccccc}
$x$ & $y$ & $w$ & $z$ & $\mathbf{x}$ ideal & $\mathbf{x}$ real & afast-dif & afast- $\%$ & PV & EV \\
\hline 1 & 1 & 4 & 4 & 1 & 1 & 0,0 & 0,0 & 1,00 & 1,00 \\
1 & 4 & 1 & 4 & 1 & 1 & 0,0 & 0,0 & 1,00 & 1,00 \\
2 & 2 & 3 & 3 & 2 & 2 & 0,0 & 0,0 & 1,00 & 1,00 \\
2 & 3 & 2 & 3 & 2 & 2 & 0,0 & 0,0 & 1,00 & 1,00 \\
3 & 2 & 3 & 2 & 3 & 3 & 0,0 & 0,0 & 1,00 & 1,00 \\
3 & 3 & 2 & 2 & 3 & 3 & 0,0 & 0,0 & 1,00 & 1,00 \\
4 & 1 & 4 & 1 & 4 & 4 & 0,0 & 0,0 & 1,00 & 1,00 \\
4 & 4 & 1 & 1 & 4 & 4 & 0,0 & 0,0 & 1,00 & 1,00 \\
\hline
\end{tabular}

TABELA 6.11 - Configurações para o cálculo de Beta

\begin{tabular}{cccccccccc}
\hline $\boldsymbol{x}$ & $\boldsymbol{y}$ & $\boldsymbol{w}$ & $\boldsymbol{z}$ & $\mathbf{x}$ ideal & $\mathbf{x}$ real & afast-dif & afast-\% & PV & EV \\
\hline 1 & 3 & 5 & 1 & 2,4 & 1 & 1,4 & 140,0 & 0,07 & 0,25 \\
1 & 4 & 4 & 1 & 2,5 & 1 & 1,5 & 150,0 & 0,06 & 0,22 \\
1 & 5 & 3 & 1 & 2,4 & 1 & 1,4 & 140,0 & 0,07 & 0,24 \\
3 & 1 & 1 & 5 & 1,6 & 3 & $-1,4$ & $-46,7$ & 0,07 & 0,24 \\
4 & 1 & 1 & 4 & 2,5 & 4 & $-1,5$ & $-37,5$ & 0,06 & 0,20 \\
5 & 1 & 1 & 3 & 3,6 & 5 & $-1,4$ & $-28,0$ & 0,07 & 0,24 \\
\hline
\end{tabular}

Repetimos os procedimentos anteriores para a obtenção dos valores de corte que minimizam alfa + beta e encontramos:

TABELA 6.12 - Valores de Corte no Teste de Independência

\begin{tabular}{ccc} 
Tamanho da Amostra (n) & Corte para PV & Corte para EV \\
\hline 10 & 0,10 & 0,40 \\
\hline
\end{tabular}


Pode-se observar novamente que para amostras pequenas os cortes que minimizam a combinação de erros tendem a ser bastante elevados em relação a amostras maiores. Além disso, como no teste de independência analisado PV é sempre menor ou igual a EV, o valor de corte para a primeira medida é também menor.

As simulações foram realizadas da mesma forma utilizada para a amostra de tamanho 60. Após a obtenção de cada alfa e cada beta foram extraídas suas médias, conforme tabelas a seguir:

TABELA 6.13 - Alfas Simulados

\begin{tabular}{cccccc}
\multicolumn{2}{c}{ Configuraçöes consideradas Independentes } & \multicolumn{3}{c}{ ALFA } \\
\hline$x$ & $y$ & $w$ & $z$ & PV & EV \\
1 & 1 & 4 & 4 & 0,15 & 0,18 \\
1 & 4 & 1 & 4 & 0,15 & 0,18 \\
2 & 2 & 3 & 3 & 0,20 & 0,30 \\
2 & 3 & 2 & 3 & 0,20 & 0,32 \\
3 & 2 & 3 & 2 & 0,20 & 0,38 \\
3 & 3 & 2 & 2 & 0,20 & 0,37 \\
4 & 1 & 4 & 1 & 0,15 & 0,25 \\
4 & 4 & 1 & 1 & 0,15 & 0,29 \\
& & & & & 0,17 \\
\end{tabular}


TABELA 6.14 - Betas Simulados

\begin{tabular}{cccccc}
\hline \multicolumn{2}{c}{ Configuraçöes consideradas Näo-Independentes } & \multicolumn{3}{c}{ BETA } \\
\hline $\boldsymbol{x}$ & $\boldsymbol{y}$ & $\boldsymbol{w}$ & $\boldsymbol{z}$ & PV & EV \\
1 & 3 & 5 & 1 & 0,28 & 0,22 \\
1 & 4 & 4 & 1 & 0,25 & 0,17 \\
1 & 5 & 3 & 1 & 0,28 & 0,23 \\
3 & 1 & 1 & 5 & 0,28 & 0,27 \\
4 & 1 & 1 & 4 & 0,25 & 0,19 \\
5 & 1 & 1 & 3 & 0,28 & 0,22 \\
& & & & & $\mathbf{0 , 2 7}$ \\
\hline
\end{tabular}

Naturalmente, como o corte para PV é 0,10 e para EV é 0,40 , esperavam-se alfas menores para a primeira medida e betas menores para a segunda, o que de fato ocorreu. Para $\mathrm{n}=10$, a média da soma dos erros foi $\alpha+\beta=0,44$ para o $\mathrm{p}$-value e $\alpha+\beta=0,50$ para EV. Houve considerável aumento dos erros em relação à amostra com $n=60(\alpha+\beta=0,06$ e $\alpha+\beta=0,16$, respectivamente). De todo modo, o p-value novamente apresentou soma de erros ligeiramente menor do que EV. 


\section{4 - Erros Empíricos - Conclusões}

As simulações feitas para a minimização dos erros mostraram que os testes tradicionais qui-quadrado, utilizados para a obtenção do p-value, e os novos testes baseados no FBST, utilizados para a obtenção da medida EV, apresentam comportamento semelhante nos casos de testes para proporção e testes de homogeneidade. Escolhendo-se adequadamente os valores de corte que minimizam $\alpha+\beta$, as duas medidas mostraram-se igualmente eficientes.

No teste de independência, uma análise comparativa mais criteriosa exigiria a simulação de erros para muitas configurações com diferentes tamanhos de amostra. Nos casos aqui selecionados, para amostras de 10 e 60 valores, os testes qui-quadrado produziram somas de erros menores do que os testes FBST. 


\section{Capítulo 7}

\section{Considerações Finais}

Os testes de hipóteses, de largo uso, têm causado controvérsia desde os primórdios da estatística. Procuramos aqui trabalhar a idéia de medida de evidência, apesar de haver tendências na inferência que negam qualquer possibilidade de quantificação neste sentido.

Ao longo do estudo, pareceu-nos importante a apresentação de métodos que utilizam apenas os dados que estão em mãos, buscando uma aproximação (ou conciliação) entre clássicos e bayesianos nos problemas em que a concordância pode ser facilitada. Para esses casos, o uso direto da razão de verossimilhanças parece bastante adequado.

Em muitos problemas, a comparação entre medidas é fundamental. No caso das hipóteses precisas relacionadas à binomial aqui trabalhadas, analisamos duas medidas tradicionais e uma proposta recentemente. Todas têm o que podemos denominar, de maneira simplificada, pontos fortes e pontos fracos. "Nada é só bom", diria o professor Carlinhos. Para evitar uma utilização mecânica e acrítica dos testes de hipóteses, é preciso que esses pontos sejam explicitados.

$\mathrm{O}$ Fator de Bayes mede comparativamente as chances de $\mathrm{H}_{0}$ e $\mathrm{H}_{1}$ antes e depois do experimento, de forma bastante útil. Mas não é uma medida de probabilidade e, para o caso de hipótese precisa, o processo bayesiano tradicional exige a introdução artificial de uma massa de probabilidade para a obtenção da posteriori.

Para muitos estatísticos o p-value apresenta problemas de fundamentos, como o cálculo baseado no espaço amostral, a consideração de eventos "mais extremos" que não ocorreram de fato mas poderiam ter ocorrido, a desconsideração da alternativa, etc. De todo modo, é inegável que em termos práticos a utilização abrangente dessa medida tem sido realizada com grande eficiência e existem maneiras de aprimorá-la, como mostram Pereira e Wechsler (1993).

O FBST é uma metodologia bayesiana nova e promissora. Seu mérito inicial é a avaliação da hipótese no espaço paramétrico sem a introdução artificial de massa de probabilidade, sem "adocheria", como dizem. Não se baseia em dados "mais extremos" mas nos efetivamente coletados. A medida EV é uma "concorrente" natural do p-value e em muitas situações as duas medidas concordam. 
Já existem diversas aplicações do FBST em casos mais complexos que demonstram sua eficiência, com o poder do teste apresentando-se maior. Aqui, limitamo-nos à comparação em três casos simples. No teste para proporção e no teste de homogeneidade, a simulação de erros sugere que o teste de significância clássico e o FBST acertam praticamente no mesmo percentual. No teste de independência, a medida EV parece ser mais "intuitiva" mas o p-value acertou mais, apesar de já termos feito a ressalva de que a simulação de erros para esse teste se mostrou bem mais complexa e é necessário realizá-la com mais configurações.

A dificuldade maior no uso do FBST reside na exigência de trabalho computacional intenso. Com o rápido desenvolvimento tecnológico esse problema tende a se tornar menos relevante. $\mathrm{O}$ avanço na área de informática tem propiciado evidentes conquistas para a Estatística, principalmente na resolução numérica de problemas antes considerados insolúveis.

Para problemas antigos e para os novos que certamente surgirão, parece-nos clara a necessidade de realização de estudos comparativos. Este trabalho reforçou ainda mais esta convicção. 


\section{Apêndice}

\section{Aspectos Computacionais no Cálculo de EV}

O cálculo da medida de evidência do FBST para testes mais simples é feito, conforme mostramos, através de simulação de Monte Carlo. Neste trabalho, usamos o pacote estatístico S-Plus para a obtenção dos valores apresentados.

Existem outros softwares que podem eventualmente facilitar os cálculos. Entre eles está o WinBUGS, utilizado principalmente por estatísticos da linha bayesiana, que se baseia no método de amostragem de Gibbs (Gibbs Sampling). Infelizmente, não tivemos a oportunidade de acessá-lo durante a elaboração deste trabalho. Por sorte, recebemos na fase de revisão a generosa colaboração do professor Josemar Rodrigues, da UFSCar, que, utilizando o software citado, verificou alguns resultados aqui expostos.

A página Web atual onde pode ser obtida uma versão gratuita do software é http://www.mrc-bsu.cam.ac.uk/bugs/welcome.shtml

O professor Josemar escreveu programas no WinBUGS para os três testes aqui realizados. Nos dois primeiros, testes para proporção e de homogeneidade, a geração de uniformes foi substituída pela geração de betas. No terceiro teste, a Dirichlet também foi gerada a partir de gamas independentes. Em todos os testes trabalhou-se com o logaritmo da posteriori.

Percebe-se que, de fato, as rotinas para o cálculo de EV tornam-se mais simples no WinBUGS. Com a permissão do professor, reproduzimos aqui esses programas.

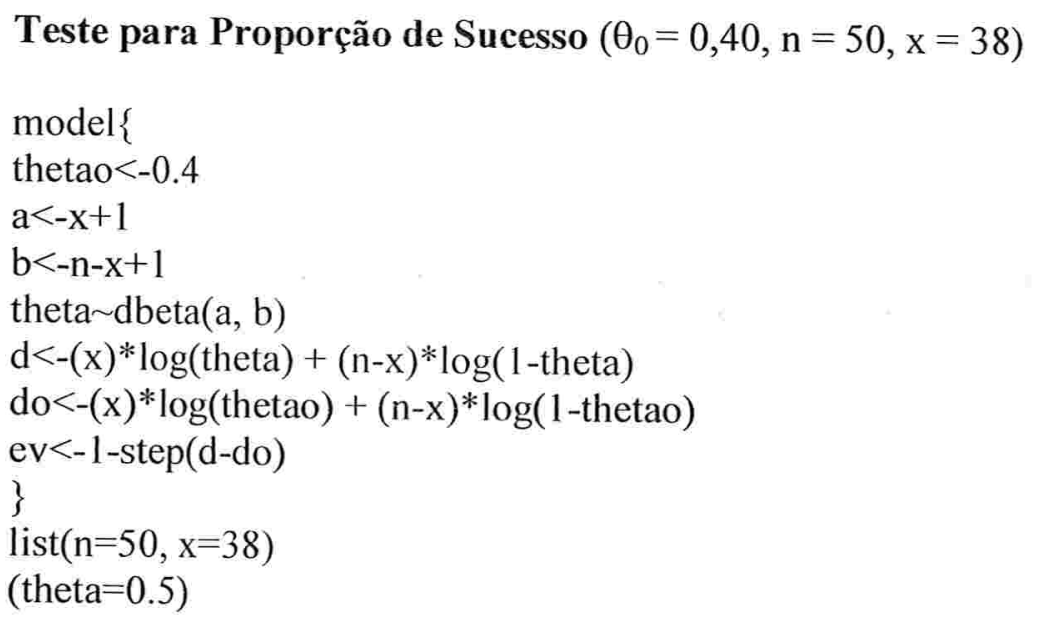


Teste de Homogeneidade $(m=n=30, x=25, y=29)$

model \{

thetahat $<-(\mathrm{x}+\mathrm{y}) /(\mathrm{n}+\mathrm{m})$

$\mathrm{a}<-\mathrm{x}+1$

$\mathrm{b}<-\mathrm{n}-\mathrm{x}+1$

thetax $\sim \operatorname{dbeta}(a, b)$

$\mathrm{c}<-\mathrm{y}+\mathrm{I}$

$\mathrm{d}<-\mathrm{m}-\mathrm{y}+1$

thetay $\sim \operatorname{dbeta}(\mathrm{c}, \mathrm{d})$

dxy<-(x)* $\log ($ thetax $)+(n-x) * \log (1-$ thetax $)+(y) * \log ($ thetay $)+(m-y) * \log (1-$ thetay $)$

do $<-(x+y) * \log ($ thetahat $)+(n+m-x-y) * \log (1-$ thetahat $)$

ev<-1-step(dxy-do)

theta $<$-thetax-thetay

\}

list $(\mathrm{n}=30, \mathrm{~m}=30, \mathrm{x}=25, \mathrm{y}=29)$

list $($ thetax $=0.5$, thetay $=0.5)$

Teste de Independência $(n=91, x=30, y=18, w=23, z=20)$

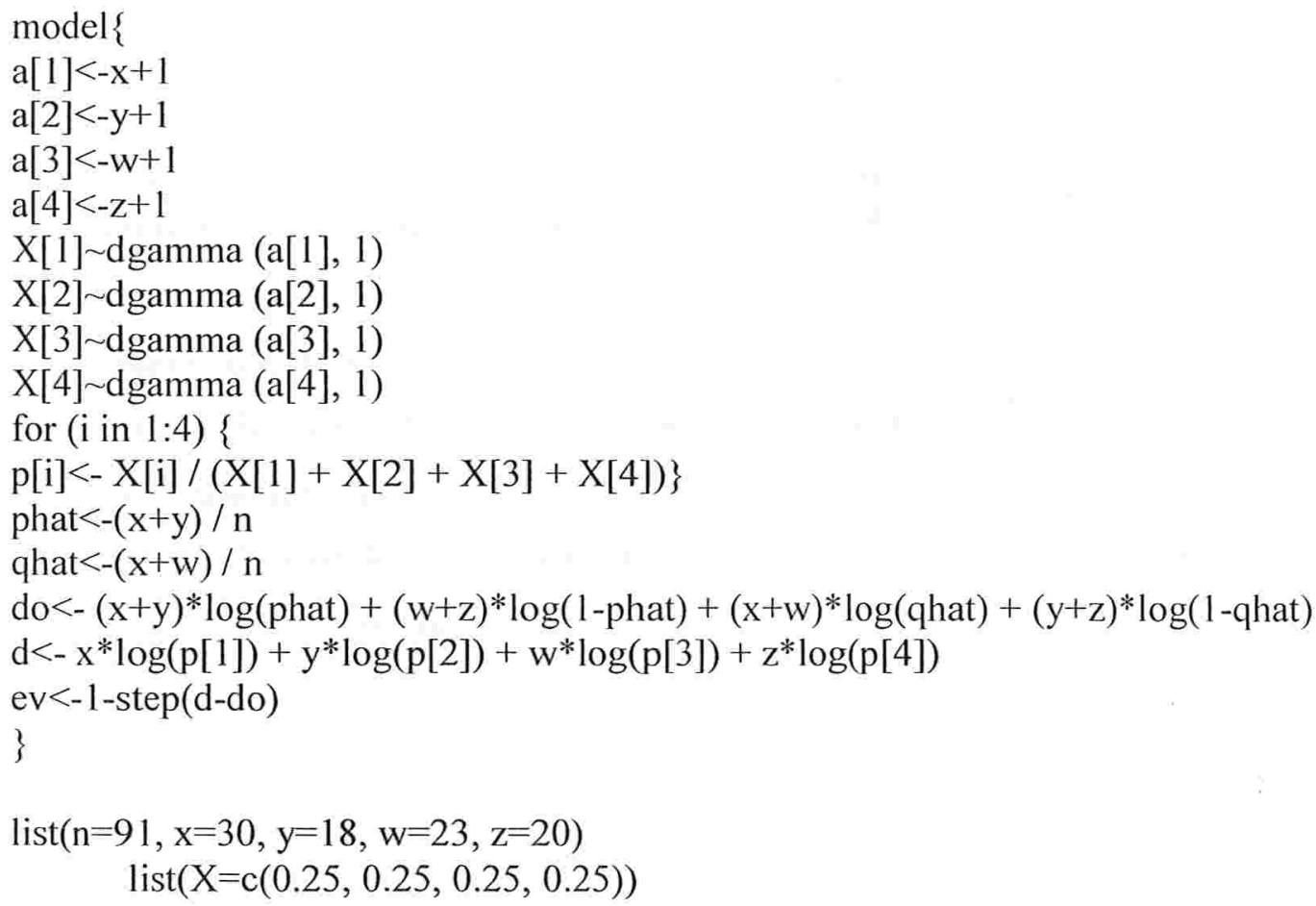




\section{Referências Bibliográficas}

[1] Barnard, G.A. (1949). Statistical Inference (with discussion). Journal of the Royal Statistical Society, XI B 2, 115-149.

[2] Barnard, G.A. et al. (1962). Likelihood Inference and Time Series. Journal of the Royal Statistical Society, 125 A, 321-352.

[3] Barnett, V. (1982). Comparative Statistical Inference. ( $2^{\text {nd }}$ edition). Chicester: John Wiley and Sons.

[4] Basu, S. (1996). Bayesian Hypotheses Testing Using Posterior Density Ratios. Statistics \& Probability Letters, 30, 79-86.

[5] Bayarri, M.J. and Berger, J.O. (2002). Hypothesis Testing and Model Selection. Webpage: www.stat.duke.edu/ berger/talks/valencia7.ps.

[6] Berger, J.O. (1985). In Defense of the Likelihood Principle: Axiomatics and Coherency. Bayesian Statistics 2 (Bernardo, J.M. et al.). B. V. (North Holland): Elsevier Science Publishers, 33-66.

[7] Berger, J.O. (2002). Could Fisher, Jeffreys, and Neyman Have Agreed on Testing? Webpage: www.stat.duke.edu/ berger/papers/02-01.html.

[8] Berger, J.O., Boukai, B. and Wang, Y. (1997). Unified Frequentist and Bayesian Testing of a Precise Hypothesis (with discussion). Statistical Science, 12, 3, 133-160.

[9] Berger, J.O. and Delampady, M. (1987). Testing Precise Hypotheses (with discussion). Statistical Science, 2, 3, 317-352.

[10] Berger, J.O. and Sellke, T. (1987). Testing a Point Null Hypothesis: The Irreconcilability of P-Values and Evidence (with discussion). Journal of the American Statistical Association, 82, 397, Theory and Methods, 112-139.

[11] Berger, J.O. and Wolpert, R.L. (1988). The Likelihood Principle (second edition). Institute of Mathematical Statistics. California: Hayward.

[12] Bernardo, J.M. (2003). Bayesian Statistics.

Webpage: ftp://matheron.uv.es/pub/personal/bernardo/BayesStat.pdf.

[13] Berry, D.A. (1987). Interim Analysis in Clinical Trials - The Role of the Likelihood Principle. The American Statistician, 41, 2, 117-122. 
[14] Biggerstaff, B.J. (2000). Comparing Diagnostic Tests: a Simple Graphic Using Likelihood Ratios. Statistics in Medicine, 19, 649-663.

[15] Birnbaum, A. (1962). On the Foundations of Statistical Inference (with discussion). Journal of the American Statistical Association, 298, 57, 269-326.

[16] Birnbaum, A. (1968). Likelihood. International Encyclopedia of the Social Sciences, 9, 299-301. New York: The Macmillan Company / The Free Press.

[17] Birnbaum, A. (1977). The Neyman-Pearson Theory as Decision Theory, and as Inference Theory; with a Criticism of the Lindley-Savage Argument for Bayesian Theory. Synthese, 36, 19-49.

[18] Blume, J.D. (2002). Likelihood Methods for Measuring Statistical Evidence. Statistics in Medicine, 21, 2563-2599.

[19] Box, G.E.P. (1983). An Apology for Ecumenism in Statistics. Scientific Inference, Data Analysis, and Robustness (Box, G.E.P., Leonard, T and Wu, C.F.). New York: Academic Press, 51-84

[20] Casella, G. and Berger, R.L. (1987). Reconciling Bayesian and Frequentist Evidence in the One-Sided Testing Problem (with discussion). Journal of the American Statistical Association, 82, 397, Theory and Methods, 106-139.

[21] Casella, G. and Berger, R.L. (1990). Statistical Inference. Belmont: Duxbury Press.

[22] Cordani, L.K. (2001). O Ensino de Estatística na Universidade e a Controvérsia sobre os Fundamentos da Inferência. São Paulo: Faculdade de Educação - USP.

[23] Cordeiro, G. (1992). Introdução à Teoria de Verossimilhança. 10 SINAPE. Rio de Janeiro: UFRJ, ABE, IBGE, LNCC.

[24] Cox, D.R. (1977). The Role of Significance Tests (with discussion). Scandinavian Journal of Statistics, 4, 49-70.

[25] DeGroot, M.H. (1986). Probability and Statistics. (2 ${ }^{\text {nd }}$ edition). London: Addison-Wesley.

[26] Dempster, A.P. (1985). Probability, Evidence and Judgement. Bayesian Statistics 2 (Bernardo, J.M. et al.). B. V. (North Holland): Elsevier Science Publishers, 119-132. 
[27] Dempster, A.P. (1997). The Direct Use of Likelihood for Significance Testing. Statistics and Computing, 7, 247-252.

[28] Edwards, A.W.F. (1972). Likelihood. Cambridge: Cambridge University Press.

[29] Efron, B. (1998). R. A. Fisher in the 21 st Century. Statistical Science, 13 (2), 95-122.

[30] Fisher, R. A. (1966). The Design of Experiments. ( $8^{\text {th }}$ edition). London: Oliver and Boyd:

[31] Fisher, R. A. (1956). Statistical Methods and Scientific Inference. London: Oliver and Boyd.

[32] Gibbons, J.D. and Pratt, J.W. (1975). P-values: Interpretation and Methodology. The American Statistician, 29, 1, 20-25.

[33] Giere, R.N. (1977). Allan Birnbaum's Conception of Statistical Evidence. Synthese, 36, 5-17.

[34] Gigerenzer, G. et al. (1989). The Empire of Chance. Cambridge: Cambridge University Press.

[35] Gómez-Villegas, M.A., Main, P. and Sanz, L. (2002). A Suitable Bayesian Approach in Testing Point Null Hypothesis: Some Examples Revisited. Commun. Statist. - Theory Meth., 31 (2), 201-217.

[36] Good, I.J. (1950). Probability and the Weighing of Evidence. London: Griffin.

[37] Good, I.J. (1985). Weight of Evidence: a Brief Survey. Bayesian Statistics 2 (Bernardo, J.M. et al.). B. V. (North Holland): Elsevier Science Publishers, 249-270.

[38] Good, I.J. (1992). The Bayes / Non-Bayes Compromise: a Brief Review. Journal of the American Statistical Association, 87, 419, Presidential Invited Papers, 597-606.

[39] Hacking, I. (1965). Logic of Statistical Inference. Cambridge: Cambridge University Press.

[40] Hacking, I. (1972). Likelihood. The British Journal for the Philosophy of Science, 23, 2, 132-137.

[41] Howson, C. and Urbach, P. (1993). Scientific Reasoning: The Bayesian Approach. ( $2^{\text {nd }}$ edition). Chicago: Open Court. 
[42] Inoue, L.Y.T. (1995). Desenvolvimento e Aplicações do Princípio da Verossimilhança. São Paulo: IME - USP.

[43] Irony, T.Z. and Pereira, C.A.B. (1995). Bayesian Hypothesis Test: Using Surface Integrals to Distribute Prior Information Among the Hypotheses. Resenhas - IME - USP, 2, 1, 27-46.

[44] Jeffreys, H. (1939). Theory of Probability. Oxford: Oxford University Press.

[45] Kempthorne, O. (1976). Of What Use Are Tests of Significance and Tests of Hypothesis. Commun. Statistic., A5 (8), Theor. Meth., 763-777.

[46] Kempthorne, O. and Folks, L. (1971). Probability, Statistics and Data Analysis. Iowa: The Iowa State University Press.

[47] Kiefer, J. (1977). The Foundations of Statistics - Are There Any? Synthese, 36, 161-176.

[48] Krauss, S. and Wassner, C. (2002). How Significance Tests Should Be Presented to Avoid Typical Misinterpretations. ICOTS6.

[49] Lecam, L. (1977). A Note on Metastatistics or 'An Essay Toward Stating a Problem in the Doctrine of Chances'. Synthese, 36, 133-160.

[50] Lee, P.M. (1997). Bayesian Statistics: an Introduction. ( $2^{\text {nd }}$ edition). London: Arnold.

[51] Lehmann, E. L. (1993). The Fisher, Neyman-Pearson Theories of Testing Hypotheses: One Theory or Two? Journal of the American Statistical Association, 88, 1242-1249.

[52] Leonard, T. (1983). Some Philosophies of Inference and Modelling. Scientific Inference, Data Analysis, and Robustness (Box, G.E.P., Leonard, T and Wu, C.F.). New York: Academic Press,.51-84.

[53] Lindley, D.V. (1957). A Statistical Paradox. Biometrika, 44, 187-192.

[54] Lindley, D.V. (1978). The Bayesian Approach (with discussion). Scandinavian Journal of Statistics, 5, 1-26.

[55] Lindsey, J.K. (1999). Some Statistical Heresies (with discussion). The Statistician, 48, 1-40. 
[56] Lindsey, J.K. (1999). Relationships among Sample Size, Model Selection and Likelihood Regions, and Scientifically Important Differences. The Statistician, 48, 401-411.

[57] Madruga, M.R. , Pereira, C.A.B. and Stern, J.M. (2003). Bayesian Evidence Test for Precise Hypotheses. Journal of Statistical Planning and Inference, 117, 185-198.

[58] Madruga-Tavares, M. R. (2002). Teste de Significância: uma Proposta Genuinamente Bayesiana. São Paulo: IME-USP.

[59] Mayo, D.G. (1996). Error and the Growth of Experimental Knowledge. $\left(2^{\text {nd }}\right.$ edition). Chicago: The University of Chicago Press.

[60] Mayo, D.G. and Kruse, M. (2001). Principles of Inference and their Consequences. Foundations of Bayesianism (Corfield, D. and Williamson, J.). Dordrecht: Kluwer Academic Publishers, 381-403.

[61] McLean, A. (2001). On the Nature an Role of Hypothesis Tests. Webpage: http://www.buseco.monash.edu.au/Depts/EBS.

[62] Oakes, M. (1986). Statistical Inference: a Commentary for the Social and Behavioural Sciences. New York: John Wiley \& Sons.

[63] Oysteyee, D.B. and Good, I.J. (1974). Information, Weight of Evidence, the Singularity between Probability Measures and Signal Detection. Lecture Notes in Mathematics, 376. Berlin: Springer-Verlag.

[64] Paulino, C.D., Turkman, M.A.A. e Murteira, B. (2003). Estatística Bayesiana. Lisboa: Fundação Calouste Gulbenkian.

[65] Pawitan, Y. (2000). Likelihood: Consensus and Controversies. Webpage: htpp://www.mep.ki.se/ yudpaw/

[66] Pereira, C.A.B. and Irony, T.Z. (1986). Exact Tests for Equality of Two Proportions: Fisher v. Bayes. J. Statist. Comput. Simul., 25, 93-114.

[67] Pereira, B.B. and Pereira, C.A.B. (2003). A Likelihood Aproach to Diagnostic Test in Clinical Medicine. RT-MAE, 2003-07. São Paulo: IME-USP.

[68] Pereira, C.A.B. and Lindley, D.V. (1987). Examples Questioning the Use of Partial Likelihood. The Statistician, 36, 15-20. 
[69] Pereira, C.A.B. and Stern, J.M. (1999). Evidence and Credibility: Full Bayesian Test for Precise Hypotheses. Entropy, 1, 99-110.

[70] Pereira, C.A.B. and Stern, J.M. (2001). Model Selection: Full Bayesian Approach. Environmetrics, 12, 559-568.

[71] Pereira, C.A.B. and Wechsler, S. (1993). On the Concept of P-Value. REBRAPE, 7, 159-177.

[72] Pratt, J.W. (1977). 'Decisions' as Statistical Evidence and Birnbaum's 'Confidence Concept'. Synthese, 36, 59-69.

[73] Rodrigues, J. (2004). Full Bayesian Significance Test for Zero-Inflated Distributions. In RT-DE, 111. São Carlos: Dep. de Estatística - USFSCar.

[74] Rosenkrantz, R.D. (1977). Support. Synthese, 36, 181-193.

[75] Royall, R. (1997). Statistical Evidence - a Likelihood Paradigm. London: Chapman \& Hall.

[76] Samartini, A.L.S. (2000). Testes de Significância Bayesianos: Aplicações a Distribuições Discretas. São Paulo: IME-USP.

[77] Savage, L.J. (1972). The Foundations of Statistics. (2 ${ }^{\text {nd }}$ edition). New York: Dover Publications.

[78] Savage, L.J. et al. (1961). The Foundations of Statistical Inference - a Discussion. London: Methuen \& Co Ltd.

[79] Schervish, M.J. (1995). Theory of Statistics. New York: Springer-Verlag.

[80] Severini, T.A. (2000). Likelihood Methods in Statistics. Oxford: Oxford University Press.

[81] Sorensen, D. and Gianola, D. (2002). Likelihood, Bayesian, and MCMC Methods in Quantitative Genetics. New York: Springer-Verlag.

[82] Stern, J.M. (2002). Significance Test, Belief Calculi and Burden of Proof in Legal and Scientific Discourse. In RT-MAC, 2002-07: São Paulo: IME-USP.

[83] Stern, J.M. and Zachs, S. (2002). Testing the Independence of Poisson Variates under the Holgate Distribution: the Power of a New Evidence Test. In RT$M A C$, 2002-03. São Paulo: IME-USP.

[84] Walley, P. (1991). Statistical Reasoning with Imprecise Probabilities. London: Chapman and Hall. 